UNIVERSIDADE DE SÃO PAULO

ESCOLA DE ENFERMAGEM

REGIANE PEREIRA MARTINS LIMA

PERCEPÇÃO DA EQUIPE MULTIDISCIPLINAR ACERCA DE FATORES INTERVENIENTES NA OCORRÊNCIA DE EVENTOS ADVERSOS EM UM HOSPITAL UNIVERSITÁRIO

SÃO PAULO 


\section{PERCEPÇÃO DA EQUIPE MULTIDISCIPLINAR ACERCA DE FATORES INTERVENIENTES NA OCORRÊNCIA DE EVENTOS ADVERSOS EM UM HOSPITAL UNIVERSITÁRIO}

Dissertação apresentada ao Programa de Pós-Graduação em Gerenciamento em Enfermagem da Escola de Enfermagem da Universidade de São Paulo para obtenção do título de Mestre em Ciências

Área de Concentração: Fundamentos e Práticas de Gerenciamento em Enfermagem e em Saúde

Orientadora: $\operatorname{Prof}^{\mathrm{a}} \operatorname{Dr}^{\mathrm{a}}$ Marta Maria Melleiro 
AUTORIZO A REPRODUÇÃO E DIVULGAÇÃO TOTAL OU PARCIAL DESTE TRABALHO, POR QUALQUER MEIO CONVENCIONAL OU ELETRÔNICO, PARA FINS DE ESTUDO E PESQUISA, DESDE QUE CITADA A FONTE.

Assinatura:

Data:

\section{Catalogação na Publicação (CIP) \\ Biblioteca "Wanda de Aguiar Horta" \\ Escola de Enfermagem da Universidade de São Paulo}

Lima, Regiane Pereira Martins

Percepção da equipe multidisciplinar acerca de fatores intervenientes na ocorrência de eventos adversos em um hospital universitário / Regiane Pereira Martins Lima.

São Paulo, 2011.

$113 \mathrm{p}$.

Dissertação (Mestrado) - Escola de Enfermagem da Universidade de São Paulo.

Orientadora: $\operatorname{Prof}^{\underline{a}} \operatorname{Dr}^{\mathrm{a}}$ Marta Maria Melleiro

1. Assistência à saúde - Qualidade 2. Serviços de saúde Avaliação 3. Serviços de saúde - Gerenciamento 4. Hospitais - Gerenciamento I. Título. 


\section{FOLHA DE APROVAÇÃO}

Nome: Regiane Pereira Martins Lima

Título: Percepção da equipe multidisciplinar acerca de fatores intervenientes na ocorrência de eventos adversos em um hospital universitário

Dissertação apresentada à Escola de Enfermagem da Universidade de São Paulo para obtenção do título de Mestre em Ciências

Aprovado em:

\section{Banca Examinadora}

Prof. Dr.: Instituição:

Julgamento: Assinatura:

Prof. Dr.: Instituição:

Julgamento: Assinatura:

Prof. Dr.: Instituição:

Julgamento: Assinatura: 
A Deus, por me abençoar a cada dia, e por se fazer presente, pois o sinto comigo...

Ao meu esposo, Washington, que acredito estar nesta e em outras jornadas ao meu lado e com seu amor, torna o caminho muito mais leve.

Aos meus pais, Anita e Wilson, por me amarem incondicionalmente.

À minha irmã, Christiane e meu cunhado Clayton, pelo carinho e dedicação. 


\section{AGRADECIMENTOS}

À minha familia,

mais que as laças de sangue, samas unidas par uma amizade infinita e a certeza de sempre pader cantar uns cam as autras.

À prafessara Dautara Marta Maria Melleira, pela acalhimenta durante a arientaçãa, pela humildade em partilhar seu canhecimenta, pela respeita e carinha em me canduzir, fazenda de cada passa, um crescimenta cansistente e inspiradar...

Às professaras Dautaras Daisy Maria Rizatta Tranchin e Sueli Fátima Sampaia, pela walarasa cantribuiçãa na exame de qualificaçãa e par serem mentaras em minha qualificaçãa prafissianal.

Aas amigas de Campinas e Sãa Paula, par partilharem camiga tadas as mamentas, pela tarcida e palawras de incentiua.

Á enfermeira Ana Luiza Ferreira Meres, par acreditar em mim e ter contriluida para que esse e autras sanhas se tarnassem realidade. 
"Não é possível insistir naquilo que eu não fui, naquilo que não vivi. Mas é possível crescer através daquilo que eu tentei, daquilo que eu busquei, daquilo que eu senti, daquilo que realizei".

(autor desconhecido)

Acredito em um Deus que se preocupa comigo, que cuida de mim...; este Deus me presenteou com uma família maravilhosa e com você (Washington), para cada vez que olhar em seus olhos ou sentir o teu abraço me lembre que sou especial. Obrigada pela torcida de sempre e pelo amor incondicional. Essa vitória é nossa! 
Lima RPM. Percepção da equipe multidisciplinar acerca de fatores intervenientes na ocorrência de eventos adversos em um hospital universitário [dissertação]. São Paulo: Escola de Enfermagem, Universidade de São Paulo; 2011.

\section{RESUMO}

Os objetivos deste estudo foram analisar a percepção da equipe multidisciplinar de um hospital universitário acerca de fatores intervenientes na ocorrência de eventos adversos (EA) e relacionar os fatores intervenientes na ocorrência de EA com as dimensões de qualidade de Parasuraman, Zeilthaml e Berry. Trata-se de um estudo exploratóriodescritivo, de abordagem quantitativa, com coleta prospectiva de dados. Foi realizado em um hospital terciário de grande porte, interior do Estado de São Paulo. A população foi composta por 98 profissionais com bacharelado em saúde. A coleta de dados ocorreu no período de maio a junho de 2010, por meio da aplicação de um questionário, após a anuência do Comitê de Ética da referida instituição. Os dados foram analisados em função da estatística descritiva e aplicados testes estatísticos com significância de 5\%. Na caracterização dos profissionais verificou-se que a população constituiu-se, em sua maioria de adultos jovens, $74,5 \%$ eram do sexo feminino e que $31,6 \%$ apresentavam pós-graduação latu senso. A percepção dos profissionais acerca dos fatores intervenientes na ocorrência de EA relacionados às dimensões de qualidade, que se destacaram foram: responsividade com o direito à recusa do usuário à ser submetido á procedimentos, empatia com satisfação dos usuários e confiabilidade referente à indicação da instituição. Dentre os participantes, as categorias profissionais que mais expressaram sua percepção foram os analistas clínicos, farmacêuticos e enfermeiros. Os EA mais citados pelas categorias foram os efeitos patológicos esperados ou inesperados em bula para tratamento medicamentoso, erro de medicação e queda. Por conseguinte, esta pesquisa possibilitou conhecer a percepção da equipe multidisciplinar acerca dos fatores intervenientes na ocorrência de EA, fornecendo subsídios para a reformulação dos processos assistenciais e gerenciais com foco no gerenciamento de risco.

Descritores: qualidade da assistência à saúde, avaliação dos serviços de saúde, gerenciamento de riscos. 
Lima RPM. Perception of the multidisciplinary team about factors involved in adverse events in a university hospital [dissertation]. São Paulo: School of Nursing, Universidade de São Paulo, 2011.

\begin{abstract}
The objectives of this study were to analyze the perception of the multidisciplinary team at a university hospital about factors involved in adverse events (AE) and list the factors involved in the occurrence of adverse events with the quality dimensions of Parasuraman, Berry and Zeilthaml. This is an exploratory-descriptive study, a quantitative approach, with prospective data collection. It was conducted in a large tertiary care hospital, the State of São Paulo. The population consisted of 98 professionals with bachelor's degree in health. Data collection occurred during May-June 2010, through the application of a questionnaire, with the permission of the Ethics Committee of that institution. The data were analyzed based on descriptive statistics and statistical tests with significance of $5 \%$. In the characterization of the professionals it was found that the population consisted mostly of young adults, $74.5 \%$ were female and the level of education showed that $31.6 \%$ had graduate lato sensu. The perception of professionals about the factors involved in the occurrence of adverse events related to the dimensions of quality that stood out were: responsiveness to the user's right to refuse to undergo procedures, empathy with users' satisfaction and confidence regarding the statement of the institution. Among the participants, the professional classes were more expressed their perception analysts, pharmacists and nurses. EA categories were most often cited by the pathological effects expected or unexpected offlabel for medical treatment, medication errors and falls. Therefore, this research has helped understand the perception of the multidisciplinary team about the factors involved in the occurrence of adverse events, supporting the redesign of care processes and management focusing on risk management.
\end{abstract}

Keywords: quality of health care, evaluation of health services, risk management. 
Lima RPM. Percepción del equipo multidisciplinario sobre los factores involucrados en los eventos adversos en un hospital universitario [disertación]. São Paulo: la Escuela de Enfermería, Universidade de São Paulo;2011.

\section{RESUMEN}

Los objetivos de este estudio fue analizar la percepción del equipo multidisciplinario en un hospital de la universidad acerca de los factores involucrados en los eventos adversos (EA) y la lista de los factores que intervienen en la ocurrencia de eventos adversos con las dimensiones de la calidad de Parasuraman, Berry y Zeilthaml. Este es un estudio exploratoriodescriptivo, un enfoque cuantitativo, con la recolección de datos prospectivos. Se llevó a cabo en un hospital de tercer nivel general, el Estado de São Paulo. La población estuvo constituida por 98 profesionales con licenciatura en salud. Los datos fueron recolectados durante mayo-junio de 2010, mediante la aplicación de un cuestionario, con la autorización del Comité de Ética de dicha institución. Los datos fueron analizados con base en la estadística descriptiva y pruebas estadísticas de significación del 5\%. En la caracterización de los profesionales se encontró que la población consistía principalmente en adultos jóvenes, el $74,5 \%$ eran mujeres y el nivel de educación mostró que $31,6 \%$ tenían de postgrado lato sensu. La percepción de los profesionales sobre los factores que intervienen en la ocurrencia de eventos adversos relacionados con las dimensiones de calidad que se destacaron fueron: la capacidad de respuesta al derecho del usuario a negarse a someterse a los procedimientos, la empatía con la satisfacción de los usuarios y la confianza con respecto a la declaración de la institución. Entre los participantes, las clases profesionales eran más expresaron su percepción de los analistas, farmacéuticos y enfermeras. Categorías de EA fueron los más frecuentemente citados por los efectos patológicos esperados o inesperados fuera de la etiqueta para recibir tratamiento médico, los errores de medicación y caídas. Por lo tanto, esta investigación ha ayudado a entender la percepción del equipo multidisciplinario sobre los factores que intervienen en la ocurrencia de eventos adversos, apoyando el rediseño de los procesos de atención y gestión que se centra en la gestión de riesgos.

Palabras clave: calidad de la atención de la salud, la evaluación de los servicios de salud, gestión de riesgos. 


\section{LISTA DE ILUSTRAÇÕES}

Quadro 1 - Modelo original comparado ao modelo refinado das cinco dimensões.

Quadro 2 - Demonstrativo das dimensões de qualidade, número de questões e temas abordados .34

Quadro 3 - Conteúdo das respostas das questões abertas de 1 a 5 acerca da dimensão tangibilidade.

Quadro 4 - Conteúdo das respostas das questões abertas de 6 a 10 acerca da dimensão confiabilidade 60

Quadro 5 - Conteúdo das respostas das questões abertas de 11 a 15 acerca da dimensão responsividade .66

Quadro 6 - EA citados pelas diferentes categorias profissionais na questão -18 . .71

Quadro 7 - Conteúdo das respostas das questões abertas 16, 17, 19 e 20 acerca da dimensão garantia .76

Quadro 8 - Conteúdo das respostas das questões abertas de 21 a 25 acerca da dimensão empatia .78

Figura 1 - Organograma de um Hospital Universitário Privado 31

Figura 2 - Distribuição da amostra por faixa etária .37

Figura 3 - Distribuição da equipe multidisciplinar, segundo o tempo de formação profissional .38

Figura 4 - Distribuição da equipe multidisciplinar, de acordo com a pósgraduação (latu e strictu senso). 38

Figura 5 - Distribuição da equipe multidisciplinar, segundo o tempo de atuação na Instituição

Figura 6 - Distribuição da equipe multidisciplinar, segundo as respostas afirmativas sobre tangibilidade, questão -1 .

Figura 7 - Distribuição da equipe multidisciplinar, segundo as respostas afirmativas sobre tangibilidade, questão -2 . 
Figura 8 - Distribuição da equipe multidisciplinar, segundo as respostas afirmativas sobre tangibilidade, questão $-3 \ldots \ldots \ldots \ldots \ldots \ldots \ldots \ldots \ldots . \ldots 48$

Figura 9 - Distribuição da equipe multidisciplinar, segundo as respostas afirmativas sobre confiabilidade, questão $-6 \ldots \ldots \ldots \ldots \ldots \ldots \ldots \ldots \ldots . \ldots . \ldots \ldots$

Figura 10 - Distribuição da equipe multidisciplinar, segundo as respostas afirmativas sobre confiabilidade, questão $-8 \ldots \ldots \ldots \ldots \ldots \ldots \ldots \ldots \ldots . \ldots 55$

Figura 11 - Distribuição da equipe multidisciplinar, segundo as respostas afirmativas sobre confiabilidade, questão $-9 \ldots \ldots \ldots \ldots \ldots \ldots \ldots \ldots \ldots . \ldots . \ldots \ldots$

Figura 12 - Distribuição da equipe multidisciplinar, segundo as respostas afirmativas sobre responsividade, questão $-11 \ldots \ldots \ldots \ldots \ldots \ldots \ldots \ldots . \ldots 2$

Figura 13 - Distribuição da equipe multidisciplinar, segundo as respostas afirmativas sobre responsividade, questão $-15 \ldots \ldots \ldots \ldots \ldots \ldots \ldots \ldots . \ldots 3$

Figura 14 - Distribuição da equipe multidisciplinar, segundo as respostas afirmativas sobre garantia, questão $-16 \ldots \ldots \ldots \ldots \ldots \ldots \ldots \ldots \ldots \ldots \ldots . . .68$

Figura 15 - Distribuição da equipe multidisciplinar, segundo as respostas afirmativas sobre garantia, questão $-17 \ldots \ldots \ldots \ldots \ldots \ldots \ldots \ldots \ldots \ldots \ldots . \ldots . \ldots \ldots$

Figura 16 - Distribuição da equipe multidisciplinar, segundo as respostas afirmativas sobre garantia, questão $-18 \ldots \ldots \ldots \ldots \ldots \ldots \ldots \ldots \ldots \ldots \ldots . \ldots \ldots$ 


\section{LISTA DE TABELAS}

Tabela 1 - Comparação das categorias em relação à sexo, pós- graduação latu e strictu senso...

Tabela 2 - Comparação das categorias em relação à idade, tempo de formação e tempo de instituição.........................................42

Tabela 3 - Distribuição das repostas segundo as dimensões.....................43

Tabela 4 - Distribuição das respostas afirmativas nas questões sobre tangibilidade................................................................ 45

Tabela 5 - Distribuição das respostas afirmativas nas questões sobre

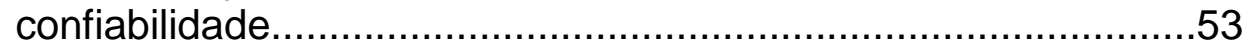

Tabela 6 - Distribuição das respostas afirmativas nas questões sobre

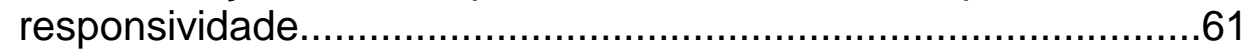

Tabela 7 - Distribuição das respostas afirmativas nas questões sobre garantia.............................................................................67

Tabela 8 - Distribuição das respostas afirmativas nas questões sobre empatia. 


\section{SUMÁRIO}

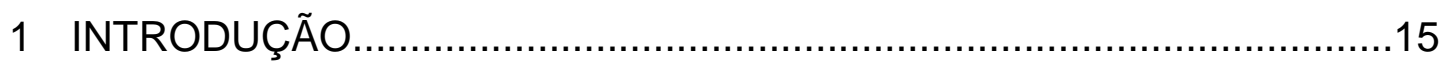

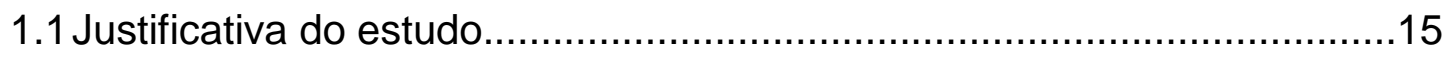

1.20 gerenciamento de risco frente ao evento adverso (EA) e suas implicações nos serviços de saúde

1.3Referencial teórico: as cinco dimensões de qualidade de Parasuraman, Zeithaml e Berry

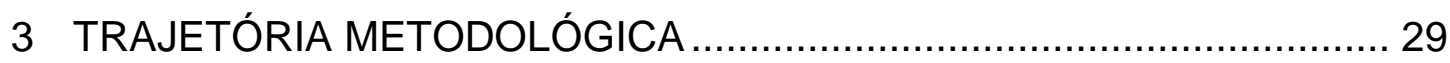

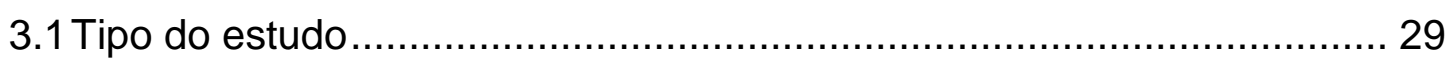

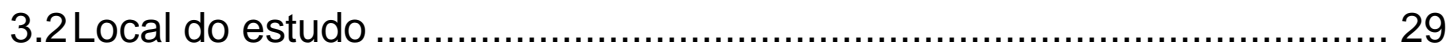

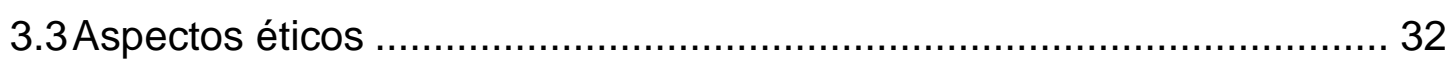

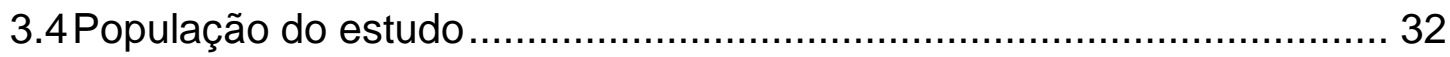

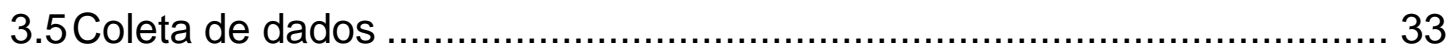

3.5.1 Instrumento de coleta de dados.......................................................

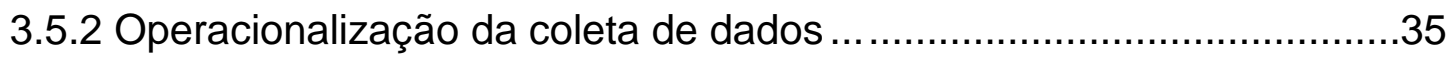

3.6 Organização e análise dos dados .......................................................... 35

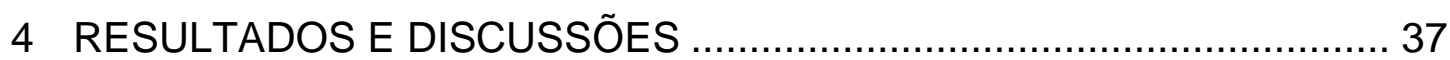

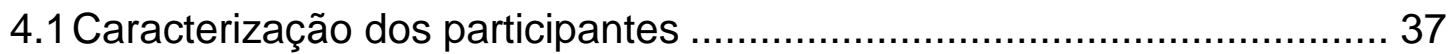

4.2Análise da relação da percepção da equipe multidisciplinar acerca de fatores intervenientes na ocorrência de EA com as cinco dimensões de qualidade de Parasuraman, Zeithaml e Berry ........................................ 43

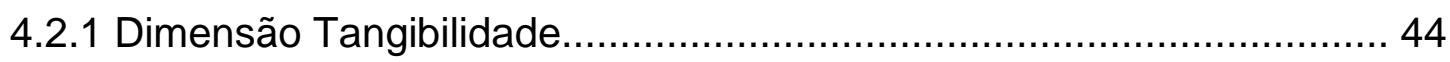

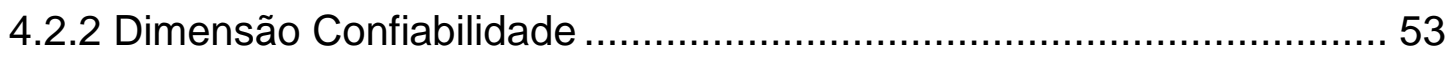

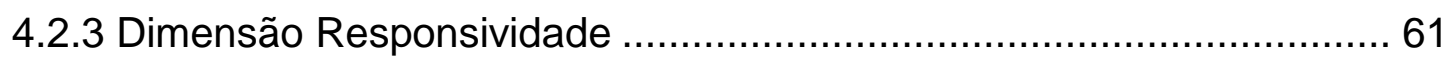

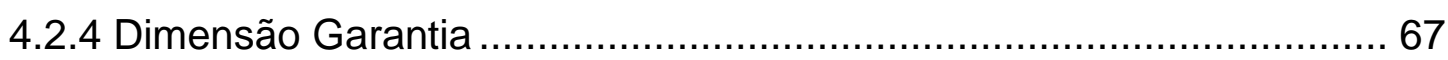

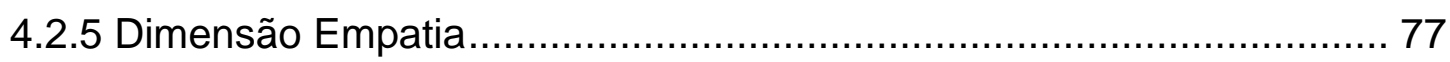

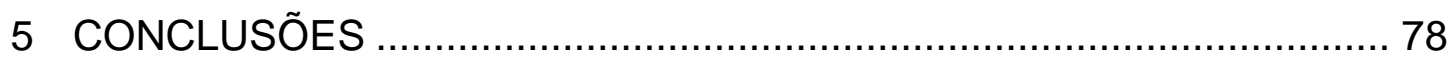

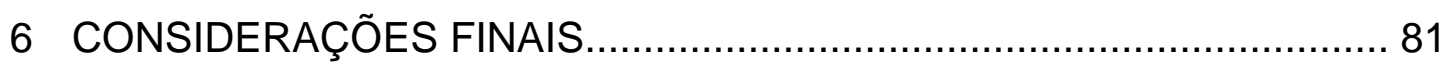

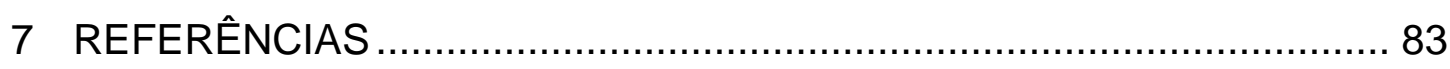

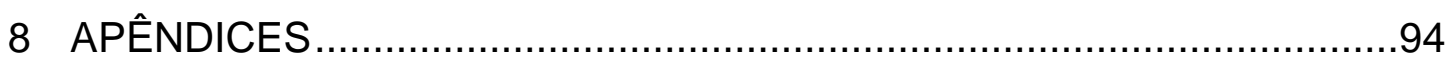




\subsection{JUSTIFICATIVA DO ESTUDO}

A avaliação sistemática dos processos de trabalho nos serviços de saúde visando à qualidade assistencial, vem constituindo-se um dos eixos norteadores das políticas que regem essas organizações. Trata-se de um processo de julgamento, mensuração e condução das estratégias institucionais, direcionadas para a melhoria da assistência, que acarretam benefícios aos usuários e aos profissionais e que garantem, dessa forma, diferencial competitivo para as referidas instituições.

Sob essa ótica, os profissionais e gestores dos serviços de saúde vêm continuamente implementando ações, que evitem ou minimizem riscos no decorrer da assistência prestada aos usuários.

Kohn (2000) destaca que os erros ou não conformidades podem ocorrer durante a assistência ao usuário e são caracterizadas como falhas na ação planejada a ser alcançada ou no emprego equivocado de um plano para atingir o objetivo desejado. Podem ocorrer em todas as fases do processo do cuidar, da prevenção ao tratamento proposto.

Nas últimas décadas com a conscientização das consequências desses erros, os profissionais de saúde passaram a envolver-se efetivamente em estratégias de prevenção. Na perspectiva de alcançar os mais elevados padrões assistenciais, iniciativas voltadas para a execução dessas estratégias tanto no âmbito das competências individuais como no emprego de novas tecnologias têm sido ponderadas por esses profissionais.

Todavia, o cenário de insatisfação dos usuários associado à máqualidade na prestação de serviços ainda encontrado em muitas organizações, demandou a criação de um padrão de qualidade, processo definido como um conjunto de atributos, que inclui nível de excelência profissional, uso eficiente de recursos, mínimo de risco ao usuário, alto grau de aceitação por parte dos usuários e efeito favorável na saúde (BRASIL, 2002).

Nesse contexto, inúmeras iniciativas governamentais ou não governamentais têm procurado desenvolver processos permanentes de avaliação e de certificação da qualidade dos serviços de saúde permitindo o 
aprimoramento contínuo da atenção ao usuário, de forma a propiciar a qualidade na assistência à saúde, bem como o cuidado humanizado (Sistema Brasileiro de Acreditação - Organização Nacional de Acrediação, 2010).

Assim, acredita-se que para atuar com qualidade é fundamental a avaliação dos serviços e a preocupação com a prevenção de riscos inerentes à área da saúde. Identificar quais são esses riscos, definir estratégias para a prevenção dos mesmos e difundir para a equipe a importância em detectá-los, é uma das propostas do gerenciamento de risco.

Para Mcclelland (1996), a definição de gerenciamento de riscos engloba um conjunto de condições que reduzem ou eliminam os erros ou não conformidades ao mínimo possível, estabelecendo padrões de qualidade no atendimento ao usuário em qualquer instituição de saúde. A auditoria de riscos é um dos métodos que viabilizam a identificação dos fatores potenciais, que ao serem analisados e tratados contribuem para a melhoria da qualidade à saúde e, consequentemente, para a segurança ao usuário.

Desse modo, os processos de auditoria tornam-se vitais para a melhoria da qualidade da assistência, podendo ser tanto retrospectivos como prospectivos.

Segundo Abboud (2009), a percepção dos profissionais relativa ao tema qualidade, leva a uma maior necessidade de atuar na previsão, provisão, execução, monitoramento e a prevenção de riscos, sendo, portanto, a avaliação da qualidade uma atividade de suma importância nos processos de trabalho dos profissionais de saúde.

Nessa direção, o corpo diretivo das organizações de saúde em consonância com seus trabalhadores, deve definir e documentar uma política para o gerenciamento de riscos. Essa política necessita ser relevante para o seu contexto estratégico e assegurar que seja incorporada, implementada e mantida em todos os níveis.

Corroborando com esses pressupostos, primeiramente atuando como enfermeira assistencial em um Serviço de Qualidade, e atualmente gerenciando as Unidades de Terapias Intensivas adulto, pediátrica e 
neonatal de uma instituição hospitalar universitária, terciária, tenho ratificado a importância de conhecer a percepção que os profissionais de saúde têm acerca de erros/não conformidades e, por consequência, de eventos adversos (EA). Isso porque a notificação de erros é um sinalizador das dificuldades ou falhas de processos/serviços que possibilitam, quando explicitados, tomadas de decisões mais assertivas.

Conforme Ribeiro (2008), a percepção "é o processo pelo qual as pessoas tomam conhecimento de si, dos outros e do mundo à sua volta". $\mathrm{O}$ processo perceptivo é uma ferramenta fundamental nos relacionamentos, pois aguça a interpretação de sinais interiores e exteriores. Provoca reflexões críticas gerando nas pessoas a necessidade de reavaliarem suas próprias crenças como mecanismo de preservação da qualidade de vida e da sua identidade humana. A percepção da sua relação de trabalho poderá advir da (re) avaliação do contrato psicológico que "assinamos" no início do relacionamento. Ele nos remete a problemas morais, relativos à prática e a cada situação específica, podendo afetar apenas a si mesmo ou a muitas pessoas. No entanto, estabelecer o que as pessoas devem fazer numa determinada situação para ser considerado positivo é um problema moral.

Diante dessas considerações e verificando as lacunas ainda existentes na literatura em relação à percepção dos profissionais de saúde acerca dos EA, é que me dispus a realizar este estudo com o intuito de conhecer essa percepção na instituição em que atuo.

\subsection{GERENCIAMENTO DE RISCO FRENTE AOS EVENTOS ADVERSOS (EA) E SUAS IMPLICAÇÕES NOS SERVIÇOS DE SAÚDE}

A gestão de riscos tem fundamental papel nas organizações de saúde, fornecendo suporte e informações aos tomadores de decisão e permitindo, dessa maneira, um ambiente seguro aos usuários e aos profissionais da área. Tem por finalidade reduzir a um nível aceitável de forma pró-ativa, os riscos identificados pelas instituições de saúde através da criação de uma cultura fundamentada na avaliação e na prevenção, em vez de ações reativas e de remediação. 
Nessa perspectiva, os programas de qualidade nos serviços de saúde têm se empenhado em promover a qualidade do ambiente, o gerenciamento dos riscos, e a observância aos padrões de conformidade, com foco na melhoria do desempenho da organização e na segurança do usuário (Hokerberg, 2006).

Os riscos devem ser identificados e analisados de acordo com a sua origem e, a partir desse diagnóstico, ações preventivas deverão ser implementadas. A análise dos riscos tem como objetivo estimar fatores que interferem na segurança e potenciais danos passíveis de acometer os usuários; tais avaliações servem de subsídios para controle e prevenção dessa exposição.

Segundo Balestrin (2003), o gerenciamento de risco é o mapeamento e o rigoroso controle de fluxos de atividades e da implantação de cultura de compartilhamento de responsabilidades, objetivando a cooperação entre as equipes e a atenção intensiva e próxima aos usuários.

Conforme Hilson (2005) existem pelo menos três áreas onde é necessário ter um desenvolvimento ativo, a curto ou médio prazo, se o gerenciamento de riscos estiver realmente comprometido em contribuir significativamente para o sucesso dos projetos e negócios. São elas: integração de gerenciamento de riscos com o gerenciamento em geral e com a cultura corporativa; aprofundamento das análises e ampliação de seu emprego e inclusão do aspecto comportamental no processo de risco; acrescenta que a significância dos riscos identificados necessita ser avaliada, priorizando os riscos-chave para futura atenção e ação. A avaliação pode ser qualitativa ao descrever características de cada risco em detalhes suficientes para permitir que eles sejam entendidos, ou quantitativa, quando emprega modelos matemáticos para simular o efeito do risco nas saídas/resultados.

Para Kohn (2000), o erro relaciona-se com dois tipos de falhas sendo a primeira de execução, quando a ação não é realizada de maneira correta e a segunda de planejamento, em que a ação planejada não é a esperada. Assim, a assistência à saúde que é por princípio uma atividade de risco, 
apresenta a necessidade de lograr pela gestão da segurança com o intuito de aprimorar e ampliar a qualidade dos seus serviços.

Feldman (2004) refere que o gerenciamento de risco é a aplicação sistêmica e contínua de políticas, procedimentos, condutas e recursos na avaliação e controle de riscos e dos EA que afetam a segurança, a saúde humana, a integridade profissional, o meio ambiente e a imagem institucional.

A gestão de riscos, segundo a Norma AS/NZS 4360:2004, elaborada pelo Comitê OB-007 de gestão de riscos, da Standards Australia e Standards New Zealand é parte integrante de uma eficaz administração e, também, elemento essencial da governança corporativa.

Kern, Lima e Feldman (2010) afirmam que a auditoria de risco complementa o conjunto de procedimentos e métodos avaliativos com 0 objetivo de estimar o potencial de danos organizacionais e à saúde. Elencam uma série de fatores de risco que, ao serem percebidos, notificados e tratados, evitam os EA. Segundo esses autores o gerenciamento de risco tem por objetivos:

- reduzir a probabilidade de ocorrência de falhas reais ou potenciais, em seus processos;

- maximizar a confiabilidade dos processos vigentes por meio da análise das falhas ocorridas;

- minimizar os erros e permitir um aumento da qualidade em procedimentos tanto clínicos como administrativos.

O risco está classificado de acordo com a probabilidade de ocorrência de um EA, situação que afeta a integridade dos profissionais de saúde ou dos usuários.

Conforme Edwards (1994), a partir da década de 1990 houve uma mudança no enfoque de EA, que evoluiu de um caráter médico-legal para estudos de melhoria da qualidade; o EA passou a ser definido como lesão que resulta em incapacidade temporária ou permanente e/ou prolongamento do tempo de permanência ou morte em serviços de saúde, como consequência do cuidado prestado. 
Adami (2000) descreve EA como toda ocorrência que resulta em um dano não intencional ao usuário e está relacionado à saúde e/ou serviços fornecidos aos usuários, não decorrente de sua condição de saúde.

$\mathrm{Na}$ literatura inglesa, segundo Galloti (2003), adverse event, é qualquer ocorrência indesejável que se apresenta durante um tratamento com um produto farmacêutico, mas não, necessariamente, tem uma relação causal com o tratamento.

O Disclosure Working Group (2008) afirma que as falhas que ocorrem durante a assistência e que resultam em injúria são chamadas de EA preveníveis.

Os EA podem ser de acordo com Marodin (2009) classificados quanto à previsibilidade, frequência, gravidade/severidade, causalidade e seriedade.

$\checkmark \quad$ Previsibilidade: são os EA descritos na literatura, no protocolo do produto a ser investigado. EA imprevisto é aquele que ainda não está descrito, incluindo eventos que possam ser sintomatologicamente e fisiopatologicamente, relacionados a outro anteriormente descrito, mas que diferem desse evento pelo grau de gravidade e especificidade;

Frequência: são considerados como muito comuns, quando a frequência é maior ou igual a 10,00\%; comuns, maior ou igual a 1,00\% e menor que $10,00 \%$; incomuns, maior ou igual a $0,10 \%$ e menor que $1,00 \%$; raros, maior ou igual a $0,01 \%$ e menor que $0,10 \%$; e muito raros, menor que $0,01 \%$;

Gravidade/Severidade: são leves, moderados, graves/severos e letais, de acordo com a intensidade das intercorrências verificadas;

Causalidade: são descritas como: definida, provável, possível, improvável, condicional (não classificado) e não classificável (não acessível), dependendo do grau de certeza da relação causa - efeito, a saber:

- Definida: situação, incluindo-se anormalidades em testes de laboratório, que ocorre em espaço de tempo plausível, em relação à administração de medicamento e que não podem ser explicados por doença de base, por medicamentos ou mesmo substâncias químicas. $O$ evento deve ser farmacologicamente ou fenomenologicamente definitivo; 
- Provável: casualidade, incluindo-se anormalidades em testes de laboratório que se apresenta em período de tempo razoável de administração do medicamento, improvável de ser atribuído a uma doença concomitante ou a outros medicamentos ou substâncias químicas;

- Possível: evento, incluindo-se anormalidades em testes de laboratório que se apresenta em período de tempo razoável de administração do medicamento, mas, que também pode ser explicado por doença concomitante, outros medicamentos ou substâncias químicas;

- Improvável: casualidade, incluindo-se anormalidades em testes de laboratório que apresenta relação temporal com a administração do medicamento que torna uma relação causal improvável e em outros medicamentos, substâncias químicas, ou doenças subjacentes, propiciam explicações plausíveis;

-Condicional (não classificado): evento, incluindo-se anormalidades em testes de laboratório notificado como sendo uma reação adversa, sobre o qual são necessários mais dados para avaliação adequada ou quando os dados adicionais estão sendo analisados;

- Não classificável (não acessível): notificação que sugere uma reação adversa que não pode ser avaliada, porque as informações são insuficientes ou contraditórias e que não pode ser completada ou verificada.

$\checkmark \quad$ Seriedade: engloba os EA sérios e não sérios que são assim classificados em função da consequência resultantes desses eventos. Um EA sério implica em morte, hospitalização, prolongamento da hospitalização ou outra consequência relevante. De acordo com a Resolução da Diretoria Colegiada - RDC ํㅜ 39, de 5 de junho de 2008, no item X, os EA sérios são definidos como aqueles em que resultem qualquer experiência adversa com fármacos ou produtos biológicos ou dispositivos, ocorrendo em qualquer dose e que resulte em qualquer um dos seguintes desfechos: óbito; EA potencialmente fatal (aquele que, na opinião do notificante, coloca 0 indivíduo sob risco imediato de morte devido ao EA ocorrido); incapacidade/invalidez persistente ou significativa que exige internação hospitalar do usuário ou prolonga internação preexistente; anomalia congênita ou defeito de nascimento. 
A Organização Mundial da Saúde (2005) considera quatro categorias de gravidade/severidade, que são: leves: reações de pouca importância e curta duração podem requerer tratamento, mas não afetam substancialmente a vida normal do usuário; moderadas: alteram a atividade normal do usuário, resultam em incapacidade transitória sem sequelas, provocam hospitalização, prolongamento da hospitalização, atenção em serviço de urgência ou falta ao trabalho; graves: reações que ameaçam diretamente a vida do usuário, anomalias congênitas, que resultem em incapacidade permanente ou significativa ou que necessitem de intervenção para prevenir sequelas e letais: reações que levam ao óbito.

A notificação de erros é uma prática adotada em vários países, em busca da diminuição dos mesmos. Sabe-se que erros notificados não representam o todo ocorrido na prática devido à subnotificação. $O$ objetivo da notificação de erros é encontrar as causas que levaram à ocorrência dos erros e quais foram as falhas ocorridas no processo. Após a identificação das causas, são implementadas estratégias de ação e correção dos processos envolvidos para evitar a repetição de erros semelhantes afetando outros usuários (Monzoni, 2006).

Para Paine (2004), os profissionais muitas vezes reconhecem o erro como perda de prestígio e pontuam que muitos dos EA poderiam ser evitados, pois são resultantes de falhas no sistema e do processo e não exclusivamente falhas humanas.

Veigas (2006) destaca que nesse contexto, o gerenciamento de riscos atrelado a um trabalho multiprofissional e interdisciplinar tem a necessidade de um planejamento estratégico, tático e operacional para caracterizar os fatores geradores de risco adequadamente, favorecer a notificação e aplicar medidas para a minimização ou eliminação dos riscos identificados.

No setor saúde, a identificação dos riscos institucionais é de fundamental importância para um adequado gerenciamento interno, pois o risco relaciona-se diretamente à qualidade da assistência, à responsabilidade civil e ao ônus decorrente dos danos causados voluntariamente ou involuntariamente, no exercício profissional (D' Innocenzo, 2006). 
Por conseguinte, torna-se imperativo que a percepção dos profissionais de saúde quanto ao EA esteja desvinculada do cunho punitivo, a fim de que essa percepção possa contribuir para uma assistência segura. Assim, quanto maior o conhecimento dos profissionais acerca do que é o gerenciamento de risco e de seus objetivos, maior a consciência dos mesmos relativa à importância da prevenção dos EA.

Frente ao que foi mencionado e acreditando que o conhecimento da percepção dos profissionais de saúde acerca dos fatores intervenientes que possibilitam a ocorrência de EA em seus processos de trabalho está intrinsecamente relacionado à melhoria da qualidade assistencial, é que se optou neste estudo, pelo estabelecimento da relação dos EA identificados com as dimensões de qualidade do referencial de qualidade descrito a seguir.

\subsection{REFERENCIAL TEÓRICO: AS CINCO DIMENSÕES DE QUALIDADE PARASURAMAN, ZEITHAML E BERRY}

A qualidade é o julgamento do usuário sobre a excelência global ou superioridade de um serviço. Assim, o conhecimento da percepção do usuário na avaliação dos serviços de saúde é relevante pela possibilidade de se adquirir informações que beneficiarão a organização desses serviços; no final da década de 80 , descreveram que a avaliação da qualidade em serviços está pautada em três características: a primeira dizia respeito à intangibilidade dos serviços, julgados pelo desempenho e experiências vivenciadas pelos usuários. A segunda considerava os serviços como heterogêneos com possibilidade de desempenho e julgamentos diferentes conforme fornecedor e o usuário. A última característica definia a produção e o consumo dos serviços como inseparáveis dificultando assim seu controle e sua avaliação (Zeithaml, Parasuraman e Berry, 1990).

A percepção de que o conhecimento existente sobre a qualidade dos produtos era insuficiente para compreender a qualidade dos serviços tornouse o ponto de partida para que Parasuraman, Zeithaml e Berry (1991) 
desenvolvessem um modelo de qualidade em serviço. Conforme esses autores, a inadequação em compreender a qualidade dos serviços procede da forma como os bens são produzidos, consumidos e avaliados. A partir do momento em que está sendo oferecido em serviço, torna-se difícil capturar, com precisão o critério que o usuário/trabalhador utiliza para sua avaliação. Sendo assim, não julgam somente um resultado, mas, também o processo da entrega do serviço e a qualidade considerando-se todos os outros aspectos essencialmente irrelevantes.

Segundo Zeithaml e Parasuraman (1990), as performances dos serviços mudam de prestador para prestador, de usuário para usuário e de dia em dia. Se a qualidade percebida está relacionada com o nível de satisfação do usuário e do trabalhador, então a satisfação é função do desempenho percebido e das expectativas.

Com o intuito de entender como os usuários percebiam e avaliavam a qualidade dos serviços, Parasuraman, Zeithaml e Berry (1991) desenvolveram um estudo constituído de doze grupos focais, sendo três em cada um dos quatro diferentes serviços investigados (banco de varejo, cartão de crédito, corretagem de ações e reparo e manutenção). Ao se basearem nas percepções comuns dos grupos focais (compostos por executivos e usuários), formalmente os referidos autores definiram qualidade do serviço como o grau e a direção da discrepância entre percepções do serviço pelos usuários e suas expectativas, sugerindo que esses utilizam os mesmos aspectos gerais do serviço para avaliação da qualidade.

Os resultados obtidos com os grupos focais confirmaram que os usuários são influenciados pelas dimensões do processo e não só pelos resultados na avaliação da qualidade do serviço. $O$ padrão de respostas obtido revelou dez critérios avaliativos gerais que os usuários utilizavam independente do tipo de serviço investigado.

Os critérios foram definidos como tangibilidade, confiabilidade, responsividade, competência, cortesia, credibilidade, segurança, acesso, compreensão do usuário e comunicação. Após a análise estatística para determinar as interrelações a respeito dessas dimensões, três permaneceram 
sem alterações: tangibilidade, confiabilidade e responsividade. Os sete critérios remanescentes foram inseridos em duas outras dimensões, a saber: garantia e empatia.

Parasuraman, Zeithaml e Berry (1991) elaboraram uma escala psicométrica das dimensões de qualidade chamada Service Quality (SERVQUAL), como a primeira tentativa para operacionalização do constructo de satisfação do usuário. A escala foi desenvolvida com o auxílio do Marketing Science Institute (MSI), com a finalidade de proporcionar um instrumento para medição da qualidade funcional aplicado a inúmeros setores de serviço.

A escala SERVQUAL após duas décadas de emprego, tem se mostrado eficiente para mensurar as percepções e expectativas dos usuários sobre a qualidade do serviço, inclusive em serviços de saúde podendo-se citar o seu emprego nas investigações de Castellanos (2002), Cruz (2010) e Pena (2010).

O estudo dessas cinco dimensões sugere que os usuários as utilizam como critérios de julgamento da qualidade do serviço. As dimensões não são mutuamente excludentes, ainda assim, fornecem uma importante estrutura para a compreensão das expectativas dos usuários sendo aspectos que delineiam o serviço sob o ponto de vista do usuário que irá julgá-lo.

Nessa direção as cinco dimensões de qualidade foram assim explicitadas:

$\checkmark \quad$ Tangibilidade: inclui a aparência das instalações físicas, equipamentos, pessoal e materiais de comunicação, representando os aspectos materiais do fornecimento que podem ser percebidos pelos cinco sentidos humanos;

Confiabilidade: é traduzida na habilidade do fornecedor executar de forma segura e eficiente o serviço. É a capacidade de prestar o serviço prometido de modo confiável. Retrata um desempenho consistente, sem falhas, no qual o usuário possa confiar. O fornecedor deve cumprir com o que foi prometido sem a possibilidade de trabalhos refeitos. Essa dimensão pode ser considerada um resultado, enquanto tangibilidade, receptividade, 
garantia e empatia são dimensões de estrutura e de processo. As expectativas dos usuários são maiores e as zonas de tolerância mais estreitas para a confiabilidade do que para as outras dimensões;

Responsividade: refere-se à disponibilidade do prestador, voluntariamente, ajudar os usuários; prestando um serviço de forma atenciosa, com precisão e rapidez de resposta. Diz respeito à disposição dos colaboradores da instituição em auxiliar os usuários e fornecer o serviço prontamente;

$\checkmark \quad$ Garantia: é identificada como a cortesia, o conhecimento dos colaboradores e suas habilidades de transmitir confiança;

Empatia: relata que a organização importa-se com o usuário e o atende de forma individualizada, referindo-se à capacidade de demonstrar interesse e atenção personalizada aos usuários. A empatia inclui acessibilidade, sensibilidade e esforço em entender as necessidades dos usuários.

A seguir, o Quadro 1 apresenta os critérios do modelo original e as alterações que resultaram no modelo refinado das dimensões de qualidade.

Quadro 1 - Modelo original comparado ao modelo refinado das cinco dimensões.

\begin{tabular}{|c|l|l|}
\hline Modelo Original & Modelo Refinado & \multicolumn{1}{|c|}{ Descrição } \\
\hline Tangibilidade & Tangibilidade & $\begin{array}{l}\text { Aspectos físicos daquilo que é fornecido aos } \\
\text { usuários. }\end{array}$ \\
\hline Confiabilidade & Confiabilidade & $\begin{array}{l}\text { Habilidade de cumprir o que foi prometido com } \\
\text { exatidão. }\end{array}$ \\
\hline Responsividade & Responsividade & $\begin{array}{l}\text { Capacidade para ajudar os usuários e fornecer o } \\
\text { serviço prontamente, capturando a noção de } \\
\text { flexibilidade e habilidade para adaptar o serviço às } \\
\text { necessidades do usuário. }\end{array}$ \\
\hline $\begin{array}{l}\text { Competência/Cortesia/ } \\
\text { Credibilidade/Segurança }\end{array}$ & Garantia & $\begin{array}{l}\text { Competência e cortesia estendida aos usuários e a } \\
\text { segurança fornecida através das operações. }\end{array}$ \\
\hline $\begin{array}{l}\text { Acesso/ Comunicação/ } \\
\text { usuário }\end{array}$ & Empreendendo o & Atenção individualizada aos usuários. \\
\hline
\end{tabular}

Fonte: Marshall G, Murdoch I. Service quality in consulting marketing engineers. International Journal for Construction Marketing (3) Oxford Brookes University, 2001. 
O emprego dessas dimensões tem se mostrado eficiente para mensurar as percepções e expectativas dos usuários sobre a qualidade do serviço. Neste estudo, a opção por este modelo avaliativo se deu por entender que as dimensões de qualidade relacionadas aos EA percebidos pelos profissionais de saúde poderão evidenciar fatores intervenientes atrelados à segurança do usuário.

Dessa forma os profissionais de saúde e usuários internos podem perceber ou não os riscos aos quais eles e os usuários externos são expostos, sendo que cada dimensão de qualidade possui uma visão abrangente das necessidades dos usuários.

Aliado a essa assertiva, as dimensões de qualidade possibilitam um olhar amplo sobre vários aspectos da assistência prestada aos usuários, os usos das mesmas focam o olhar para uma busca mais minuciosa das situações as quais os usuários são expostos e se essas oferecem ou não algum tipo de risco. Portanto, uma vez detectado o risco ou percebido um EA, é possível investigá-lo, tratá-lo e prevení-lo.

Sob esse prisma os pressupostos acima descritos fundamentaram a necessidade da realização deste estudo que tem os objetivos a seguir. 
- Analisar a percepção da equipe multidisciplinar de um hospital universitário acerca de fatores intervenientes na ocorrência de EA;

- Relacionar os fatores intervenientes na ocorrência de EA com as cinco dimensões de qualidade de Parasuraman, Zeilthaml e Berry. 


\subsection{TIPO DE ESTUDO}

Trata-se de um estudo exploratório-descritivo de abordagem quantitativa.

\subsection{LOCAL DO ESTUDO}

O estudo foi realizado em um hospital universitário privado de grande porte, nível terciário e localizado em Campinas, interior do Estado de São Paulo (SP).

Atualmente o referido hospital conta com 350 leitos, sendo 240 destinados ao Sistema Único de Saúde (SUS), por meio de contrato com a Prefeitura Municipal e 110 direcionados aos usuários particulares e portadores de convênios privados.

A citada instituição hospitalar possui 28 leitos destinados às Unidades de Terapia Intensiva Adulto e Coronária; 25 à Unidade de Terapia Intensiva Infantil e Neonatal; 23 à Urgência e Emergência, e 274 à Internação, divididos em: Clínica Médica, Cirúrgica, Materno-infantil, Moléstias infectocontagiosas, Pediatria e Psiquiatria; quatro salas de procedimentos obstétricos e 12 salas para procedimentos cirúrgicos.

A estrutura organizacional dessa instituição (Figura 1) é composta por uma Superintendência, um Colegiado de Diretores (Clínico, Administrativo e de Enfermagem), Gestores das Unidades de Negócio (Administrativas, Apoio e Assistenciais). Tem por missão interna implementar políticas de aprimoramento contínuo e tratamento em equipe, considerando seus objetivos e sua vocação de hospital universitário. A missão externa é fundamentada no supremo valor da vida e na dignidade humana e em proporcionar atendimento de qualidade e contribuir para a promoção do conhecimento.

A instituição possui como recursos próprios não terceirizados: uma farmácia central e cinco satélites, serviço de nutrição e dietética e laboratório de análises clínicas, todos localizados nas dependências da instituição. 
Frente à preocupação constante com a qualidade dos serviços, conta com um Serviço de Qualidade que atua como consultor para todos os setores e, ainda, acompanha e intervém nos resultados por eles apresentados.

Quanto aos recursos humanos a instituição tem em seu quadro aproximadamente 2.100 colaboradores. 


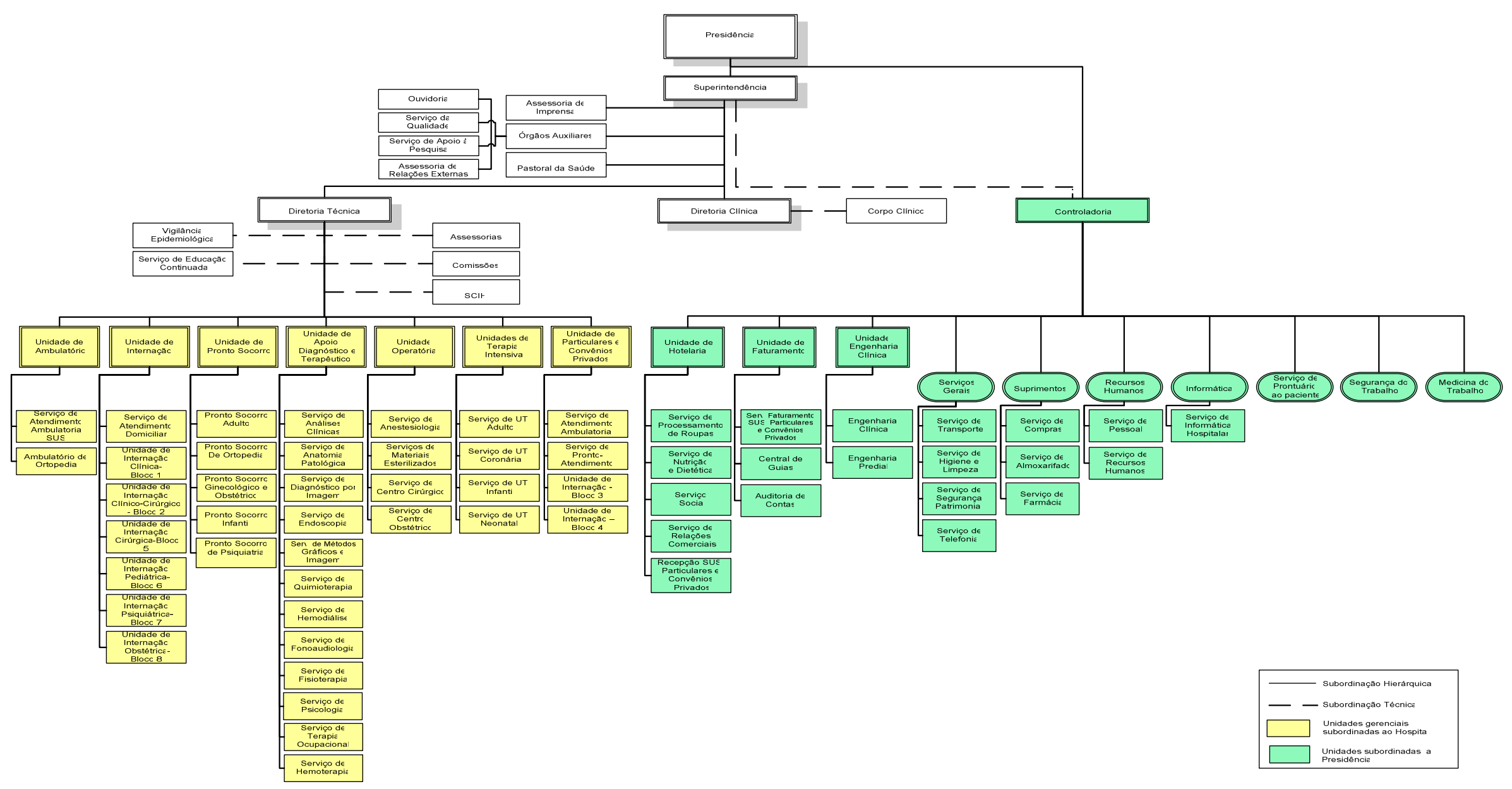

Figura 1 - Organograma de um Hospital Universitário Privado, 2011.

Fonte: Gerência de Projetos, da referida instituição, 2011 


\subsection{ASPECTOS ÉTICOS}

O projeto de pesquisa foi encaminhado ao Comitê de Ética em Pesquisa* - CEP (Apêndice 1), respeitando-se os trâmites legais estabelecidos por esse órgão e a Superintendência da instituição com esclarecimentos sobre o teor e os objetivos da pesquisa (Apêndice 2).

Após a anuência desses órgãos para a realização do estudo, os participantes que atendiam aos critérios de inclusão foram convidados e esclarecidos acerca dos objetivos da pesquisa e receberam o Termo de Consentimento Livre e Esclarecido (Apêndice 3), elaborado conforme as normas da Resolução 196/96, que versa sobre os aspectos éticos em pesquisa envolvendo seres humanos (Conselho Nacional de Saúde, 1996), em duas vias para sua assinatura. Garantiu-se aos participantes, o sigilo das informações, a voluntariedade na participação e a possibilidade de interromper o preenchimento do instrumento e a qualquer momento, sem penalidade alguma e sem prejuízo em seu tratamento.

Cabe salientar que este estudo não incorreu em nenhum risco de caráter físico ou psicológico aos participantes, estando o mesmo livre para optar em não participar do estudo.

\subsection{POPULAÇÃO DO ESTUDO}

A população foi constituída por profissionais da saúde, com ensino superior, que atenderam aos seguintes critérios de elegibilidade:

- Profissionais que estivessem atuando na assistência direta ao usuário;

- Profissionais com no mínimo 12 meses de atuação na instituição cenário deste estudo.

\footnotetext{
* O documento de aprovação da pesquisa não se encontra anexado a esta dissertação, em virtude do compromisso de anonimato. Todavia, encontra-se em poder da pesquisadora podendo ser solicitado quando necessário.
} 
Desse modo, 241 profissionais atendiam aos critérios e aceitaram participar da pesquisa correspondendo a seis nutricionistas, sete farmacêuticas, dez fisioterapeutas, 15 analistas clínicos, 97 enfermeiros e 106 médicos. Desses 98 (41\%) devolveram o instrumento de coleta de dados, sendo: 3 (50\%) nutricionistas, 4 (57\%) farmacêuticos, 7 (70\%) fisioterapeutas, 11 (73\%) analistas clínicos, 47 (48\%) enfermeiros e 26 (24\%) médicos, os quais constituíram-se os sujeitos desta pesquisa .

\subsection{COLETA DE DADOS}

A coleta de dados ocorreu no período de maio a julho de 2010, por meio da aplicação de um questionário, intitulado: "Percepção de uma equipe multidisciplinar acerca de fatores intervenientes na ocorrência de eventos adversos em um hospital universitário" (Apêndice 4).

\subsubsection{Instrumento de Coleta de Dados}

O instrumento de coleta de dados constituiu-se de suas partes sendo a primeira parte relativa aos dados sócio-demográficos dos participantes e a segunda parte referente à percepção dos profissionais em relação ao EA, a qual foi subdividida em questões fechadas e abertas. Nas questões abertas os participantes tinham a oportunidade de se manifestarem frente a positividade e negatividade de sua resposta.

$O$ referido instrumento teve por finalidade avaliar a percepção das diferentes categorias profissionais sobre EA relacionando-as com as cinco dimensões de qualidade de Parasuraman, Zeithaml e Berry: confiabilidade, responsividade, tangibilidade, garantia e empatia. Para cada dimensão, foram elaboradas cinco questões relacionando-se fatores intervenientes à ocorrência de EA com as dimensões de qualidade.

O Quadro 2 demonstra as dimensões com as questões e temas abordados. 
Cabe salientar que um pré-teste foi realizado no intuito de verificar a pertinência do instrumento não sendo necessária a reestruturação do mesmo.

Quadro 2 - Demonstrativo das dimensões de qualidade, número de questões e temas abordados, São Paulo (Interior de SP) - 2010

\begin{tabular}{|c|c|c|}
\hline DIMENSÃO & QUESTÃO & TEMÁTICA \\
\hline \multirow{5}{*}{ Tangibilidade } & 01 & Recursos humanos, materiais e físicos. \\
\hline & 02 & Segurança relacionada aos equipamentos. \\
\hline & 03 & $\begin{array}{l}\text { Participação nas políticas de aquisição de } \\
\text { recursos materiais. }\end{array}$ \\
\hline & 04 & Dimensionamento de pessoal. \\
\hline & 05 & Riscos relacionados à estrutura. \\
\hline \multirow{5}{*}{ Confiabilidade } & 06 & Protocolos estabelecidos. \\
\hline & 07 & Execução das atividades com segurança. \\
\hline & 08 & Indicação da instituição. \\
\hline & 09 & $\begin{array}{l}\text { Participação dos profissionais em quanto } \\
\text { ouvintes dos usuários. }\end{array}$ \\
\hline & 10 & $\begin{array}{l}\text { Informação aos usuários quanto aos } \\
\text { riscos. }\end{array}$ \\
\hline \multirow{5}{*}{ Responsividade } & 11 & Avaliação dos processos. \\
\hline & 12 & Direito à recusa ao tratamento. \\
\hline & 13 & Comunicação. \\
\hline & 14 & Manual de orientações. \\
\hline & 15 & Elaboração de protocolos. \\
\hline \multirow{5}{*}{ Garantia } & 16 & Monitorização dos processos. \\
\hline & 17 & Monitorização dos riscos. \\
\hline & 18 & Conceito de EA. \\
\hline & 19 & Informação dos EA ocorridos. \\
\hline & 20 & Ações frente aos EA. \\
\hline \multirow{5}{*}{ Empatia } & 21 & Atendimento empático. \\
\hline & 22 & Foco nas necessidades dos usuários. \\
\hline & 23 & Satisfação dos usuários. \\
\hline & 24 & Capacitação profissional. \\
\hline & 25 & Inserção do tema para os profissionais. \\
\hline
\end{tabular}




\subsubsection{Operacionalização da Coleta de Dados}

De posse do documento de anuência para a realização da pesquisa, a pesquisadora realizou reuniões com os coordenadores dos profissionais envolvidos, a fim de esclarecer os objetivos do estudo.

Aos profissionais, orientações e esclarecimentos foram feitos pessoalmente e uma vez que manifestavam o interesse em participar e atendiam os critérios de inclusão, era entregue o instrumento junto com uma carta elucidativa e solicitado que devolvessem o instrumento no prazo de dez dias.

Para a devolução do instrumento a pesquisadora comprometeu-se a retirá-lo no local de trabalho dos participantes.

Ressalta-se que o prazo para devolução do instrumento necessitou ser estendido por mais 30 dias.

\subsection{ORGANIZAÇÃO E A ANÁLISE DOS DADOS}

Os dados foram armazenados em planilha eletrônica Excel $^{R}$ para o processamento. Para a análise, foram utilizados os recursos de computação por meio do processamento no sistema Windows Excel ${ }^{R}$ e Statistic Package for Social Sciences ${ }^{R}\left(\right.$ SPSS $\left.^{R}\right)$ versão 15.0, ambos em ambiente Windows $X P$.

As variáveis foram estatisticamente analisadas de forma descritiva e da mesma maneira foi conduzida à apresentação dos resultados da pesquisa.

Inicialmente todas as variáveis foram analisadas descritivamente. Para as variáveis quantitativas esta análise foi feita através da observação dos valores mínimos e máximos e do cálculo de médias, desvios-padrão e mediana. Para as variáveis qualitativas calcularam-se frequências absolutas e relativas.

As questões, majoritariamente, foram elaboradas de forma que as respostas afirmativas apontassem para a percepção dos profissionais, uma 
vez que a negação pode indicar o desconhecimento, ou ainda, a não percepção.

Para a comparação das categorias em relação à idade, tempo de formação e tempo de instituição foi utilizado o teste não-paramétrico de Kruskal-Wallis, com comparações múltiplas realizadas através do teste de Duun, pois a suposição de normalidade dos dados foi rejeitada.

A homogeneidade entre as proporções foi testada utilizando-se 0 teste exato de Fisher, o qual ocorre conforme Rosner (1986), quando forem observadas frequências menores que 5 . O nível de significância utilizado para os testes foi de $5 \%$. 
4 RESULTADOS E DISCUSSÃO 
Os achados deste estudo foram analisados em dois itens, a saber: caracterização dos participantes e análise da relação da percepção da equipe multidisciplinar acerca dos fatores intervenientes na ocorrência de EA com as cinco dimensões de qualidade de Parasuraman, Zeithaml e Berry.

\subsection{CARACTERIZAÇÃO DOS PARTICIPANTES}

Os resultados apresentados a seguir caracterizam os participantes deste estudo quanto à faixa etária, gênero, tempo de formação, tipo de pósgraduação latu e strictu-senso e tempo na instituição.

A Figura 2 contempla a idade dos participantes, que variou entre $23 \mathrm{e}$ 55 anos (média de 35,84 anos com desvio-padrão de 8,59 anos e mediana de 33 anos).

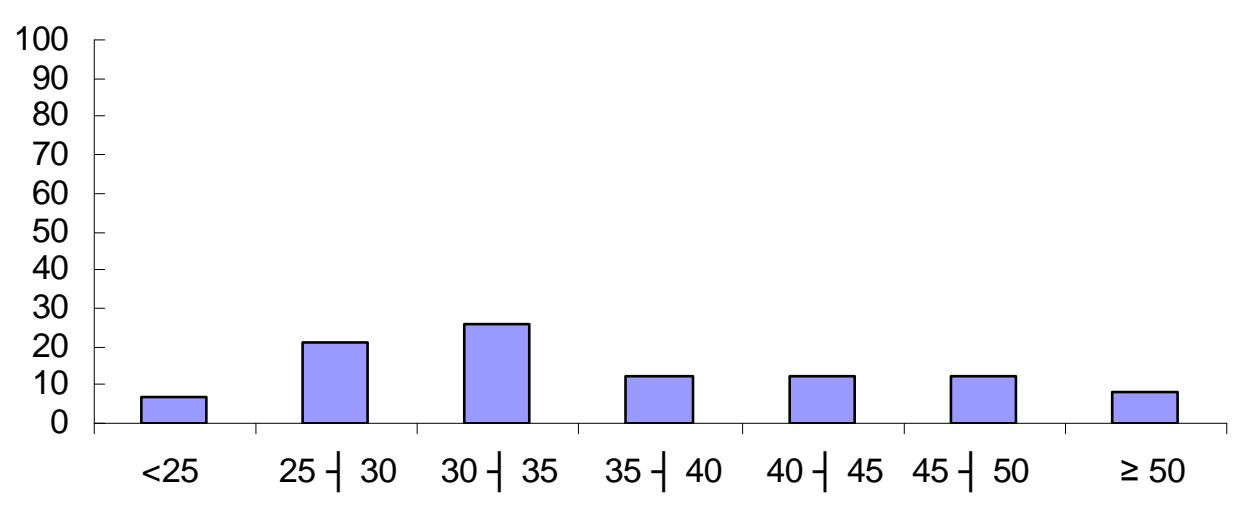

Faixa etária (em anos)

Figura 2 - Distribuição da amostra por faixa etária, São Paulo (Interior - SP) - 2010

Observou-se, na Figura 2, que a idade predominante esteve na faixa etária de 30 a 35 anos, representada por 26 (26,5\%) dos participantes, seguida de 21 (21,4\%) participantes, com idade entre 25 a 30 anos e 12 $(12,2 \%)$ entre 35 a 50 anos evidenciando a predominância de adultos jovens.

A referida instituição investe no desenvolvimento e na qualificação profissional possuindo programa de residência multidisciplinar, incentivo a pós-graduação e acolhimento ao recém-formado, justificando a concentração de adultos jovens em seu quadro funcional. 
Quanto ao gênero constatou-se que $73(74,5 \%)$ profissionais eram do sexo feminino e $25(25,5 \%)$ do sexo masculino.

O tempo de formado variou de 1 a 32 anos (média de 11,36 anos com desvio-padrão de 7,80 anos e mediana de 9 anos), conforme Figura 3.

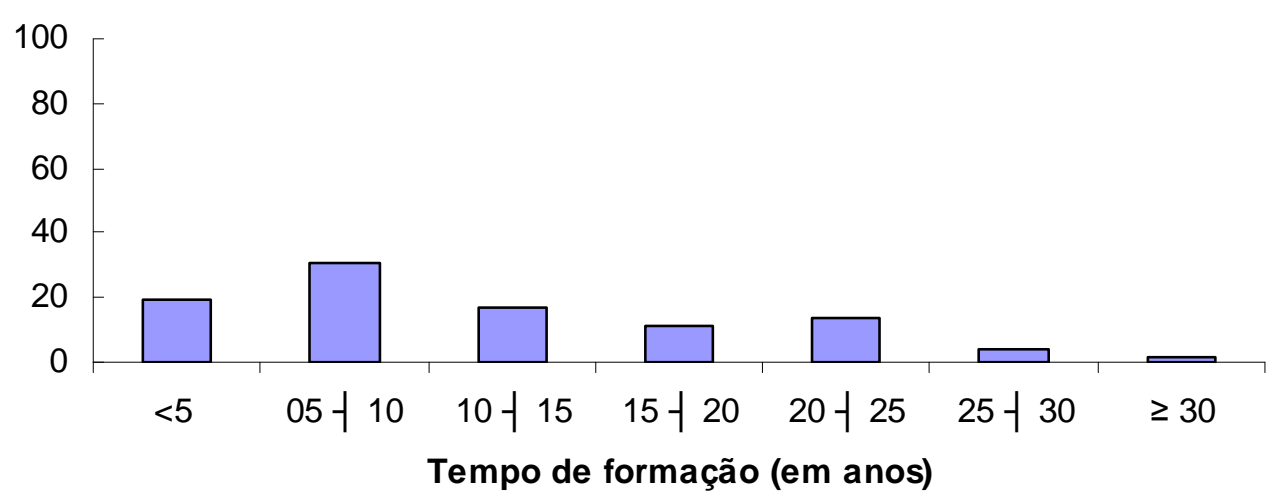

Figura 3 - Distribuição da equipe multidisciplinar, segundo o tempo de formação profissional, São Paulo (Interior - SP) - 2010

Por tratar-se de um hospital universitário, há um expressivo contingente de profissionais $50(51 \%)$ com até 10 anos de formação profissional conforme referido anteriormente. Isso também permite inferir que os participantes são profissionais com relativa experiência e que detêm elementos para perceber e analisar a qualidade da assistência prestada na instituição.

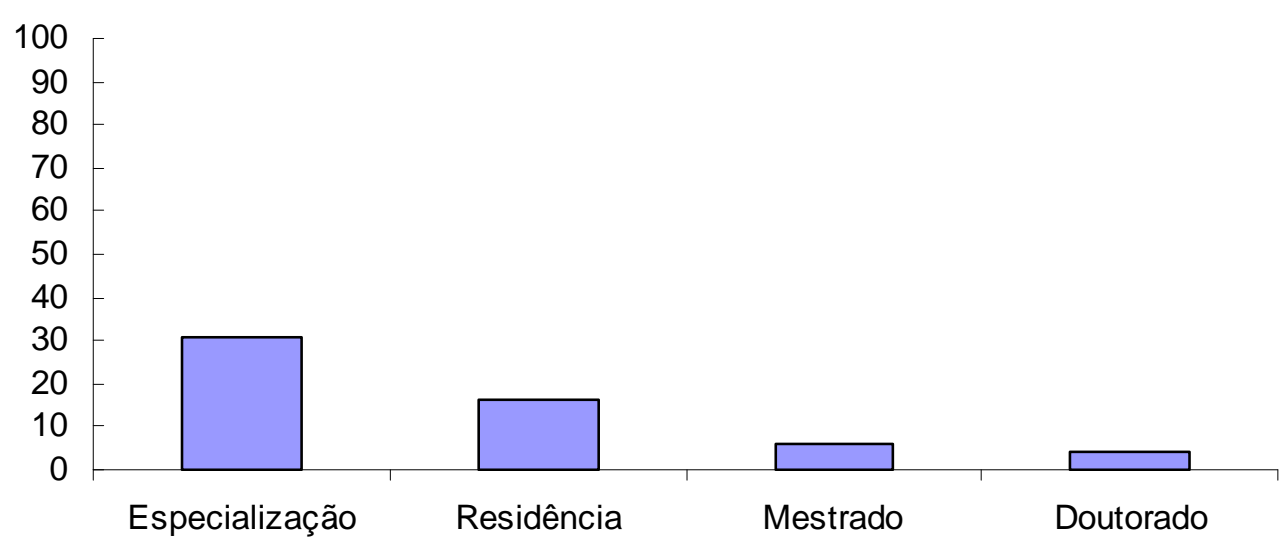

Figura 4 - Distribuição da equipe multidisciplinar, de acordo com a pós - graduação (latu e strictu senso), São Paulo (Interior - SP) - 2010

Verificou-se por meio da Figura 4 que $31(31,6 \%)$ profissionais tinham especialização, $16(16,3 \%)$ residência, $6(6,1 \%)$ mestrado e $4(4,1 \%)$ doutorado. 
Embora haja nesta instituição política de desenvolvimento de recursos humanos, constatou-se que o ingresso de profissionais na pós-graduação strictu senso não é o esperado quantitativamente.

Acredita-se que as dificuldades para aquisição de bolsas devido à exigência dos órgãos de fomento do não vínculo empregatício, favorecem muitas vezes, o distanciamento dos profissionais dos cursos de pósgraduação. Aliado a isso, muitos profissionais têm a idéia de que o ingresso na pós-graduação strictu senso está atrelado, unicamente, à carreira acadêmica.

Nessa direção, inúmeras são as iniciativas para melhorar o cenário da pós-graduação nos serviços de saúde. Segundo Hortale et al. (2010), há mais de quatro décadas o Ministério da Educação implementou um programa de formação de pessoal de nível superior (mestrado e doutorado), tendo como referência o modelo norte-americano de formação pósgraduada. Ainda segundo estes autores, até 1995, a expressão "mestrado" não distinguia a natureza acadêmica ou profissional do curso embora fosse crescente o número de instituições que qualificavam profissionais para atuar nos serviços e não somente na docência. Nesse ano, a Coordenação de Aperfeiçoamento de Pessoal de Nível Superior (CAPES), órgão do Ministério da Educação que atua na expansão, regulação e avaliação da pósgraduação stricto sensu no país, ao constatar que mudanças técnicas, econômicas e sociais demandavam profissionais com perfis de alta qualificação e produtividade, flexibilizou seu modelo criando a modalidade profissional de mestrado, que não se destinava necessariamente à formação de docentes e pesquisadores do ensino superior. Além de fomentar os processos de qualificação acadêmico-científica - que orientam o mestrado acadêmico e o doutorado, a CAPES passou a credenciar uma nova modalidade de mestrado, o profissional ou profissionalizante (MP). Este inclui em seus objetivos a inovação na orientação curricular, na composição do corpo docente e discente e no financiamento e nas parcerias institucionais, tornando-se dessa forma, uma alternativa para os profissionais de saúde. 


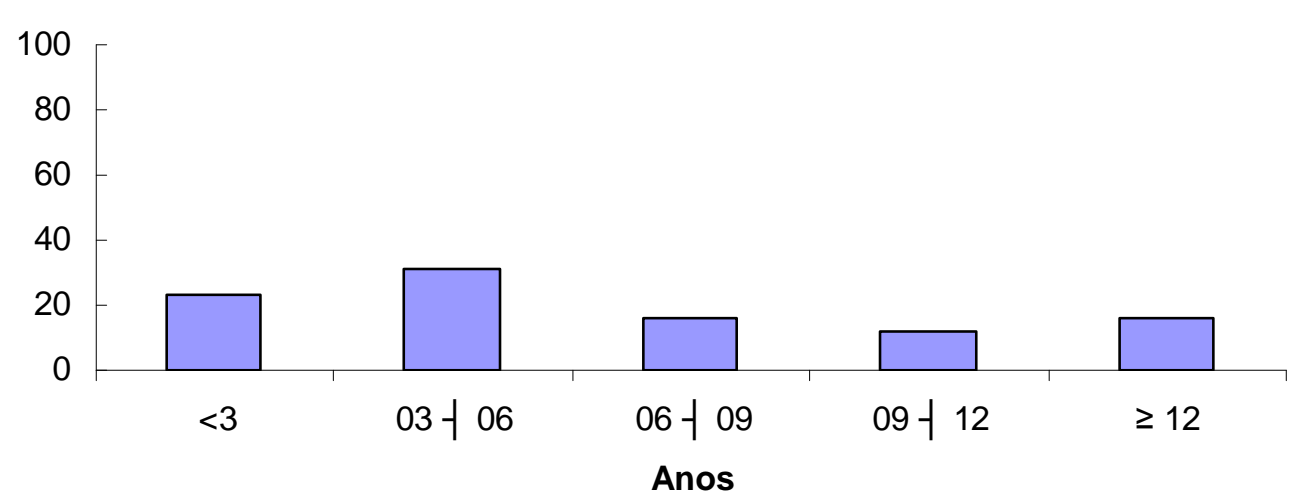

Figura 5 - Distribuição da equipe multidisciplinar, segundo o tempo de atuação na Instituição, São Paulo (Interior - SP) - 2010

O tempo de trabalho na instituição variou de 1 a 24 anos (média de 6,73 anos com desvio-padrão de 5,67 anos e mediana de 5 anos), conforme averiguou-se na Figura 5.

Nesse contexto constatou-se a predominância de profissionais que atuam na instituição na faixa de 3 a 6 anos, representados por 31 (31,6\%).

De acordo com Anselmi, Guarte e Angerami (2001) até a década de 70, o emprego em saúde vinha crescendo numa taxa média de $13 \%$ ao ano, mas, no final desse período, passou a ser de $8,6 \%$ ao ano. Entre 1980 e 1984, o número de postos de trabalho em saúde cresceu em torno de $4 \%$ e, na presente década, o emprego formal em serviços de saúde apresenta uma média anual geométrica de crescimento de aproximadamente $2 \%$ ao ano. Ainda de acordo com essas autoras, estimativas baseadas em dados da Relação Anual de Informações Sociais (RAIS) e do Cadastro Geral de Empregados e Desempregados (CAGED) do Ministério do Trabalho, existem cerca de 2,15 milhões de pessoas empregadas em atividades de saúde, o que representava cerca de $9 \%$ do total de empregos existentes na economia formal do país.

A existência de planos de carreira nas instituições vem se mostrando uma estratégia para a retenção dos profissionais. Conforme Almeida (2009) o plano de carreira tem por objetivo colocar a pessoa nos trilhos do sucesso pessoal, profissional, familiar e comunitário, programando, assim, o crescimento nas quatro áreas de maneira eficaz. Possibilita, também, programar o tempo necessário para alcançar os objetivos e avaliar se os conhecimentos são suficientes ou não para realizar os projetos. 
Para melhor caracterização da população apresentada neste estudo, as categorias foram comparadas em relação às variáveis: idade, sexo, tempo de formação, tempo de instituição, pós-graduação latu senso (especialização e residência) e strictu senso (mestrado e doutorado).

Tabela 1 - Comparação das categorias em relação à sexo, pós- graduação latu e strictu senso, São Paulo (Interior - SP) - 2010

Categorias

\begin{tabular}{|c|c|c|c|c|c|c|c|c|}
\hline Variável & & $\begin{array}{c}\text { Analista } \\
\text { Clínico } \\
\end{array}$ & $\begin{array}{l}\text { Farma- } \\
\text { cêutico }\end{array}$ & $\begin{array}{c}\text { Fisiotera- } \\
\text { peuta }\end{array}$ & $\begin{array}{l}\text { Enfer- } \\
\text { meiro }\end{array}$ & Médico & $\begin{array}{c}\text { Nutrício- } \\
\text { nista }\end{array}$ & $\mathrm{p}^{*}$ \\
\hline Sexo & $\mathrm{n}$ & 9 & 4 & 7 & 34 & 16 & 3 & 0,263 \\
\hline Fem & $\%$ & 12,3 & 5,5 & 9,6 & 46,6 & 21,9 & 4,1 & \\
\hline Latu & $\mathrm{n}$ & 4 & 2 & 5 & 19 & 13 & 2 & 0,627 \\
\hline senso & $\%$ & 8,9 & 4,4 & 11,1 & 42,2 & 28,9 & 4,4 & \\
\hline Strictu & $\mathrm{n}$ & 3 & 0 & 0 & 2 & 5 & 0 & 0,116 \\
\hline Senso & $\%$ & 30 & 0 & 0 & 20 & 50 & 0 & \\
\hline
\end{tabular}

Observou-se pela Tabela 1, que as categorias não diferem em relação ao sexo, pós-graduação latu e strictu senso. 
Tabela 2 - Comparação das categorias em relação à idade, tempo de formação e tempo de instituição, São Paulo (Interior - SP) - 2010

\begin{tabular}{llccccc}
\hline Variável & Categorias & $\mathrm{n}$ & Média & $\mathrm{dp}$ & Mediana & $\mathrm{p}^{*}$ \\
\hline \multirow{4}{*}{ Idade } & Analista Clínico & 11 & 37,82 & 4,94 & 37 & \\
& Farmacêutico & 4 & 31 & 4,24 & 31,5 & \\
& Fisioterapeuta & 7 & 36,71 & 7,74 & 38 & $<0,001$ \\
& Enfermeiro & 47 & 32,06 & 6,94 & 31 & \\
& Médico & 26 & 43,08 & 8,87 & 46 & \\
& Nutricionista & 3 & 29,33 & 3,21 & 28 & \\
Tempo & Analista Clínico & 11 & 13,18 & 5,72 & 13 & \\
de & Farmacêutico & 4 & 8,25 & 2,36 & 9 & \\
Formação & Fisioterapeuta & 7 & 13,29 & 7,06 & 13 & $<0,001$ \\
& Enfermeiro & 47 & 7,98 & 5,5 & 7 & \\
& Médico & 26 & 17,46 & 9,15 & 20 & \\
& Nutricionista & 3 & 4,33 & 3,21 & 3 & \\
& & & & & & \\
& Analista Clínico & 11 & 12,91 & 6,04 & 14 & \\
Tempo de & Farmacêutico & 4 & 4 & 2,45 & 3,5 & \\
Instituição & Fisioterapeuta & 7 & 7,29 & 6,95 & 5 & $<0,001$ \\
& Enfermeiro & 47 & 4,28 & 3,15 & 4 & \\
& Médico & 26 & 9,35 & 6,35 & 8,5 & \\
\hline
\end{tabular}

$\left(^{*}\right)$ nível descritivo de probabilidade do teste não-paramétrico de Kruskal-Wallis

Por meio da Tabela 2, averiguou-se que os as categorias diferem em relação à idade, tempo de formação e tempo de instituição.

Em relação à idade a categoria de médicos difere significativamente da categoria de enfermeiros, farmacêuticos e nutricionistas (teste de Dunn, $p<0,05)$, apresentando maior idade que as outras três categorias.

Concernente ao tempo de formação dos médicos difere significativamente da categoria de enfermeiros e de nutricionistas (teste de Dunn, $p<0,05$ ), apresentando maior tempo que as outras duas categorias.

Quanto ao tempo de instituição a categoria de analistas difere significativamente da categoria de farmacêuticos, enfermeiros e nutricionistas (teste de Dunn, $\mathrm{p}<0,05$ ), apresentando tempo significativamente maior que as outras três categorias. 


\subsection{ANÁLISE DA PERCEPÇÃO DA EQUIPE MULTIDISCIPLINAR} ACERCA DE FATORES INTERVENIENTES RELACIONADOS À OCORRÊNCIA DE EA COM AS CINCO DIMENSÕES DE QUALIDADE DE PARASURAMAN, ZEITHAML E BERRY

Neste tópico são apresentados e analisados os dados coletados referentes às questões fechadas (tabelas e gráficos) e abertas (quadros) relacionados às dimensões de qualidade. A Tabela 3 apresenta as respostas afirmativas e negativas frente às cinco dimensões de qualidade.

Tabela 3 - Distribuição das repostas segundo as dimensões, São Paulo (Interior - SP) 2010

\begin{tabular}{|c|c|c|c|c|c|}
\hline \multirow{2}{*}{ Dimensão } & \multirow{2}{*}{ Questões } & \multicolumn{2}{|c|}{ Afirmativas } & \multicolumn{2}{|c|}{ Negativas } \\
\hline & & $\mathbf{n}$ & $\%$ & $\mathbf{n}$ & $\%$ \\
\hline \multirow{5}{*}{ Tangibilidade } & P1 & 83 & 84,7 & 14 & 14,3 \\
\hline & P2 & 72 & 73,5 & 26 & 26,5 \\
\hline & P3 & 58 & 59,2 & 40 & 40,8 \\
\hline & P4 & 40 & 40,8 & 57 & 58,2 \\
\hline & P5 & 38 & 38,8 & 60 & 61,2 \\
\hline \multirow{5}{*}{ Confiabilidade } & P6 & 76 & 77,6 & 22 & 22,4 \\
\hline & P7 & 83 & 84,7 & 14 & 14,3 \\
\hline & P8 & 86 & 87,8 & 11 & 11,2 \\
\hline & P9 & 78 & 79,6 & 20 & 20,4 \\
\hline & P10 & 60 & 61,2 & 38 & 38,8 \\
\hline \multirow{5}{*}{ Reponsividade } & P11 & 56 & 57,1 & 41 & 41,8 \\
\hline & P12 & 94 & 95,9 & 4 & 4,1 \\
\hline & P13 & 53 & 54,1 & 45 & 45,9 \\
\hline & P14 & 48 & 49 & 50 & 51 \\
\hline & P15 & 67 & 68,4 & 31 & 31,6 \\
\hline \multirow{5}{*}{ Garantia } & P16 & 59 & 60,2 & 37 & 37,8 \\
\hline & P17 & 61 & 62,2 & 36 & 36,7 \\
\hline & P18 & 53 & 54,1 & 42 & 42,9 \\
\hline & P19 & 43 & 43,9 & 53 & 54,1 \\
\hline & P20 & 43 & 43,9 & 53 & 54,1 \\
\hline \multirow{5}{*}{ Empatia } & P21 & 79 & 80,6 & 16 & 16,3 \\
\hline & P22 & 73 & 74,5 & 25 & 25,5 \\
\hline & P23 & 92 & 93,9 & 6 & 6,1 \\
\hline & P24 & 55 & 56,1 & 40 & 40,8 \\
\hline & P25 & 60 & 61,2 & 38 & 38,8 \\
\hline
\end{tabular}


Por meio da Tabela 3, evidenciou-se que a dimensão que possui maior predominância de respostas afirmativas foi a responsividade 94 $(95,9 \%)$ referente ao direito à recusa do usuário em submeter-se a algum tipo de tratamento, seguida da dimensão empatia $92(93,9 \%)$ relativa à satisfação dos usuários e a dimensão de confiabilidade 86 (87,8\%) quanto à indicação da instituição.

Observou-se que as dimensões que predominavam relacionam-se a aspectos subjetivos, sendo possível inferir a preocupação dos participantes com relação aos processos e aos resultados dos serviços prestados.

A dimensão com menor predominância de respostas afirmativas foi a tangibilidade $38(38,8 \%)$ referente a riscos relacionados à estrutura; tal fato é preocupante abrindo precedente para questionamentos quanto às estratégias que estão sendo empregadas para a monitorização dos riscos e a eficiência das ações frente aos mesmos.

Cabe destacar a convergência entre este estudo e os resultados encontrados previamente por Parasuraman, Zeithaml e Berry (1991) de que a confiabilidade é uma das dimensões mais pontuadas e a tangibilidade a menos citada para o alcance da qualidade dos serviços.

Com o intuito de descrever o comportamento das categorias em relação às 25 questões, os resultados da Tabela 3 foram subdivididos, no que tange à análise das respostas frente às cinco dimensões, conforme Tabelas 4, 5, 6, 7 e 8.

\subsubsection{Dimensão Tangibilidade}

Os aspectos tangíveis abordados neste estudo dizem respeito às instalações físicas, aos recursos humanos, materiais e equipamentos, representando, dessa forma, a estrutura propriamente dita na oferta dos serviços de saúde. 
Tabela 4 - Distribuição das respostas afirmativas nas questões sobre tangibilidade, São Paulo (Interior - SP) - 2010

\section{Categorias}

\begin{tabular}{|c|c|c|c|c|c|c|c|c|}
\hline Questões & & $\begin{array}{c}\text { Analista } \\
\text { Clínico }\end{array}$ & $\begin{array}{l}\text { Farma- } \\
\text { cêutico } \\
\end{array}$ & $\begin{array}{c}\text { Fisiotera- } \\
\text { peuta }\end{array}$ & $\begin{array}{l}\text { Enfer- } \\
\text { meiro }\end{array}$ & Médico & $\begin{array}{c}\text { Nutrício- } \\
\text { nista }\end{array}$ & $p^{*}$ \\
\hline \multirow[t]{2}{*}{1} & $n$ & 9 & 4 & 6 & 45 & 18 & 1 & 0,005 \\
\hline & $\%$ & 81,8 & 100 & 85,7 & 95,7 & 69,2 & 33,3 & \\
\hline \multirow[t]{2}{*}{2} & $\mathrm{n}$ & 11 & 4 & 3 & 41 & 11 & 2 & 0,003 \\
\hline & $\%$ & 100 & 100 & 42,9 & 87,2 & 42,3 & 66,7 & \\
\hline \multirow[t]{2}{*}{3} & $n$ & 10 & 2 & 3 & 32 & 8 & 3 & 0,001 \\
\hline & $\%$ & 90,9 & 50 & 42,9 & 68,1 & 30,8 & 100 & \\
\hline \multirow[t]{2}{*}{4} & $\mathrm{n}$ & 4 & 2 & 3 & 21 & 8 & 2 & 0,776 \\
\hline & $\%$ & 36,4 & 50 & 42,9 & 44,7 & 30,8 & 66,7 & \\
\hline \multirow[t]{2}{*}{5} & $\mathrm{n}$ & 4 & 0 & 5 & 20 & 8 & 1 & 0,262 \\
\hline & $\%$ & 36,4 & 0 & 71,4 & 42,6 & 30,8 & 33,3 & \\
\hline
\end{tabular}

$\left({ }^{*}\right)$ nível descritivo de probabilidade do teste exato de Fisher

Constatou-se na Tabela 4 que as categorias diferem em relação às questões 1,2 e 3 , as quais versam sobre recursos humanos, materiais e físicos; segurança relacionada aos equipamentos e participação nas políticas de aquisição de recursos materiais. As Figuras 6, 7 e 8, na sequência, descrevem os achados referentes às questões de 1 a 3 .

A Figura 6 possibilitou averiguar que na questão 1 sobre se os recursos humanos, materiais e físicos eram adequados, a categoria de nutricionistas apresenta menor percentual $1(33,3 \%)$ de profissionais que responderam afirmativamente, seguida dos profissionais médicos 18 $(69,2 \%)$. 


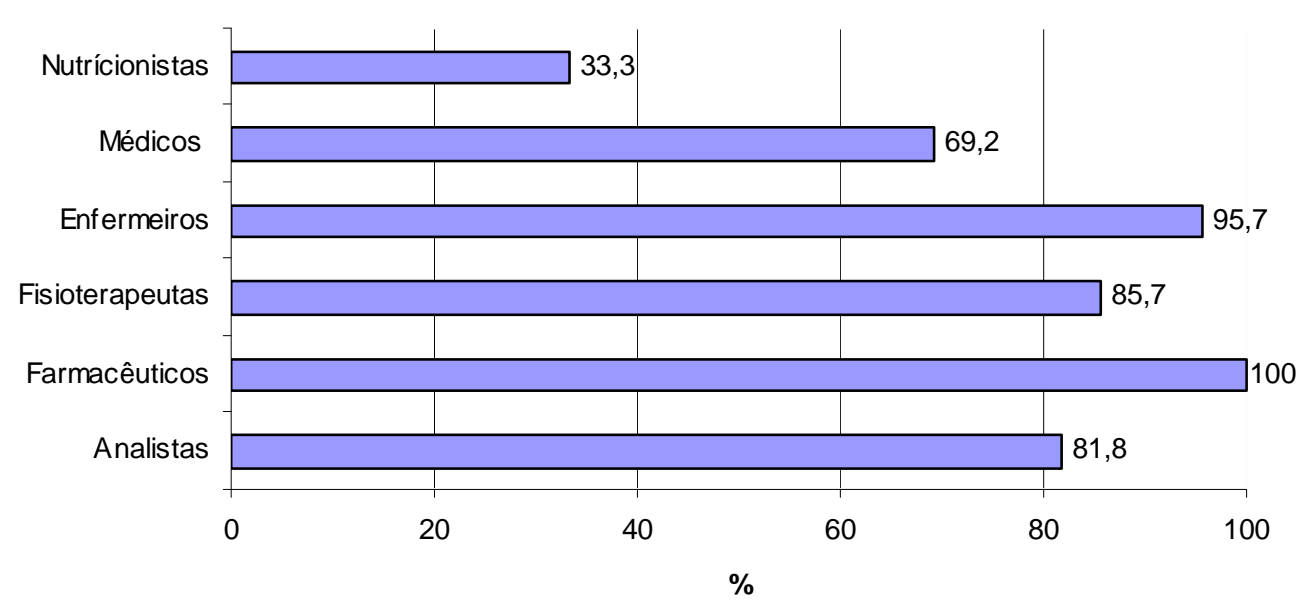

Figura 6 - Distribuição da equipe multidisciplinar, segundo as respostas afirmativas sobre tangibilidade, questão - 1, São Paulo (Interior - SP) - 2010

Tal resultado pode ser atribuído à expressiva demanda existente do Serviço de Nutrição frente ao quantitativo de nutricionistas responsáveis pela assistência.

Cabe ressaltar que conforme descrito na metodologia, na referida instituição existem sete nutricionistas para atendimento dos 350 leitos sendo uma delas responsável pela chefia desse serviço.

A Lei no 8234 que regulamenta a profissão de nutricionista não trata da proporção de profissionais versus número de leitos hospitalares (Brasil, 1991); no entanto, tramita no Senado um projeto de lei que visa reverter esse panorama.

O Projeto de Lei no 6819 estabelece que a jornada de trabalho do nutricionista não poderá exceder trinta horas semanais. Quanto ao número de profissionais, os hospitais, clínicas, ambulatórios gerais e congêneres devem ter em seu quadro de pessoal um nutricionista por até trinta leitos, com tolerância de até sete leitos acima desse limite. Para hospitais, clínicas e ambulatórios especializados esse número passa a ser de um nutricionista para cada quinze leitos, com tolerância de até três leitos acima do limite.

De acordo com tal projeto, o número adequado de nutricionistas para o hospital em questão seria de doze nutricionistas, no mínimo, considerando a proporção de um nutricionista para cada 30 leitos. 


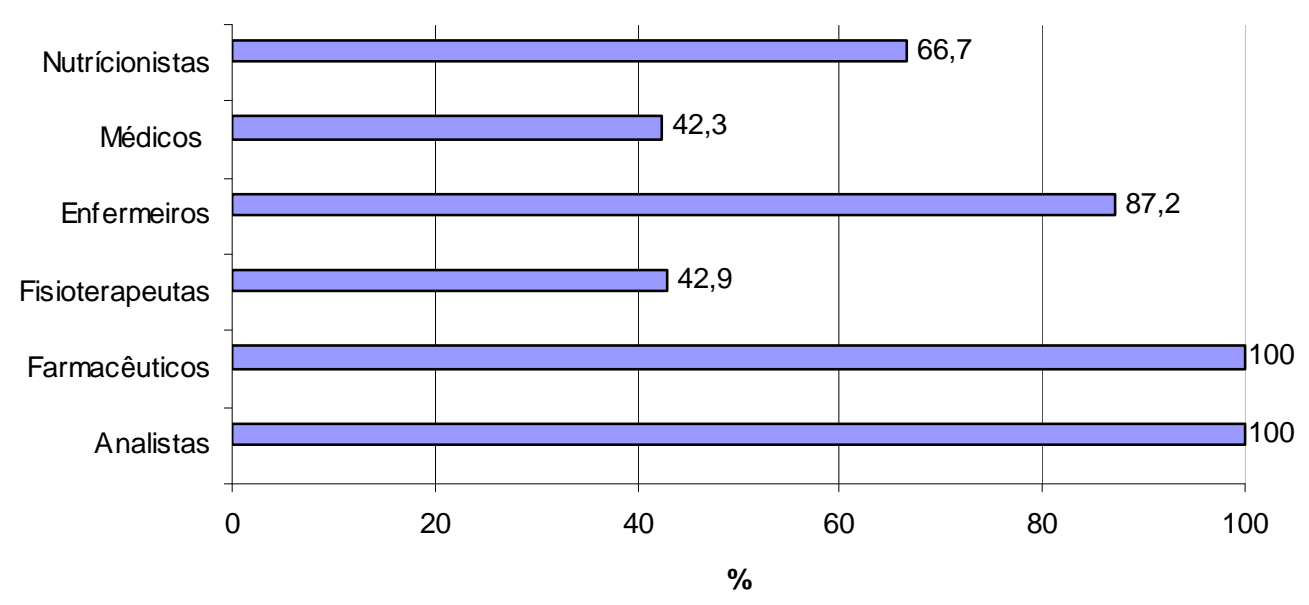

Figura 7 - Distribuição da equipe multidisciplinar, segundo as respostas afirmativas sobre tangibilidade, questão - 2, São Paulo (Interior - SP) - 2010

Constatou-se com a Figura 7, referente à segurança relacionada aos equipamentos, que a categoria de médicos apresenta menor percentual 11 $(42,3 \%)$ de profissionais que responderam afirmativamente, seguidos dos fisioterapeutas $3(42,9 \%)$ e nutricionistas $2(66,7 \%)$.

Para Calil (1998) a manutenção preventiva é necessária para ampliar a vida útil do equipamento com a consequente redução dos custos e aumento da sua segurança e desempenho. Referente ainda, que a limitação de recursos materiais, humanos e financeiros tem restringido o desenvolvimento de programas de manutenção preventiva nos serviços de manutenção de equipamentos hospitalares.

Segundo esse mesmo autor, é de extrema importância que a equipe multidisciplinar seja treinada constantemente quanto ao manuseio correto dos equipamentos, sobretudo, quanto às medidas de segurança. Envolver os profissionais quanto à funcionalidade e detecção de falhas dos equipamentos implica em prevenção de eventos.

Neste estudo observou-se que médicos e fisioterapeutas foram os que apresentaram menores percentuais com relação ao conhecimento dos processos de manutenção preventiva. Este achado pode ser atribuído aos processos de trabalho desses profissionais, os quais estão mais voltados à dimensão assistencial. 
Em contrapartida, a enfermagem, os farmacêuticos e analistas clínicos por empregarem em seus processos de trabalho e por gerenciarem as unidades de atendimento mostraram maior envolvimento com esse tema.

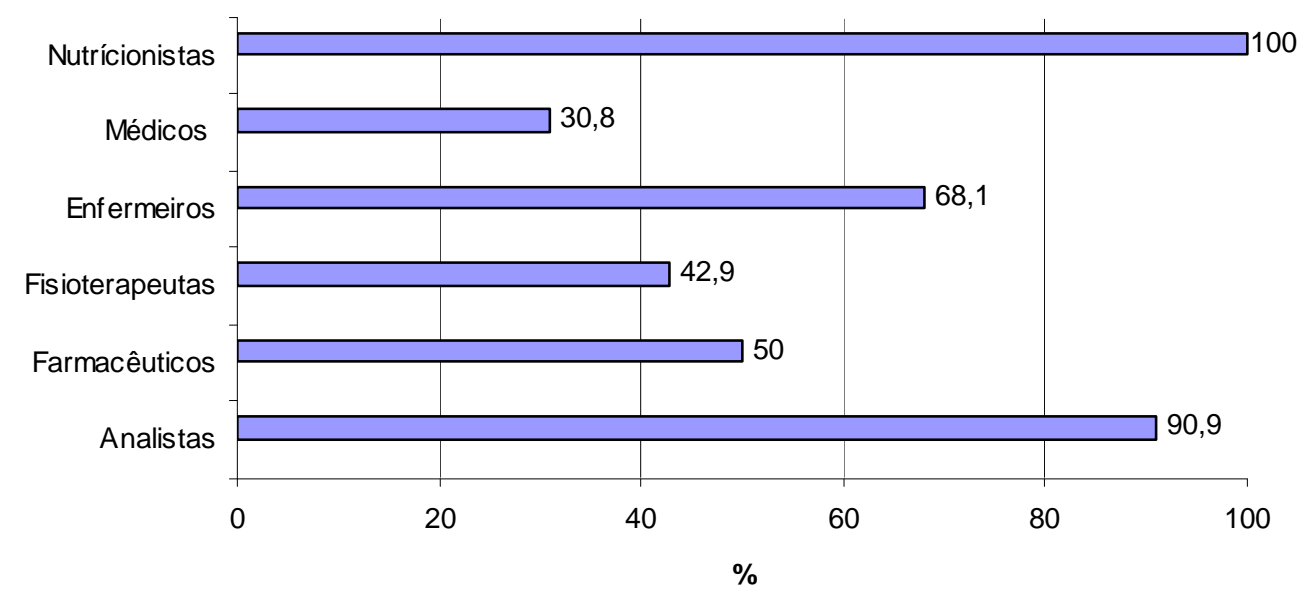

Figura 8 - Distribuição da equipe multidisciplinar, segundo as respostas afirmativas sobre tangibilidade, questão - 3, São Paulo (Interior - SP) - 2010

Observou-se na Figura 8, acerca da participação nas políticas de aquisição de recursos materiais, que os profissionais médicos apresentaram menor percentual $8 \quad(30,8 \%)$ de profissionais que responderam afirmativamente, seguidos dos fisioterapeutas $3(42,9 \%)$ e farmacêuticos 2 (50\%).

De acordo com a Agência Nacional de Vigilância Sanitária (ANVISA, 2011), é preconizado que as instituições de saúde formem equipes de profissionais qualificados para participar da aquisição ou testes de materiais, equipamentos ou novas tecnologias.

Apesar de ter sido mencionada apenas pela categoria de enfermeiros nas questões abertas, há nessa instituição uma comissão de padronização de recursos materiais composto por diversas categorias profissionais com 0 objetivo de atuar como preconizado pela ANVISA.

Acredita-se que o não mencionamento da existência dessa comissão pelas demais categorias, merece uma maior divulgação da mesma para a comunidade hospitalar, salientando-se a sua responsabilidade técnica, bem como o controle de entrada de materiais, equipamentos e tecnologias de forma padronizada. 
Para Florence (2005) o uso seguro de equipamentos nas organizações de saúde depende de diversos fatores que dizem respeito à tecnologia, infra-estrutura hospitalar, treinamento da equipe de saúde na utilização de equipamentos, prestação de serviços técnicos especializados de manutenção e à adoção de uma política de segurança pelo hospital. Nesse sentido, o gerenciamento de risco apresenta uma nova perspectiva no controle dos riscos do uso de tecnologias, atuando nos variados fatores que interferem na segurança.

O futuro reserva aos profissionais que atuam na área da saúde equipamentos e instrumentos mais sofisticados, bem como responsabilidades adicionais. Dessa forma, esses profissionais deverão estar plenamente conscientes das possibilidades e riscos desses novos recursos, devendo, portanto, em conjunto com a instituição, examinar cuidadosamente cada risco e determinar a melhor forma de gerenciá-lo.

Concernente às questões 4 sobre dimensionamento de recursos humanos e 5 referente aos riscos relacionados à estrutura, não houve diferença significativa entre as categorias.

Inferiu-se que a maioria dos participantes 57 (58,2\%) demonstrou descontentamento com o qualitativo dos recursos humanos da instituição, uma vez que na primeira questão, a maioria, exceto fisioterapeutas, pontuou a adequação dos recursos humanos para o atendimento ao usuário.

Da mesma maneira, foi possível evidenciar a percepção dos participantes frente aos riscos que a estrutura expõe o usuário.

A necessidade de um planejamento adequado de pessoal, previsto em legislação para o dimensionamento quantitativo e qualitativo da força de trabalho é refinado com Leis complementares nำ 674 de 8/4/92 e nำ 712 de 12/4/93, que estabeleceram uma importante inovação na gestão de pessoal adotando critérios técnicos como padrão de lotação, que permitem a contratação imediata com caráter emergencial ou efetivo, respaldando assim as instituições (Coelho Júnior, 2006).

Os gestores devem orientar-se pelos eixos estratégicos (características dos usuários atendidos, política institucional de recursos humanos, modelo de gestão, clima organizacional e mobilidade de recursos 
financeiros), pois esses fatores incidem na determinação da força de trabalho necessária. No contexto do processo de mudanças na gestão de recursos humanos, o planejamento e o dimensionamento da força de trabalho assumem um papel fundamental dentro das instituições, uma vez que mediante a proposta de objetivos e metas num criterioso processo interno de planejamento, busca-se adequar as necessidades da instituição a nova realidade conjuntural. Assim, o planejamento de investimentos em capital humano visa que as instituições atinjam níveis satisfatórios de desempenho e resultados, tornando-as competitivas em sua excelência e qualidade, atendendo não só suas próprias necessidades, mas também, as de seus usuários internos e externos e, principalmente, ao bem-estar e autoestima dos profissionais que compõem o quadro funcional dessas instituições (Coelho Júnior, 2006).

Para a ANVISA (2011) o principal objetivo de um hospital é a prestação de serviços na área da saúde com qualidade, eficiência e eficácia, devendo desenvolver continuamente essa política assegurando que gerentes e profissionais estejam cientes de suas responsabilidades na redução de riscos e acidentes. Devem, ainda, promover e reforçar práticas seguras de trabalho e proporcionar ambientes livres de riscos em conformidade com as obrigatoriedades das legislações municipais, estaduais e federais.

Nessa dimensão estão incluídos os aspectos referentes à estrutura física que são comprovadamente intervenientes na recuperação dos usuários podendo influenciar a assistência através dos aspectos ergonômicos, o nível de saúde e a própria causa da doença, ao proteger ou expor o usuário à infecção (Guelli, Zucchi, 2005).

$O$ ambiente exerce forte influência sobre os indivíduos e pode estimular ou inibir a interação entre os envolvidos. Engloba não apenas 0 espaço físico utilizado pelas pessoas, como também as pessoas que interagem nesse contexto, a sua cultura, o mobiliário, o arejamento, a temperatura, os ruídos e as condições de espaço (Stefanelli, 2005).

A qualidade no processo de atenção, quando inclui a percepção do espaço pelos diferentes usuários, requer um ambiente "saudável" que é 
preconizado pelo chamado "Healing Environment", uma forma de cuidado à saúde que envolve a influência do espaço físico na recuperação do usuário (Varni et al., 2004).

No Brasil a Resolução da Diretoria Colegiada ํ50 da ANVISA, em vigor desde 21 de fevereiro de 2002, dispõe sobre o regulamento técnico para planejamento, programação, elaboração e avaliação de projetos físicos de estabelecimentos assistenciais de saúde, enfatizando a preocupação com o aspecto físico e estrutural de tais instituições (Brasil, 2002).

Segundo Castellanos (2002), a dimensão de tangibilidade permite avaliações mais objetivas levando o usuário a expressar exatamente suas expectativas e percepções em relação ao serviço oferecido, o que pode explicar a homogeneidade das respostas das diferentes categorias profissionais.

Complementando as questões fechadas o Quadro 3, a seguir, retrata o conteúdo das questões abertas, sendo possível perceber a preocupação das categorias com a qualidade dos processos relacionados aos recursos humanos e a assistência direta ao usuário.

Quanto ao conhecimento referente à segurança relacionada aos equipamentos destacou-se a necessidade de intensificar a divulgação da importância da manutenção preventiva e de que maneira os profissionais podem participar desse processo.

Acerca da participação nas políticas de aquisição de recursos materiais verificou-se que a estratégia de centralização pode comprometer a participação e o envolvimento dos profissionais nesse processo.

Apesar da maioria das categorias terem respondido afirmativamente quanto ao quantitativo dos recursos humanos, evidenciou-se um descontentamento quanto à qualificação profissional. 
Quadro 3 - Conteúdo das respostas das questões abertas de 1 a 5 acerca da dimensão tangibilidade, São Paulo (Interior - SP) - 2010

\begin{tabular}{|c|c|}
\hline & Tangibilidade \\
\hline Questão & Conteúdo das respostas \\
\hline \multirow{4}{*}{1} & $\begin{array}{l}\text { Alta complexidade do usuário pode dificultar o atendimento aos } \\
\text { demais }\end{array}$ \\
\hline & $\begin{array}{l}\text { Carga horária alta, contribui para comprometimento da } \\
\text { qualidade da assistência }\end{array}$ \\
\hline & $\begin{array}{l}\text { Remuneração insatisfatória, promove a desmotivação do } \\
\text { recurso humano }\end{array}$ \\
\hline & Processo de contratação moroso, gera a sobrecarga da equipe \\
\hline \multirow{5}{*}{2} & Falta de manutenção preventiva dos equipamentos \\
\hline & Mudança da gestão da engenharia \\
\hline & $\begin{array}{l}\text { Não existe participação quanto à manutenção preventiva dos } \\
\text { equipamentos }\end{array}$ \\
\hline & Equipamentos mal conservados \\
\hline & $\begin{array}{l}\text { Poucas informações sobre manutenção preventiva são } \\
\text { fornecidas aos profissionais }\end{array}$ \\
\hline \multirow{6}{*}{3} & $\begin{array}{l}\text { Apenas as chefias são envolvidas nas políticas de aquisição de } \\
\text { materiais }\end{array}$ \\
\hline & $\begin{array}{l}\text { Apenas os profissionais contratados são envolvidos na } \\
\text { aquisição de materiais }\end{array}$ \\
\hline & Envolvimento apenas nos testes dos materiais \\
\hline & Nem sempre é adquirido o material que foi testado e escolhido \\
\hline & $\begin{array}{l}\text { Comissão de Padronização é responsável pelas políticas de } \\
\text { aquisição }\end{array}$ \\
\hline & $\begin{array}{l}\text { Não existe participação efetiva dos profissionais na aquisição } \\
\text { de materiais }\end{array}$ \\
\hline \multirow{3}{*}{4} & Falta de qualificação profissional \\
\hline & Falhas na escolha do perfil de profissional \\
\hline & Pouco treinamento voltados para a qualificação profissional \\
\hline \multirow{5}{*}{5} & Rampa de acesso em estado precário \\
\hline & Setores pequenos sem área para isolamento \\
\hline & Áreas e mobiliários necessitam de reforma \\
\hline & Falhas no controle de acesso à instituição \\
\hline & $\begin{array}{l}\text { Não respeito às diretrizes da Comissão de Controle de } \\
\text { Infecção Hospitalar }\end{array}$ \\
\hline
\end{tabular}




\subsubsection{Dimensão Confiabilidade}

Concernente à confiabilidade foram analisados as questões sobre a habilidade de o fornecedor executar de forma segura e eficiente o serviço, consistindo na capacidade de prestar o serviço prometido de modo confiável e retratando desempenho sem falhas.

Tabela 5 - Distribuição das respostas afirmativas nas questões sobre confiabilidade, São Paulo (Interior - SP) -2010

Categorias

\begin{tabular}{|c|c|c|c|c|c|c|c|c|}
\hline Questões & & $\begin{array}{c}\text { Analista } \\
\text { Clínico }\end{array}$ & $\begin{array}{l}\text { Farma- } \\
\text { cêutico } \\
\end{array}$ & $\begin{array}{c}\text { Fisiotera- } \\
\text { peuta }\end{array}$ & $\begin{array}{l}\text { Enfer- } \\
\text { meiro } \\
\end{array}$ & Médico & $\begin{array}{c}\text { Nutrício- } \\
\text { nista }\end{array}$ & $\mathrm{p}^{*}$ \\
\hline \multirow[t]{2}{*}{6} & $n$ & 9 & 4 & 4 & 36 & 23 & 0 & 0,02 \\
\hline & $\%$ & 81,8 & 100 & 57,1 & 76,6 & 88,5 & 0 & \\
\hline \multirow[t]{2}{*}{7} & $n$ & 11 & 4 & 5 & 38 & 23 & 2 & 0,333 \\
\hline & $\%$ & 100 & 100 & 71,4 & 80,9 & 88,5 & 66,7 & \\
\hline \multirow[t]{2}{*}{8} & $n$ & 11 & 4 & 3 & 44 & 23 & 1 & 0,002 \\
\hline & $\%$ & 100 & 100 & 42,9 & 93,6 & 88,5 & 33,3 & \\
\hline \multirow[t]{2}{*}{9} & $n$ & 11 & 3 & 6 & 41 & 15 & 2 & 0,017 \\
\hline & $\%$ & 100 & 75 & 85,7 & 87,2 & 57,7 & 66,7 & \\
\hline \multirow[t]{2}{*}{10} & $n$ & 9 & 3 & 4 & 28 & 13 & 3 & 0,391 \\
\hline & $\%$ & 81,8 & 75 & 57,1 & 59,6 & 50 & 100 & \\
\hline
\end{tabular}

$\left.{ }^{*}\right)$ nível descritivo de probabilidade do teste exato de Fisher

Observou-se na Tabela 5, que as categorias diferem em relação às questões 6,8 e 9, que se referem aos protocolos estabelecidos, indicação da instituição e participação dos profissionais, respectivamente. Esses temas estão relacionados com o comprometimento, entusiasmo e motivação dos profissionais, sendo, atualmente, um dos maiores desafios das instituições de saúde. 


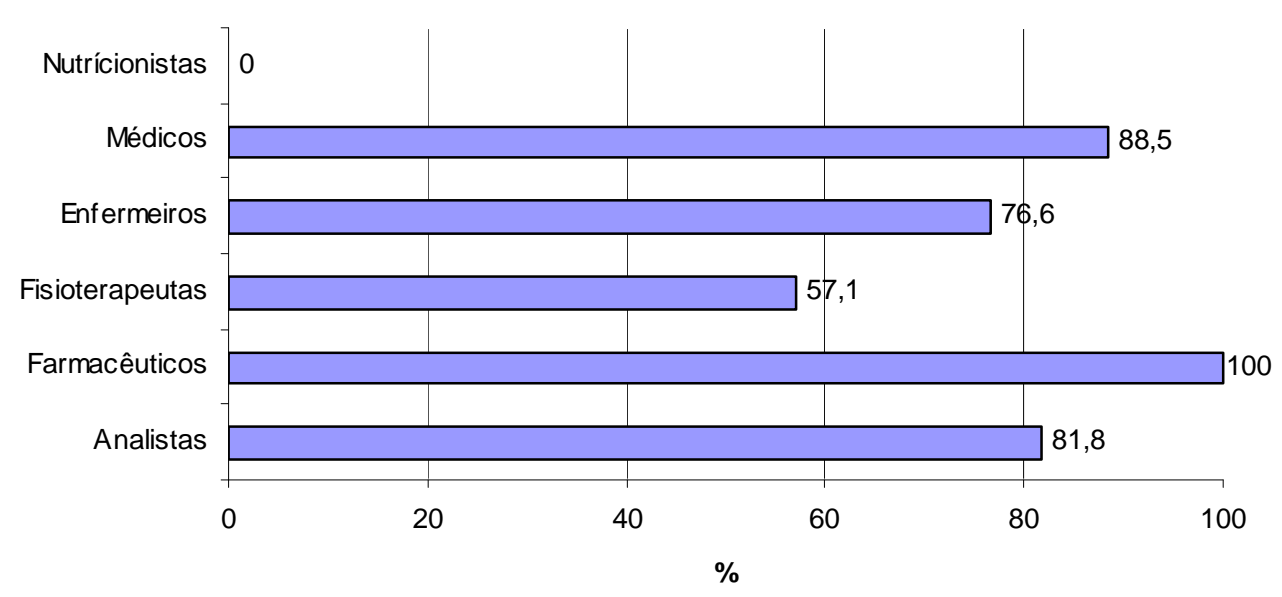

Figura 9 - Distribuição da equipe multidisciplinar, segundo as respostas afirmativas sobre confiabilidade, questão - 6, São Paulo (Interior - SP) - 2010

Constatou-se na Figura 9, que aborda os protocolos estabelecidos pela instituição que as nutricionistas não se posicionaram sobre essa temática. As demais categorias investigadas mostraram-se cientes da execução de procedimentos de acordo com os protocolos implementados.

Para Kern, Lima e Feldman (2010) a padronização de procedimentos, as análises críticas sistemáticas, o uso dos protocolos clínicos, a aplicação dos processos, os consensos transdisciplinares, as notificações, as ferramentas de gestão, entre outros, são avaliações, métodos e planos de ação que promovem transformações.

Para esses autores, por meio da medição e dos registros documentados é possível analisar os dados, resgatar a história organizacional, traçar metas e definir os indicadores que balizam a excelência, a comunicação eficaz e o mérito individual e coletivo.

De acordo com Fundação Hospitalar do Estado de Minas Gerais (FHEMIG, 2010) os protocolos são diretrizes a serem seguidas pelos profissionais das unidades de saúde que estabelecem claramente os critérios de diagnóstico, tratamento e mecanismos de controle para o acompanhamento e a verificação de resultados. Os protocolos clínicos permitem ainda, garantir a segurança do usuário, qualidade da assistência prestada e medição das ações de assistência com ciclo de melhoria constante. 
Protocolos clínicos são instrumentos construídos com o objetivo de atenuar a variabilidade de conduta clínica e garantir um atendimento mais qualificado ao usuário. Os fatores relacionados com a forma de construção destes instrumentos e a sua prática dos protocolos estão associados ao processo de tomada de decisão e ao tipo de estrutura organizacional que possibilita sua implantação (Mahmud, 2002).

Neste estudo, no período em que ocorreu a coleta de dados, iniciavase um movimento para o desenvolvimento de protocolos multidisciplinares. Nessa oportunidade algumas categorias participaram mais ativamente desse processo influenciando os achados deste estudo.

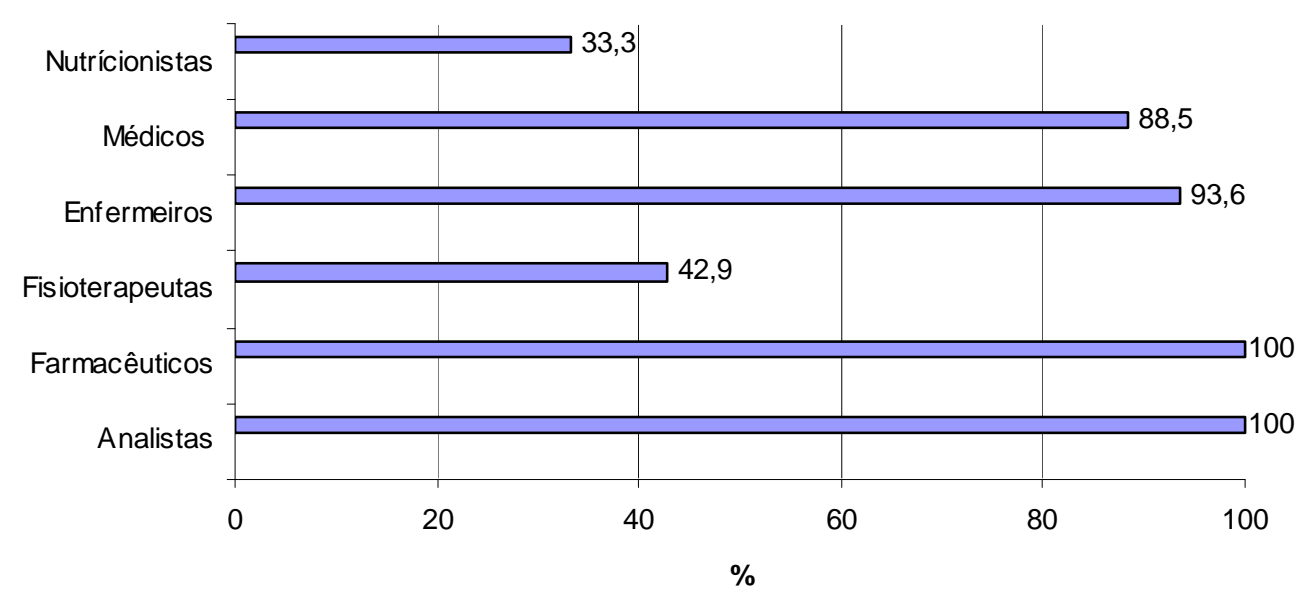

Figura 10 - Distribuição da equipe multidisciplinar, segundo as respostas afirmativas sobre confiabilidade, questão - 8, São Paulo (Interior - SP) - 2010

Verificou-se na Figura 10 que na questão 8 referente a indicação da instituição a categoria de nutricionistas apresenta menor percentual 1 $(33,3 \%)$ de profissionais que responderam afirmativamente seguidos dos fisioterapeutas $3(42,9 \%)$. Acredita-se, mais uma vez, que o quadro de pessoal desses profissionais esteja interferindo em suas percepções. Afinal, se na percepção desses profissionais o quantitativo de sua equipe não atende ao preconizado, como demonstrar satisfação com a instituição?

No entendimento do usuário interno ou externo, o nível de satisfação engloba as condições assistenciais e ambientais que o hospital oferece. $\mathrm{Na}$ prática esses usuários não se satisfazem apenas com a competência técnica-profissional, o que se verifica e avalia é a forma de atendimento, a consciência do saber fazer e do saber ser, devendo haver estreita relação 
entre competência técnica e afetividade, quando se busca qualidade (Nogueira, 1999).

$\mathrm{Na}$ pesquisa realizada por Castellanos (2002), 96,7\% dos usuários relataram predisposição em indicar o hospital a parentes e amigos, enquanto no estudo de Cruz (2008) este índice atingiu 91,5\% dos entrevistados.

Millan e Trez (2005) apontam para o crescente nível de competitividade do mercado, apontando que a retenção dos usuários é fundamental e que o grande desafio passa a ser o de reconhecê-los, mostrando-lhes o quanto a instituição os estima por ter sido eleita como preferida.

Segundo Schiffman e Kanuk (2000), os grupos mais comuns e importantes para o usuário são: família, amigos, grupos sociais formais e grupos de trabalho. Tais grupos concentram os chamados "formadores de opinião", fontes de alta credibilidade para informações relacionadas aos serviços. Esses indivíduos são comumente percebidos como objetivos em relação à informação ou conselho que fornecem. Além disso, seus conselhos reduzem o risco percebido ou ansiedade referente a um novo serviço para os receptores de opinião pelo fato de frequentemente basearem seus comentários sobre um serviço em suas próprias experiências.

Na maioria dos casos os grupos de referência não dizem aos usuários o que fazer; na verdade, os usuários é que se deixam influenciar pela opinião do grupo ou por se preocupar com os sentimentos dos membros desse grupo (Churchill, Peter, 2003).

Convergindo com esses aspectos, devem ser consideradas as evidências de que uma postura mais direcionada ao desenvolvimento de relacionamentos por parte de uma organização que é valorizada pelos usuários, proporcionando a criação de confiança e comprometimento desses em relação à instituição (Mückenberger, 2000).

Ratifica-se que usuários satisfeitos, além de estabelecerem vínculos com o serviço, também recrutam novos usuários através das informações positivas que fornecem sobre o atendimento recebido.

A busca pela qualidade e segurança no atendimento e nos procedimentos hospitalares é essencial para garantir o bom 
desenvolvimento de uma unidade de internação e o vínculo usuário/instituição. Demonstrar esses padrões de excelência, em um mercado cada vez mais competitivo, é requisito essencial para ampliar o diferencial de qualidade (Medeiros, 2003).

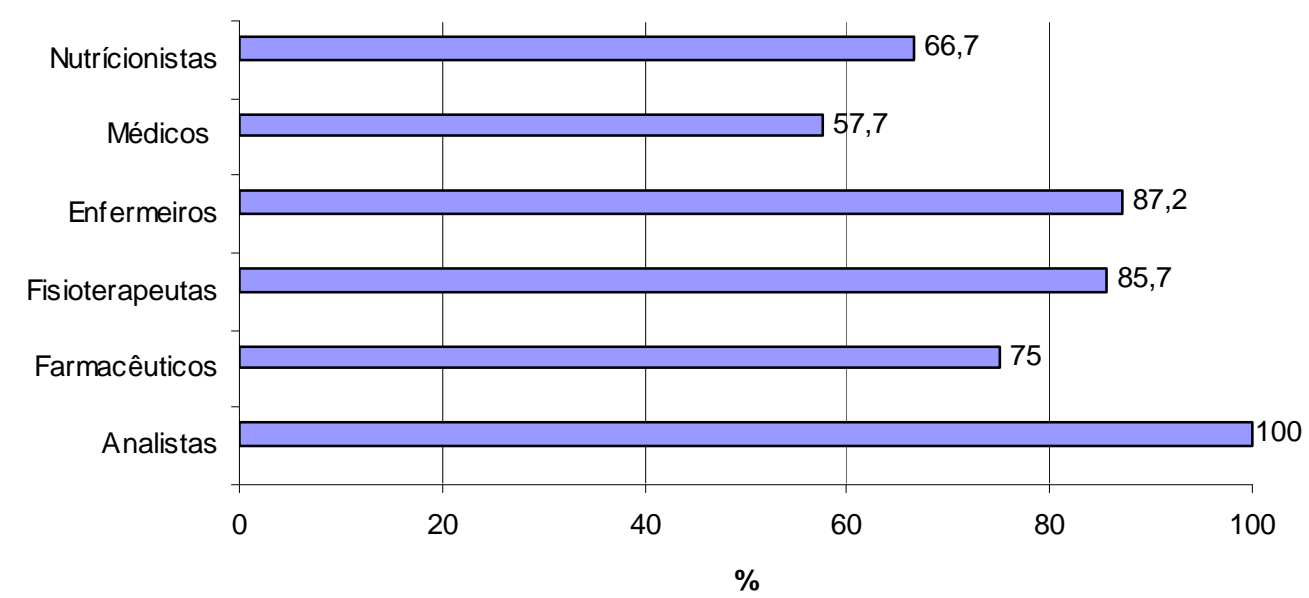

Figura 11 - Distribuição da equipe multidisciplinar, segundo as respostas afirmativas sobre confiabilidade, questão - 9, São Paulo (Interior - SP) - 2010

A Figura 11 possibilitou averiguar que quanto à participação dos profissionais acerca da manifestação do usuário, a categoria de médicos apresenta menor percentual $15(57,7 \%)$ de profissionais que responderam afirmativamente, seguidos dos nutricionistas 2 (66,7\%).

Para Donabedian (1982) e Fitzpatrick (1991) quando o usuário manifesta-se está implícito não apenas a resolução de seu problema de saúde, mas também a resolução de sua ansiedade. Sabendo que o usuário não tem subsídio técnico para avaliar as dimensões técnicas do cuidado, os critérios por ele utilizados são aqueles relacionados ao suporte emocional que acompanha o curso do tratamento. Sendo assim, o usuário mostra-se satisfeito em consequência do modo com que o profissional responde ao problema e não unicamente do conteúdo da resposta.

Conforme Carvalho, Santana e Santana (2009) a questão da humanização e da qualidade dos serviços começou a aparecer a partir da XI Conferência Nacional de Saúde, intitulada "Efetivando o SUS: acesso, qualidade e humanização na atenção à saúde com controle social", realizada no ano 2000. A XII Conferência Nacional de Saúde, realizada em 2003, propôs a criação de uma política nacional de ouvidorias do SUS para 
as três esferas de governo, com a aprovação dos respectivos conselhos e com a garantia de recursos humanos e financeiros para a sua implementação nos Estados e Municípios. O objetivo dessa política deve ser ampliar os canais de participação da população no controle social do SUS, entendendo que as ouvidorias são microestruturas institucionais de controle social, nas quais a ação individual é priorizada juntamente ao nível local, tendo na figura do ouvidor um mediador das demandas produzidas pelos usuários dos serviços. A relação profissional de saúde/usuário quando provida de dificuldade, provoca o denominado "baixo comprometimento do usuário com seu tratamento". Os profissionais de saúde têm dificuldade de compreender esse baixo comprometimento terapêutico, no entanto, o elevado número de reclamações e críticas recebidas e a baixa resolutividade nas ações, revelam tal falência assistencial. Necessário se faz considerar a subjetividade dos usuários para melhor entendimento das condições necessárias para um comprometimento consciente, crítico e informado por parte dos usuários em relação à assistência que lhes é prestada pelos serviços de saúde.

Cabe lembrar que, na instituição, cenário do estudo, existe um Serviço de Ouvidoria para atendimento do usuário externo.

Referente às questões 7 sobre a execução das atividades com segurança e 10 referente à informação aos usuários quanto à riscos não houve diferença significativa entre as categorias.

De modo esclarecedor Manzo (2009) aborda que alguns pontos são fundamentais para a qualidade na assistência ao usuário, como recursos humanos compatíveis com a complexidade, qualificação adequada dos profissionais e responsáveis técnicos com habilitação correspondente para as áreas de atuação. Além disso, precisa oferecer atendimento seguro aos usuários e para que isso ocorra é imprescindível o controle de riscos aos mesmos.

A esse respeito Mezomo (2001) afirma que o processo de excelência centrado no usuário é um conceito estratégico, porque associa os esforços em atender suas necessidades com o sistema que apóia a melhoria contínua da qualidade dos produtos e dos serviços fazendo com que a 
organização consiga obter mais espaço no mercado. Nesse contexto, é fundamental que a organização tenha flexibilidade e ofereça respostas às expectativas dos usuários e não apenas diagnóstico e tratamento, mas também eficiência, conhecimento e atenção das pessoas que prestam serviços.

Notou-se, neste estudo, que é de conhecimento das diferentes categorias dos profissionais de saúde os direitos dos usuários, ratificando que o primeiro princípio assegura ao cidadão o acesso ordenado e organizado aos sistemas de saúde visando a um atendimento mais justo e eficaz, e que o segundo princípio assegura ao cidadão o tratamento adequado e efetivo para seu problema, visando à melhoria da qualidade dos serviços prestados, e que é dever do profissional explicar de forma objetiva e clara os possíveis riscos inerentes à terapêutica proposta (Brasil, 2006).

Quanto à dimensão de confiabilidade, o consumo de ações de saúde difere do consumo de serviços em geral, pois, não se operam escolhas livres no ato da decisão do consumo. O usuário não se porta como um consumidor comum diante da mercadoria por ser desprovido de conhecimentos técnicos e por não deter as informações necessárias para a tomada de decisão sobre o que irá consumir. Não cabem as premissas comuns ao mercado, como a livre escolha e a concorrência. Muitas vezes, o consumo em saúde é imposto por situações de emergência, quando até a escolha do serviço e do profissional torna-se muitas vezes imposta por outros determinantes, como, por exemplo, a proximidade e a disponibilidade (Malta et al, 2004).

No Quadro 4, referente às questões abertas acerca da dimensão de confiabilidade, a segurança do usuário é um dos principais tópicos citados.

Percebeu-se, ainda, a necessidade de um serviço de ouvidoria para os usuários internos, demonstrando ser um veículo para que os profissionais possam expressar-se. 
Quadro 4 - Conteúdo das respostas das questões abertas de 6 a 10 acerca da dimensão confiabilidade, São Paulo (Interior - SP) - 2010

\begin{tabular}{|c|c|}
\hline \multicolumn{2}{|r|}{ Confiabilidade } \\
\hline Questão & Conteúdo das respostas \\
\hline \multirow{4}{*}{6} & $\begin{array}{l}\text { Não preenchimento de documentação conforme protocolo } \\
\text { estabelecido. }\end{array}$ \\
\hline & Não adesão aos protocolos implantados. \\
\hline & $\begin{array}{l}\text { Falha de comunicação com relação à divulgação dos } \\
\text { protocolos. }\end{array}$ \\
\hline & Não avaliação dos protocolos vigentes. \\
\hline \multirow{3}{*}{7} & $\begin{array}{l}\text { As diretrizes da Comissão de Controle de Infecção Hospitalar } \\
\text { nem sempre são seguidas. }\end{array}$ \\
\hline & $\begin{array}{l}\text { A presença dos alunos compromete o sentimento de } \\
\text { segurança dos usuários. }\end{array}$ \\
\hline & $\begin{array}{l}\text { Sobrecarga de trabalho prejudica a transmissão de segurança } \\
\text { para o usuário. }\end{array}$ \\
\hline \multirow{3}{*}{8} & Familiares dos profissionais são usuários da instituição. \\
\hline & $\begin{array}{l}\text { Falta de recursos humanos (nutricionistas), } \\
\text { insegurança quanto à indicação da instituição. }\end{array}$ \\
\hline & Conheço o funcionamento da instituição. \\
\hline \multirow{3}{*}{9} & Ouvidoria para usuários externos e não internos. \\
\hline & Desconheço setor ou estratégia destinado à manifestação. \\
\hline & Usuários verbalizam descontentamento para os profissionais. \\
\hline \multirow{4}{*}{10} & $\begin{array}{l}\text { Apenas na vigência de um evento adverso os usuários são } \\
\text { comunicados. }\end{array}$ \\
\hline & $\begin{array}{l}\text { Depende do bom senso do profissional a informação sobre os } \\
\text { riscos ao usuário ser fornecida. }\end{array}$ \\
\hline & $\begin{array}{l}\text { Desconhece à prática de informação sobre os possíveis } \\
\text { riscos inerentes à terapêutica. }\end{array}$ \\
\hline & $\begin{array}{l}\text { Somente em casos cirúrgicos os riscos são informados aos } \\
\text { usuários. }\end{array}$ \\
\hline
\end{tabular}




\subsubsection{Dimensão Responsividade}

A responsividade abordou a disponibilidade dos profissionais em atender os usuários de forma atenciosa, com precisão e rapidez de resposta.

Tabela 6 - Distribuição das respostas afirmativas nas questões sobre responsividade, São Paulo (Interior - SP) - 2010

\begin{tabular}{|c|c|c|c|c|c|c|c|c|}
\hline \multirow[b]{2}{*}{ Questões } & & \multicolumn{7}{|c|}{ Categorias } \\
\hline & & $\begin{array}{c}\text { Analista } \\
\text { Clínico } \\
\end{array}$ & $\begin{array}{l}\text { Farma- } \\
\text { cêutico }\end{array}$ & $\begin{array}{c}\text { Fisiotera- } \\
\text { peuta }\end{array}$ & $\begin{array}{l}\text { Enfer- } \\
\text { meiro } \\
\end{array}$ & Médico & $\begin{array}{c}\text { Nutrício- } \\
\text { nista }\end{array}$ & $p^{*}$ \\
\hline \multirow[t]{2}{*}{11} & $n$ & 9 & 4 & 2 & 30 & 9 & 2 & 0,009 \\
\hline & $\%$ & 81,8 & 100 & 28,6 & 63,8 & 34,6 & 66,7 & \\
\hline \multirow[t]{2}{*}{12} & $\mathrm{n}$ & 11 & 3 & 6 & 45 & 26 & 3 & 0,148 \\
\hline & $\%$ & 100 & 75 & 85,7 & 95,7 & 100 & 100 & \\
\hline \multirow[t]{2}{*}{13} & $\mathrm{n}$ & 9 & 2 & 5 & 26 & 10 & 1 & 0,172 \\
\hline & $\%$ & 81,8 & 50 & 71,4 & 55,3 & 38,5 & 33,3 & \\
\hline \multirow[t]{2}{*}{14} & $\mathrm{n}$ & 4 & 2 & 4 & 25 & 11 & 2 & 0,846 \\
\hline & $\%$ & 36,4 & 50 & 57,1 & 53,2 & 42,3 & 66,7 & \\
\hline \multirow[t]{2}{*}{15} & $\mathrm{n}$ & 9 & 4 & 7 & 35 & 11 & 1 & 0,004 \\
\hline & $\%$ & 81,8 & 100 & 100 & 74,5 & 42,3 & 33,3 & \\
\hline
\end{tabular}

Constatou-se pela Tabela 6 que as categorias diferem em relação às questões 11 e 15 que se referem à avaliação dos processos de trabalho e participação na elaboração de protocolos, esses temas são relativamente inovadores no cenário da saúde uma vez que os mesmos vêm sendo mais discutidos após as iniciativas de certificação das instituições. 


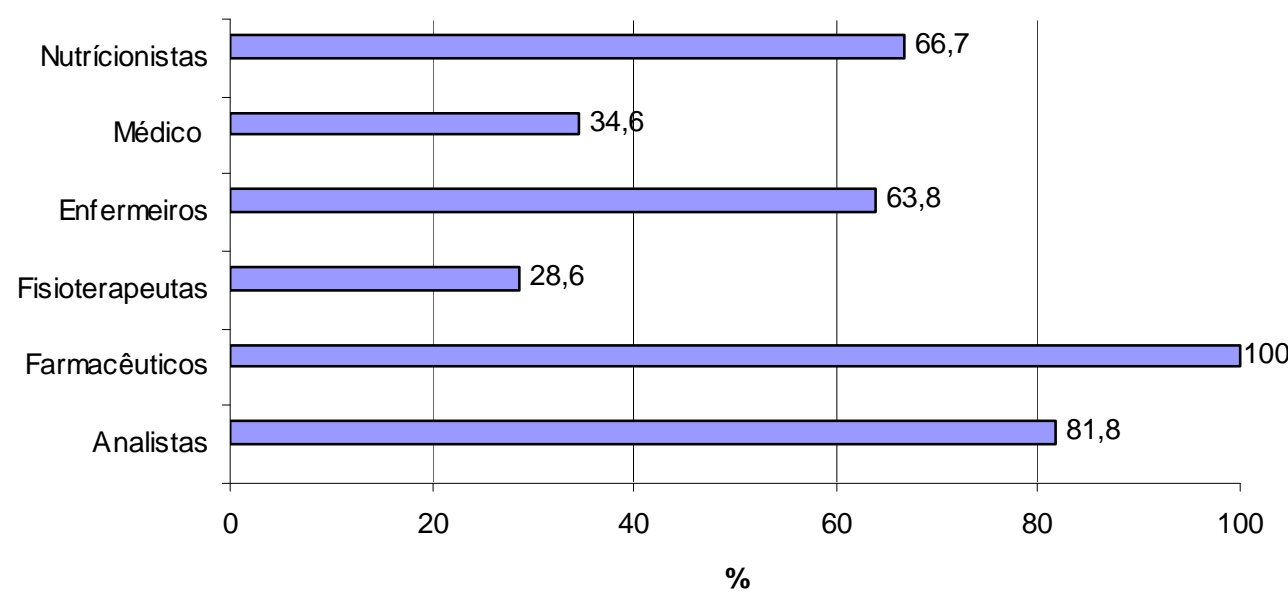

Figura 12 - Distribuição da equipe multidisciplinar, segundo as respostas afirmativas sobre responsividade, questão - 11, São Paulo (Interior - SP) - 2010

Verificou-se por meio da Figura 12 que a avaliação dos processos de trabalho foi considerada ineficaz pelas fisioterapeutas $2(28,6 \%)$ e pelos médicos 9 (34,6\%). Segundo Carvalho (2000) a avaliação é um componente inseparável do processo de planejamento que permite descrever, medir, analisar e explicar uma série de aspectos da prestação de serviços em saúde. Os objetivos oficiais da avaliação são colaborar no planejamento de uma ação, fornecer informações para melhorar uma intervenção e determinar seus efeitos para decidir sobre sua continuidade ou não.

Corroborando com essa assertiva Melleiro e Tronchin (2010) referem que a percepção dos usuários e dos profissionais de saúde acerca dos serviços oferecidos pelas instituições e o modo como são avaliados são considerados importantes aparatos para o aperfeiçoamento dos processos assistenciais e gerenciais, à medida que possibilita aos gestores desses serviços revisarem suas metas e atenderem as necessidades e expectativas dos usuários e dos trabalhadores.

Evidenciou-se que a categoria de fisioterapeutas demonstrou insatisfação no que tange à avaliação dos processos de trabalho na instituição. Isso pode estar atrelado ao fato dessa categoria não reconhecer que seu processo de trabalho seja avaliado pela instituição; o mesmo pode ter ocorrido com a categoria médica, que, muitas vezes, vê sua atividade profissional desvinculada de processos formais de avaliação. 


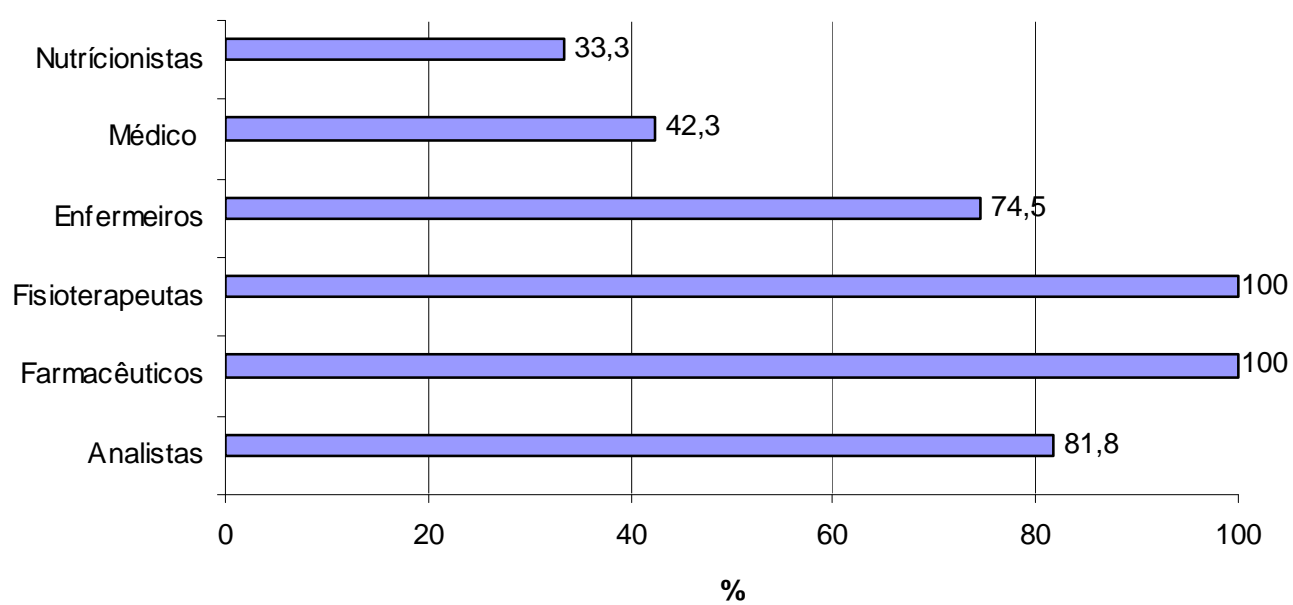

Figura 13 - Distribuição da equipe multidisciplinar, segundo as respostas afirmativas sobre responsividade, questão - 15, São Paulo (Interior - SP) - 2010

A Figura 13 retrata a participação do profissional na elaboração de protocolos. Percebeu-se que, novamente a categoria de nutricionistas apresenta menor percentual $1(33,3 \%)$ de profissionais que responderam afirmativamente, seguidos dos médicos $11(42,3 \%)$.

Os protocolos assistenciais, também, chamados de clínicos ou institucionais, são produtos da Medicina Baseada em Evidências (MBE).

A MBE, segundo Sackett (2003), é a integração das melhores evidências decorrentes de pesquisas cientificamente orientadas, com a habilidade clínica do médico responsável pela decisão e a preferência do usuário. É um método de organização do trabalho em saúde que visa vários resultados através da qualificação do processo decisório. Nesse sentido, salienta-se que as diretrizes assumem a responsabilidade pela organização hospitalar e que os protocolos estão intrinsecamente relacionados à responsabilidade da equipe assistencial que decide por sua utilização.

De qualquer forma, para o referido autor, tanto a construção de diretrizes clínicas e seus desdobramentos em protocolos assistenciais, como sua implementação e aplicações são processos ricos em aprendizagem organizacional. Trata-se, portanto, de prática formal exaustiva que envolve vários profissionais, técnicos e meios de informação

Pelo exposto por Coffey et al. (2005), é possível inferir que a construção e implementação de protocolos assistenciais são a criação de parte significativa do conhecimento técnico e atualizado da organização, 
permeando através de questões estratégicas, táticas e operacionais, vários departamentos, processos e interesses.

Os protocolos assistenciais são instrumentos que surgem do acordo expresso entre equipes assistenciais e usuários/familiares. Por essa razão, tão ou mais importante que o conteúdo são os elementos envolvidos na sua construção em seguimento às diretrizes clínicas.

Sendo assim, é de suma importância que as partes envolvidas sintam-se definitivamente comprometidas criando um ambiente favorecedor, desafio importante para os gestores.

Quanto às questões 12, 13 e 14, que versavam sobre o direito à recusa, comunicação e manual de orientações respectivamente, não houve diferença significativa entre as categorias profissionais. Isso sugere que é de conhecimento de todas as categorias profissionais envolvidas neste estudo, o direito do usuário em recusar-se a ser submetido a algum procedimento, direito este expresso na Carta dos Direitos dos Usuários da Saúde (Brasil, 2006).

A prática clínica dos profissionais de saúde no ambiente hospitalar é caracterizada por uma grande e complexa rede de relacionamentos na qual muitas informações tramitam pelos diversos subsistemas da organização hospitalar.

Para Conceição et al (2006) o sucesso da prestação de serviço na saúde é dependente da qualidade e veracidade das informações, assim falhas nos sistemas de comunicação afetam negativamente o processo de transmissão de informações e geração do conhecimento entre os participantes dos subsistemas hospitalares.

Nessa ótica, um atendimento integral requer constante troca de dados e informações por todas as pessoas envolvidas no processo terapêutico: profissionais, usuários e gestores.

Assim, nesse sistema ocorrem diversos fatos que são filtrados por pessoas ou programas (softwares) tornando-se dados, os quais dotados de significado passam a ser informação que quando apropriada por cada membro do sistema é chamada de conhecimento. 
Nesse cenário, a instituição, em questão neste estudo, tem uma busca contínua na melhoria da comunicação, investimentos em sistema de informática e serviço de assessoria de imprensa são um demonstrativo dessa preocupação. A instituição lança mão, ainda, de estratégias como painéis no local onde é registrada a entrada/saída dos profissionais, informes nos holerites e um jornal interno.

Com relação à comunicação com os usuários, folders informativos são empregados, visando direcioná-los por ocasião de seu acesso à instituição.

Para Vaitsman e Andrade (2005), a dimensão de responsividade diz respeito ao modo como o desenho do sistema de saúde reconhece e consegue responder às expectativas, universalmente legítimas dos indivíduos, em relação aos aspectos não técnicos do cuidado.

De acordo com esses autores, pesquisas sobre responsividade consideram dois elementos: o primeiro é medir o que acontece quando as pessoas interagem com o sistema de saúde, o que implica coletar dados sobre o comportamento, evento ou ação do sistema de saúde; o segundo é medir como as pessoas atendidas pelo sistema de saúde percebem e avaliam o que acontece.

Trata-se, portanto, de dois procedimentos distintos quanto ao desempenho do sistema de saúde. Uma coisa é medir o que acontece e a outra é medir a percepção das pessoas sobre o que acontece, uma vez que as pessoas podem ter uma percepção negativa ou positiva sobre o sistema de saúde, mesmo que os indicadores sobre "o que acontece" apontem o contrário.

O Quadro 5, a seguir, explicita fatores relacionados à dimensão de responsividade, sob a ótica dos participantes, constatando-se que a maioria dos profissionais desconhecem a avaliação dos processos de trabalho, que a elaboração de protocolos, ainda, não é compartilhada com todas as categorias e que a comunicação das alterações e mudanças necessitam ser melhor difundidas. 
Quadro 5 - Conteúdo das respostas das questões abertas de 11 a 15 acerca da dimensão responsividade, São Paulo (Interior - SP) - 2010

\begin{tabular}{|c|c|}
\hline \multicolumn{2}{|r|}{ Responsividade } \\
\hline Questão & Conteúdo das respostas \\
\hline \multirow{4}{*}{11} & Supervisão sobrecarregada na avaliação dos processos. \\
\hline & $\begin{array}{l}\text { A avaliação dos processos ocorre por meio do Serviço de } \\
\text { Educação Continuada. }\end{array}$ \\
\hline & $\begin{array}{l}\begin{array}{l}\text { Desconhece qualquer estratégia de avaliação dos } \\
\text { processos. }\end{array} \\
\end{array}$ \\
\hline & $\begin{array}{l}\text { Sobrecarga de trabalho prejudica a execução correta dos } \\
\text { processos. }\end{array}$ \\
\hline \multirow{2}{*}{12} & $\begin{array}{l}\text { Apenas se assinar um termo de responsabilidade o usuário } \\
\text { pode recusar-se a ser submetido à algum procedimento. }\end{array}$ \\
\hline & $\begin{array}{l}\text { Apenas três participantes desconhece o direito do usuário a } \\
\text { se recusar a ser submetido à algum procedimento. }\end{array}$ \\
\hline \multirow{3}{*}{13} & $\begin{array}{l}\text { A comunicação das mudanças na instituição acontece de } \\
\text { forma ineficaz. }\end{array}$ \\
\hline & $\begin{array}{l}\text { As alterações e mudanças na instituição não são informadas } \\
\text { aos profissionais. }\end{array}$ \\
\hline & $\begin{array}{l}\text { As informações quanto às mudanças e alterações são } \\
\text { passadas por terceiros. }\end{array}$ \\
\hline \multirow{4}{*}{14} & $\begin{array}{l}\text { Apenas no ambulatório de especialidades são entregues } \\
\text { materiais impressos aos usuários com esclarecimentos } \\
\text { sobre internação/terapêutica. }\end{array}$ \\
\hline & $\begin{array}{l}\text { Desconhece qualquer forma de material impresso entregue } \\
\text { ao usuário. }\end{array}$ \\
\hline & $\begin{array}{l}\text { Folders, cartilhas, folhas avulsas e manual de internação são } \\
\text { entregues aos usuários. }\end{array}$ \\
\hline & $\begin{array}{l}\text { São entregues apenas relatório, resumo de alta e receituário } \\
\text { aos usuários. }\end{array}$ \\
\hline \multirow{2}{*}{15} & $\begin{array}{l}\text { A participação na elaboração/alteração de protocolos é } \\
\text { centralizada nas chefias. }\end{array}$ \\
\hline & $\begin{array}{l}\text { Desconhece } 0 \text { envolvimento dos } \\
\text { elaboração/alteração dos protocolos. }\end{array}$ \\
\hline
\end{tabular}




\subsubsection{Dimensão Garantia}

Os aspectos que abrangeram a dimensão de garantia versaram sobre a cortesia e o conhecimento das necessidades e expectativas dos usuários e das habilidades dos profissionais em transmitir confiança.

Tabela 7 - Distribuição das respostas afirmativas nas questões sobre garantia, São Paulo (Interior - SP) - 2010

Categorias

\begin{tabular}{|c|c|c|c|c|c|c|c|c|}
\hline Questões & & $\begin{array}{c}\text { Analista } \\
\text { Clínico }\end{array}$ & $\begin{array}{l}\text { Farma- } \\
\text { cêutico }\end{array}$ & $\begin{array}{c}\text { Fisiotera- } \\
\text { peuta }\end{array}$ & $\begin{array}{l}\text { Enfer- } \\
\text { meiro }\end{array}$ & Médico & $\begin{array}{c}\text { Nutrício- } \\
\text { nista }\end{array}$ & $p^{*}$ \\
\hline \multirow[t]{2}{*}{16} & $\mathrm{n}$ & 8 & 4 & 5 & 31 & 9 & 2 & 0,036 \\
\hline & $\%$ & 72,7 & 100 & 71,4 & 66 & 34,6 & 66,7 & \\
\hline \multirow[t]{2}{*}{17} & $\mathrm{n}$ & 10 & 4 & 5 & 34 & 7 & 1 & $<0,001$ \\
\hline & $\%$ & 90,9 & 100 & 71,4 & 72,3 & 26,9 & 33,3 & \\
\hline \multirow[t]{2}{*}{18} & $\mathrm{n}$ & 9 & 4 & 5 & 24 & 10 & 1 & 0,044 \\
\hline & $\%$ & 81,8 & 100 & 71,4 & 51,1 & 38,5 & 33,3 & \\
\hline \multirow[t]{2}{*}{19} & $\mathrm{n}$ & 9 & 1 & 4 & 20 & 8 & 1 & 0,073 \\
\hline & $\%$ & 81,8 & 25 & 57,1 & 42,6 & 30,8 & 33,3 & \\
\hline \multirow[t]{2}{*}{20} & $\mathrm{n}$ & 5 & 3 & 2 & 25 & 7 & 1 & 0,202 \\
\hline & $\%$ & 45,5 & 75 & 28,6 & 53,2 & 26,9 & 33,3 & \\
\hline
\end{tabular}

$\left.{ }^{*}\right)$ nível descritivo de probabilidade do teste exato de Fisher

Averiguou-se por meio da Tabela 7, que as categorias diferem em relação às questões 16, 17 e 18 que se referem à monitorização dos processos, monitorização dos riscos e conceito de EA. Tais monitorizações necessitam de indicadores bem definidos para possibilitar um diagnóstico e facilitar uma tomada de decisão mais assertiva.

Mello e Camargo (1998) relatam que Codman foi um dos precursores do movimento pela iniciativa de implantação de padrões para avaliação da qualidade nas instituições de saúde. O referido médico publicou em 1913 uma obra intitulada $O$ produto dos hospitais, na qual, segundo esses autores, "teve como objetivo a discussão da padronização das organizações por meio da avaliação de indicadores". 
Em 1917, o recém-criado Colégio Americano de Cirurgiões, acreditando nesta idéia, desenvolveu o Minimum Standard for Hospitals, com requisitos básicos para a avaliação de hospitais.

Desde então é fato que as instituições têm procurado inserir, em seus processos gerenciais ferramentas que possibilitem a avaliação de seus serviços.

Dentre essas estratégias os indicadores vêm se firmando como afirmam Tronchin et al (2011) como uma das ferramentas destinadas a monitorar a qualidade de um serviço, visando à obtenção de eficiência, confiabilidade e completude dos processos de trabalho. Os indicadores constituem, desse modo, uma prática valiosa para avaliação dos serviços de saúde, estando intimamente relacionados às políticas e metas a serem alcançadas pela avaliação da qualidade de serviços de saúde. Salienta-se a relevância do emprego de referenciais teóricos e de políticas organizacionais que sustentem tanto a elaboração dos indicadores como a sua aplicabilidade nos contextos assistenciais e gerenciais.

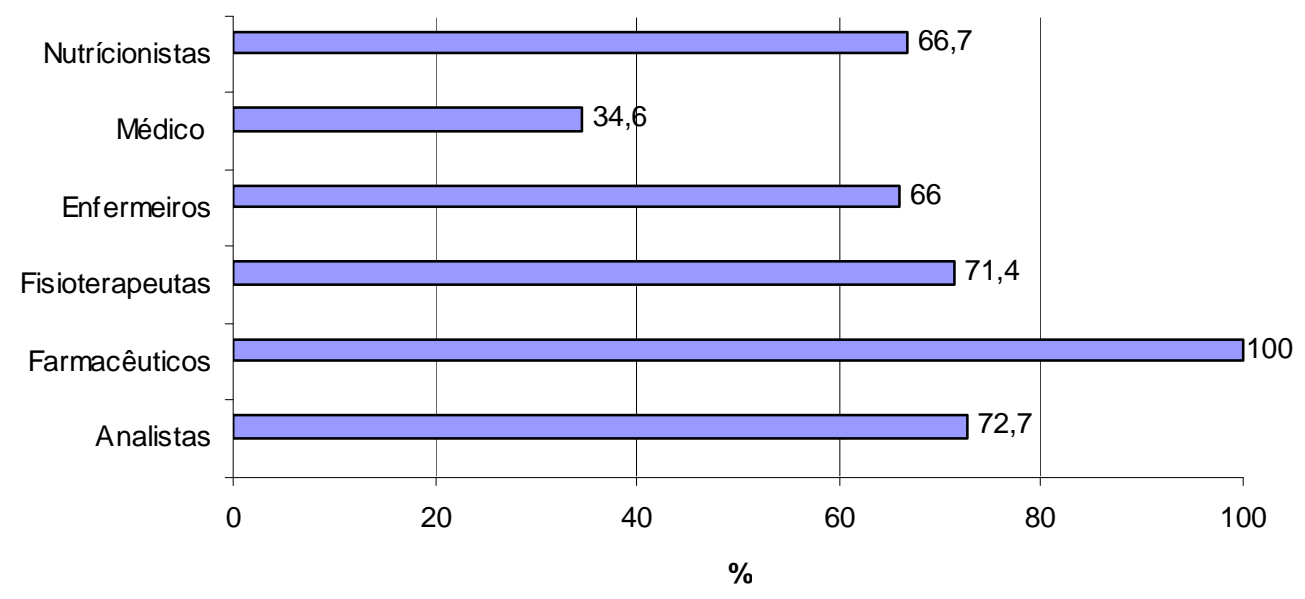

Figura 14 - Distribuição da equipe multidisciplinar, segundo as respostas afirmativas sobre garantia, questão - 16, São Paulo (Interior - SP) - 2010

Conforme a Figura 14 averiguou-se que a monitorização dos processos é menos percebidos pelos médicos 9 (34,6\%), seguidos dos enfermeiros 31 (66\%) e dos nutricionistas $2(66,7 \%)$.

A avaliação das variações de práticas clínicas entre serviços e, sobretudo, de cada serviço, é de grande importância para que os órgãos 
gestores reflitam sobre os indicadores dos resultados clínicos e sua influência nos custos assistenciais (Mendes, 2005).

Isso se deve ao fato de que conhecimento científico e experiência clínica não serem suficientes para julgar um processo assistencial (Rattner, 1996).

Estratégias que permitam o monitoramento e a tomada de decisão mais assertiva vêm sendo desenvolvidas na instituição em questão, a qual emprega indicadores assistenciais e administrativos.

Consultorias para aprimorar as análises e, consequentemente, melhorar os resultados também fazem parte da realidade desta instituição.

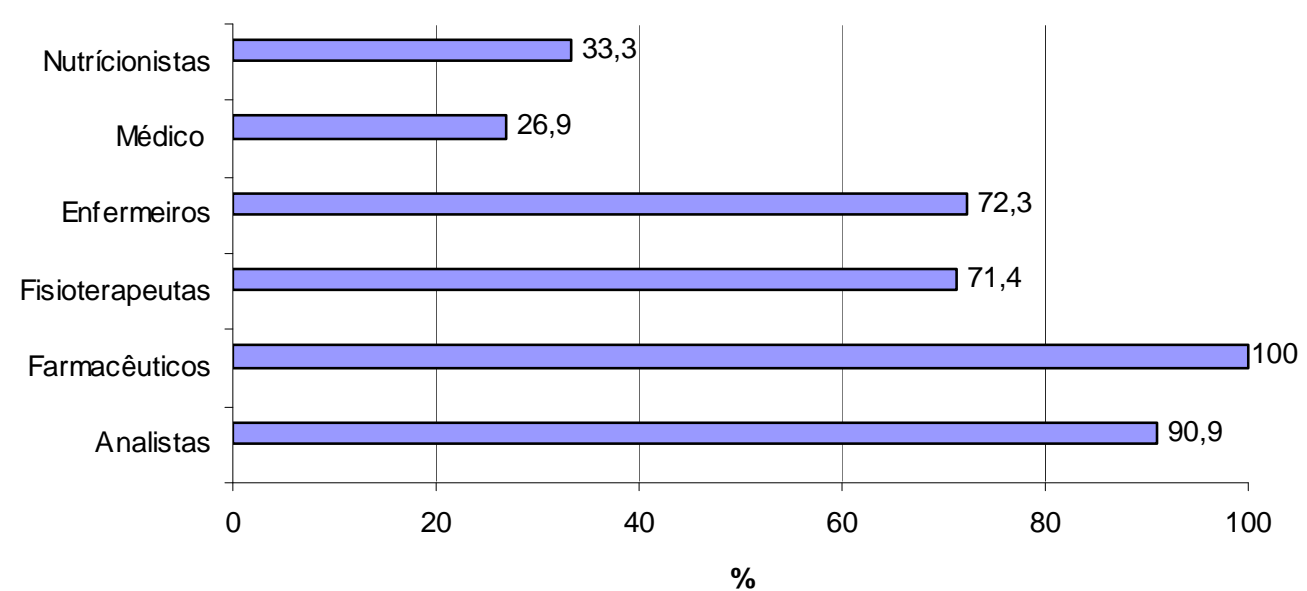

Figura 15 - Distribuição da equipe multidisciplinar, segundo as respostas afirmativas sobre garantia, questão - 17, São Paulo (Interior - SP) - 2010

De acordo com a Figura 15, foi possível averiguar que na questão 17 a divergência entre as demais categorias e a categoria dos médicos 7 $(26,9 \%)$ que foi a que menos percebeu a monitorização dos riscos pela instituição, seguidos das nutricionistas 1 (33,3\%).

Há dez anos o Institute of Medicine dos EUA publicava o livro "Errar é Humano: Construindo um Sistema de Saúde Mais Seguro", onde se mostravam os dados alarmantes do impacto dos eventos adversos no sistema de saúde norte-americano, que tinha nada menos que cerca de 1 milhão de usuários sofrendo danos e quase 100.000 morrendo por ano, decorrente de uma assistência inadequada (Leape, 2009). 
Para o citado autor, muitos estudos subsequentes mostraram que esses dados ainda subestimavam a realidade. Muito dessa falta de progresso na segurança do usuário pode ser atribuída à situação estanque da relação dos profissionais com o sistema, algo ainda muito institucionalizado na estrutura hierárquica acadêmica e das organizações da área da saúde, o que desencoraja o trabalho em equipe e a transparência, além de prejudicar a criação de sistemas claros de responsabilização quanto a uma assistência segura.

Os profissionais de saúde trabalham muito focados em seu próprio desempenho e a comunicação entre eles é muito deficitária, prejudicando ainda mais a possibilidade de um bom trabalho de equipe. Salienta-se ainda, o fato que os usuários raramente são incluídos no planejamento organizacional ou na análise de eventos adversos que os prejudicaram (Leape, 2009).

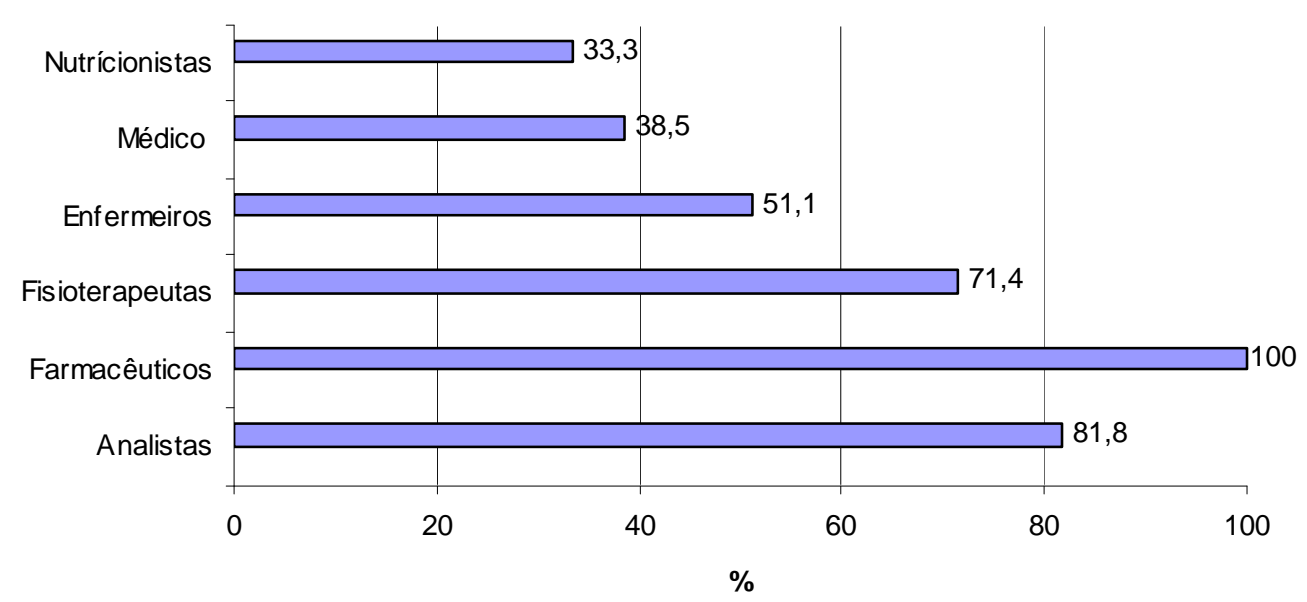

Figura 16 - Distribuição da equipe multidisciplinar, segundo as respostas afirmativas sobre garantia, questão - 18, São Paulo (Interior - SP) - 2010

Por meio da Figura 16, que aborda o significado de EA, a categoria de nutricionistas apresentaram menor percentual $1(33,3 \%)$ de profissionais que responderam afirmativamente seguidos dos médicos 10 (38,5\%) e de enfermeiros $24(51,1 \%)$.

Foram apontados no Quadro 6 pelas diferentes categorias profissionais, 10 eventos, ou situações que os profissionais elencam como EA; esses apareceram mais de uma vez para algumas categorias profissionais. 
Quadro 6 - EA citados pelas diferentes categorias profissionais na questão - 18, São Paulo (Interior - SP) - 2010

\begin{tabular}{|l|}
\multicolumn{1}{c|}{$($ Eventos Adversos $-\mathrm{SP})-2010$} \\
\hline Erro de medicação \\
\hline $\begin{array}{l}\text { Efeito patológico esperado ou inesperado em bula para tratamento } \\
\text { medicamentoso }\end{array}$ \\
\hline Queda do usuário \\
\hline Extubação Acidental \\
\hline Flebite \\
\hline Suspensão de cirurgia \\
\hline Perda de material biológico \\
\hline Contaminação de material de exame laboratorial \\
\hline Parada do sistema de informática \\
\hline Recoleta de exame laboratorial \\
\hline
\end{tabular}

Os EA que mais foram citados foram:

$\checkmark \quad$ Erros de medicação: mencionado apenas pelos enfermeiros, demonstrando que tal prática, por mais cotidiana, não deixa de oferecer menos risco aos usuários.

Os erros na medicação são considerados eventos adversos ao medicamento passíveis de prevenção, podendo ou não causar dano ao usuário com possibilidade de ocorrer em um ou em vários momentos dentro do processo de medicação (Bates et al., 1995; Leape et al. 1995).

Os erros de medicação só são detectados quando as consequências são clinicamente manifestadas pelo usuário tais como a presença de sintomas ou reações adversas após algum tempo em que foi ministrada a medicação alertando o profissional do erro cometido. Os profissionais devem estar alerta e, depois de administrada a medicação, esta deve ser documentada imediatamente no registro do usuário possibilitando rapidamente a descoberta de erro pelo profissional e a realização de intervenções que podem minimizar ou prevenir possíveis complicações ou consequências mais graves (Carvalho, 2002).

A administração de medicamentos é uma das intervenções mais utilizadas no ambiente hospitalar, no entanto, estudos ao longo dos últimos anos têm evidenciado a presença de erros no tratamento medicamentoso 
causando prejuízos aos usuários que vão desde o não-recebimento do medicamento necessário até lesões e mortes (Leape et al. 1995; Táxis e Barber, 2003).

\section{$\checkmark \quad$ Efeito patológico esperado ou inesperado em bula para} tratamento medicamentoso, (reação medicamentosa): citado pelos farmacêuticos, médicos e enfermeiros.

De acordo com Capellá e Laporte (1989), os termos "reação adversa", "efeito indesejável" e "doença iatrogênica" são equivalentes. No entanto, diversos termos são empregados provocando confusões resultantes da própria dificuldade conceitual.

As reações adversas a medicamentos constituem um problema importante na prática do profissional da área da saúde. Sabe-se que essas reações são causas significativas de hospitalização, de aumento do tempo de permanência hospitalar e, até mesmo, de óbito. Além disso, afetam negativamente a qualidade de vida do usuário influenciando na perda de confiança nos profissionais de saúde, aumentando os custos, podendo também, atrasar os tratamentos uma vez que podem assemelhar-se à enfermidades (Gomes e Reis, 2001).

Lesões não intencionais associadas à terapia medicamentosa têm afetado 1,3 milhões de pessoas por ano nos Estados Unidos da América e o custo relacionado à hospitalização do usuário devido ao efeito adverso chega a atingir, anualmente, 76,6 bilhões de dólares. Importa ressaltar que, nos Estados Unidos da América, o número de usuários atingidos anualmente, representa um montante de 60.000 a 140.000 usuários. Desses, $31 \%$ vivenciam um evento adverso de medicação durante a hospitalização, e $0,31 \%$ destes apresentam eventos adversos fatais (Carvalho, 2002).

$\checkmark$ Queda: apontada apenas pela categoria de enfermeiros, provavelmente por estarem diretamente relacionados ao cuidado direto ao usuário.

O enfermeiro tem papel imprescindível na avaliação dos fatores que podem contribuir para a ocorrência de queda. O estado mental do usuário, nível de consciência, estado de locomoção motora e estados específicos de 
pós-operatório são definidores da capacidade do usuário para realizar atividades da vida diária. A identificação dessas variáveis permite o desenvolvimento de um sistema operacional para prevenção de quedas, sendo atualizado assim que novas avaliações de enfermagem são realizadas conhecendo os usuários com maior chance para quedas, os profissionais podem adotar específicas medidas preventivas e de segurança preservando a saúde dos usuários e a qualidade do atendimento prestado (Marin, 2000).

Estudo realizado por Cintra et al. (2010) evidenciou que a prevenção de quedas foi o quinto item mais citado pelos enfermeiros. A enfermagem atua por 24 horas prestando cuidados aos usuários sendo a maior provedora de assistência especializada durante o período de internação hospitalar. Portanto, tem o papel de destaque no que diz respeito à prevenção de quedas de usuários nesse ambiente, pois a ocorrência deste evento pode aumentar o tempo de internação, o custo do tratamento, além de causar desconforto ao usuário e desconfiança com relação à qualidade do serviço de enfermagem e a responsabilidade do profissional.

Queda é definida como o evento não planejado que levou o usuário ao chão, com ou sem lesão. As quedas normalmente ocorrem por causas intrínsecas: decorrentes das alterações fisiológicas, que surgem com o processo natural de envelhecimento, alterações patológicas, fatores psicológicos e efeitos colaterais de medicamentos, e/ou por causas extrínsecas: aquelas relacionadas ao comportamento e atividades dos indivíduos e ao seu meio ambiente (Paiva, 2010).

A preocupação com o gerenciamento de riscos e, consequentemente, a prevenção dos EA é um desafio atual, onde a conscientização e a promoção de discussões sobre o assunto tem por objetivo sensibilizar os profissionais quanto à importância da inserção dessa proposta em suas atividades.

O termo EA refere-se ao aparecimento de um problema de saúde causado pelo cuidado/intervenção e não pela doença de base. Trata-se de uma lesão não intencional que resultou em incapacidade temporária ou permanente e/ou prolongamento do tempo de permanência ou morte como 
consequência do cuidado/ intervenção prestado. São observados EA oriundos de procedimentos cirúrgicos, utilização de medicamentos, procedimentos, tratamento não-medicamentoso, demora ou incorreção no diagnóstico. Os EA relacionados a medicamentos são responsáveis por cerca de $20 \%$ do total de casos observados, atrás apenas daqueles associados a procedimentos cirúrgicos (OMS, 2004, Mendes et al.,2005).

Segundo Gallotti (2004) alguns fatores favorecem sobremaneira a ocorrência de EA, destacando-se a idade dos usuários, a gravidade do quadro clínico inicial, a existência de co-morbidades, a duração e a intensidade do cuidado prestado, a fragmentação da atenção à saúde, a inexperiência de jovens profissionais envolvidos no atendimento, a sobrecarga de trabalho, as falhas de comunicação, a introdução de novas tecnologias e $O$ atendimento de urgência. A presença de EA deve ser interpretada como decorrente de falências nos complexos sistemas técnicos e organizacionais relacionados à atenção à saúde e não como resultado de ações isoladas.

Segundo esse autor os EA são definidos como complicações indesejadas, decorrentes do cuidado prestado aos usuários e não atribuídas à evolução natural da doença de base, sendo, em sua maioria, evitáveis. Atualmente, esses eventos têm despertado o interesse dos pesquisadores em saúde tornando-se um desafio para o aprimoramento da qualidade na saúde. Estima-se que EA afetam 10\% dos usuários admitidos em hospitais podendo levar de uma debilidade temporária até a morte.

Nas questões 19 sobre informação aos usuários acerca da ocorrência de $E A$ e na 20 referente às ações frente aos EA, não houve diferença significativa entre as categorias.

Admitir que ocorreu um EA para os usuários e seus familiares é uma dificuldade para os profissionais uma vez que tal erro, implica muitas vezes em consequências como a perda de credibilidade. Também vem à tona a preocupação com os processos judiciais que poderão ocorrer.

Para Ferreira (2007) uma das formas para melhoria continua dos cuidados de saúde é a redução dos eventos adversos, o que na perspectiva da gestão pela qualidade traduz-se no gerenciamento de processos. Um dos 
métodos atualmente, de gerência de processos é o ciclo: Plan, Do, Check e Act (PDCA), criado por Shewhart (1939) e complementado, posteriormente, por Deming (1990). Esses autores acreditavam que de $85 \%$ a $95 \%$ dos problemas durante a produção do cuidado eram resultados de falhas no processo de trabalho e não individuais.

A dimensão garantia é o conhecimento dos profissionais e suas habilidades de transmitir confiança (Zeithaml e Parasuramen, 1990). Desse modo, a dimensão garantia está relacionada aos valores interpessoais como determinantes.

Observou-se no Quadro 7 que as categorias reconhecem as ferramentas usadas pela instituição para monitoramento dos processos assistenciais e administrativos assim como o monitoramento dos riscos, no entanto, chamou a atenção o fato de referirem em sua maioria não informar os usuários quanto aos EA ocorridos.

Verificou-se, ainda, uma não padronização das ações que deveriam ser tomadas na vigência de um EA. 
Quadro 7 - Conteúdo das respostas das questões abertas 16, 17, 19 e 20 acerca da dimensão garantia, São Paulo (Interior - SP) - 2010

\begin{tabular}{|c|c|}
\hline \multicolumn{2}{|r|}{ GARANTIA } \\
\hline Questão & Conteúdo das respostas \\
\hline \multirow{8}{*}{16} & $\begin{array}{l}\text { Desconhece qualquer tipo de mecanismos de monitoramento } \\
\text { de processos. }\end{array}$ \\
\hline & Estatísticas. \\
\hline & Serviço da Qualidade. \\
\hline & Gerenciamento de Risco. \\
\hline & Indicadores. \\
\hline & Relatório de Não Conformidade. \\
\hline & Sistematização da Assistência de Enfermagem - SAE. \\
\hline & Gerência de Projetos. \\
\hline \multirow{6}{*}{17} & Avaliação de risco. \\
\hline & Classificação de risco do usuário. \\
\hline & $\begin{array}{l}\text { Desconhece qualquer tipo de mecanismo de monitorização de } \\
\text { riscos. }\end{array}$ \\
\hline & Indicadores. \\
\hline & Mapeamento de risco. \\
\hline & Comissão de Controle de Infecção Hospitalar. \\
\hline \multirow{2}{*}{19} & $\begin{array}{l}\text { Apenas quando questionado, os profissionais informam os EA } \\
\text { ocorridos. }\end{array}$ \\
\hline & $\begin{array}{l}\text { Desconhece qualquer iniciativa de informar os usuários quanto } \\
\text { aos EA ocorridos. }\end{array}$ \\
\hline \multirow{5}{*}{20} & Plano de ação para que não se repita o EA. \\
\hline & $\begin{array}{l}\text { Desconhece as medidas tomadas quando um EA é } \\
\text { identificado. }\end{array}$ \\
\hline & $\begin{array}{l}\text { Na ocorrência de um EA é comunicado o médico, aberto } \\
\text { relatório de não conformidade e enviado ao Serviço da } \\
\text { Qualidade. }\end{array}$ \\
\hline & $\begin{array}{l}\mathrm{Na} \text { vigência de EA ocorrem mudanças } \\
\text { Procedimento protocolos, } \\
\text { orientações. }\end{array}$ \\
\hline & Investigar a causa raiz para a prevenção de EA. \\
\hline
\end{tabular}




\subsubsection{Dimensão: Empatia}

Nesta investigação a dimensão de empatia foi retratada por questões que verificavam a capacidade do profissional de colocar-se no lugar do usuário, de atendê-lo de forma individualizada, incluindo acessibilidade, sensibilidade e esforço em atender suas expectativas e necessidades.

Tabela 8 - Distribuição das respostas afirmativas nas questões sobre Empatia, São Paulo (Interior - SP) - 2010

\section{Categorias}

\begin{tabular}{|c|c|c|c|c|c|c|c|c|}
\hline Questões & & $\begin{array}{c}\text { Analista } \\
\text { Clínico } \\
\end{array}$ & $\begin{array}{l}\text { Farma- } \\
\text { cêutico }\end{array}$ & $\begin{array}{c}\text { Fisiotera- } \\
\text { peuta }\end{array}$ & $\begin{array}{l}\text { Enfer- } \\
\text { meiro } \\
\end{array}$ & Médico & $\begin{array}{c}\text { Nutrício- } \\
\text { nista }\end{array}$ & $p^{*}$ \\
\hline \multirow[t]{2}{*}{21} & $n$ & 9 & 4 & 4 & 37 & 23 & 2 & 0,384 \\
\hline & $\%$ & 81,8 & 100 & 57,1 & 78,7 & 88,5 & 66,7 & \\
\hline \multirow[t]{2}{*}{22} & $\mathrm{n}$ & 6 & 2 & 4 & 37 & 22 & 2 & 0,163 \\
\hline & $\%$ & 54,5 & 50 & 57,1 & 78,7 & 84,6 & 66,7 & \\
\hline \multirow[t]{2}{*}{23} & $n$ & 11 & 2 & 7 & 45 & 24 & 3 & 0,081 \\
\hline & $\%$ & 100 & 50 & 100 & 95,7 & 92,3 & 100 & \\
\hline \multirow[t]{2}{*}{24} & $\mathrm{n}$ & 7 & 3 & 3 & 31 & 9 & 2 & 0,124 \\
\hline & $\%$ & 63,6 & 75 & 42,9 & 66 & 34,6 & 66,7 & \\
\hline \multirow[t]{2}{*}{25} & $\mathrm{n}$ & 9 & 2 & 4 & 31 & 12 & 2 & 0,36 \\
\hline & $\%$ & 81,8 & 50 & 57,1 & 66 & 46,2 & 66,7 & \\
\hline
\end{tabular}

$\left({ }^{*}\right)$ nível descritivo de probabilidade do teste exato de Fisher

Constatou-se na Tabela 8 que as categorias não diferem em relação às questões sobre empatia. Referente a essa dimensão foram abordadas questões relativas ao atendimento empático, com foco nas expectativas/necessidades dos usuários, na satisfação dos usuários, capacitação profissional com foco no usuário e qualificação profissional/empatia. Os direitos dos usuários variam de acordo com contextos culturais e sócio-políticos, resultando do modo como se estruturam, implementam e distribuem os direitos individuais, sociais e políticos em cada contexto e também de modo como se instituíram as formas de relação profissional da saúde/usuário. Mesmo assim, vem se 
construindo crescente consenso internacional em relação aos princípios de que todo usuário deve ter direito fundamental à privacidade, confidencialidade de sua informação diagnóstica, em consentir ou recusar tratamento e ser informado sobre os riscos relevantes dos procedimentos. (Vaitsman, Andrade, 2005).

O Quadro 8 destaca que a empatia dos profissionais está diretamente relacionada ao perfil individual e que há empenho em adaptar ambiente e dispositivos de forma a atender ao usuário. Constatou-se, ainda, sob a ótica dos participantes, que a referida instituição não promove capacitação profissional com foco na empatia e que esse tema não está presente nos treinamentos ou na avaliação de desempenho dos profissionais.

Quadro 8 - Conteúdo das respostas das questões abertas de 21 a 25 acerca da dimensão empatia, São Paulo (Interior - SP) - 2010

\begin{tabular}{|c|c|}
\hline & EMPATIA \\
\hline Questão & Conteúdo das respostas \\
\hline \multirow{3}{*}{21} & Profissionais da rede pública não são empáticos. \\
\hline & Não soube responder. \\
\hline & Falta treinamento com foco em empatia. \\
\hline \multirow{6}{*}{22} & Forma de atendimento acontece de acordo com o usuário. \\
\hline & $\begin{array}{l}\text { O tempo de atenção dispensado ao usuário ocorrede acordo } \\
\text { com sua necessidade. }\end{array}$ \\
\hline & Adaptações de dispositivos e do ambiente conforme o usuário. \\
\hline & $\begin{array}{l}\text { Liberação do horário de visita segundo a necessidade do } \\
\text { usuário. }\end{array}$ \\
\hline & $\begin{array}{l}\text { Elaboração de agenda de atendimento e encaixes quando } \\
\text { necessários. }\end{array}$ \\
\hline & São respeitadas as preferências alimentares dos usuários. \\
\hline \multirow[t]{2}{*}{23} & $\begin{array}{l}\text { Desconhece a manifestação de satisfação dos usuários com } \\
\text { relação à empatia dos profissionais. }\end{array}$ \\
\hline & Poucas vezes os profissionais são elogiados pelos usuários. \\
\hline \multirow[t]{2}{*}{24} & $\begin{array}{l}\text { Não há orientação da instituição quanto ao atendimento } \\
\text { empático. }\end{array}$ \\
\hline & Não há capacitação pela instituição com foco em empatia. \\
\hline 25 & $\begin{array}{l}\text { Não há preocupação da instituição em integrar a empatia como } \\
\text { foco na avaliação de desempenho dos profissionais. }\end{array}$ \\
\hline
\end{tabular}


5 CONCLUSÃO 
O presente estudo permitiu constatar que:

\section{Quanto à caracterização dos participantes:}

- Os participantes eram adultos jovens em sua maioria, a média de idade foi de 35,84 anos e a mediana 33 anos;

- A maioria dos participantes era do sexo feminino 73 (74,5\%);

- O tempo de formado foi em média de 11,36 anos e mediana de 9 anos;

- Quanto à pós-graduação $31 \quad(31,6 \%)$ profissionais tinham especialização - latu sensu, 16 (16,3\%) residência, 6 (6,1\%) mestrado e 4 (4,1\%) doutorado;

- O tempo de atuação na instituição foi em média de 6,73 anos e mediana de 5 anos.

\section{Quanto à percepção dos profissionais acerca dos fatores intervenientes na ocorrência dos EA relacionadas com as cinco dimensões de qualidade:}

- Tangibilidade: dimensão que apresentou menor índice $38(38,8 \%)$ de respostas afirmativas com o tópico referente aos riscos relacionados à estrutura. O maior índice $83(84,7 \%)$ nessa dimensão foi sobre os recursos humanos, materiais e físicos. As categorias profissionais diferiram sobre recursos humanos, materiais e físicos, segurança relacionada aos equipamentos e participação nas políticas de aquisição de recursos materiais e não diferiram quanto ao dimensionamento de recursos humanos aos riscos relacionados à estrutura. Inferiu-se que a maioria dos participantes 57 (58,2\%) demonstrou descontentamento com o qualitativo dos recursos humanos da instituição; 
- Confiabilidade: nesta dimensão sobressaiu-se que $86(87,8 \%)$ dos participantes indicariam a instituição à parentes e amigos. $O$ menor índice $60(61,2 \%)$ foi quanto às informações aos usuários em relação aos riscos. As categorias profissionais diferiram em relação aos protocolos estabelecidos, indicação da instituição e participação dos profissionais respectivamente e não diferiram quanto à execução das atividades com segurança e a informação aos usuários quanto aos riscos;

- Responsividade: dimensão que apresentou maior predominância de respostas afirmativas $94(95,9 \%)$ no que s refere ao direito de recusa do usuário em submeter-se a algum tipo de tratamento. $O$ menor índice 48 (49\%) foi com relação a ter manuais de orientação para o usuário. As categorias diferiram quanto aos temas: avaliação dos processos de trabalho e participação na elaboração de protocolos;

- Garantia: nessa dimensão o maior índice encontrado foi de 61 $(62,2 \%)$ sobre monitorização dos riscos e o menor índice 43 (43,9\%) quanto as informações dos EA ocorridos aos usuários e o conhecimento relacionado às ações frente aos EA. As categorias diferiram quanto à monitorização dos processos, monitorização dos riscos e conceito de EA e não diferiram sobre informação aos usuários acerca da ocorrência de EA e às ações frente aos EA. Os EA mais citados foram os efeitos patológicos esperados ou inesperados em bula para tratamento medicamentoso, erro de medicação e queda;

- Empatia: foi segunda dimensão com maior índice 92 (93,9\%) referente à satisfação do usuário e o menor índice 55 (56,1\%) quanto a capacitação profissional com foco no usuário. Não houve divergência das categorias profissionais quanto às questões sobre essa dimensão. 
Quanto aos fatores intervenientes na ocorrência de EA relacionados às dimensões de qualidade por categorias, observou-se que:

- os analistas clínicos pontuaram com maior ênfase as dimensões de tangibilidade, confiabilidade e responsividade;

- os médicos apresentaram menor percepção quanto as dimensões de tangibilidade, responsividade e garantia;

- os nutricionistas referiram menor percepção quanto à dimensão de confiabilidade;

- os fisioterapeutas relataram menor percepção referente à dimensão empatia;

- os farmacêuticos apresentaram maior percepção em relação a dimensão garantia;

- os enfermeiros demonstraram maior percepção quanto a dimensão empatia. 
6 CONSIDERAÇÕES FINAIS 
O presente estudo permitiu conhecer a percepção de uma equipe multidisciplinar sobre potenciais fatores intervenientes nos EA e relacioná-los com as cinco dimensões de qualidade. Assim, algumas considerações são necessárias, a fim de contribuir com a instituição pesquisada e com novos estudos relacionados ao tema.

Frente aos achados acredita-se que este estudo possa fornecer subsídios para a gerência, assistência e ensino-pesquisa.

No que tange aos aspectos gerenciais constatou-se a necessidade de incrementar ações e programas referentes aos pontos abordados nas cinco dimensões de qualidade descritas neste estudo, podendo-se destacar a capacitação profissional com foco no usuário e as melhorias nos processos, influenciando decisivamente na satisfação dos usuários internos e externos.

Quanto à contribuição para a assistência verificou-se que para a melhoria da qualidade do cuidado recomenda-se a estratégia de promoção das análises dos indicadores de qualidade e com base nos resultados, conscientizar e despertar comprometimento dos profissionais.

Referente ao ensino-pesquisa acredita-se que os achados deste estudo possam auxiliar nas reformulações que se fizerem necessárias nos âmbitos da gerência e da assistência, de modo a ser um fator facilitador para o ensino e a pesquisa.

Cabe salientar que, verificou-se um baixo retorno do instrumento de coleta de dados, levando ao questionamento do quanto a equipe multidisciplinar está voltada para os processos de investigação na instituição.

Também se verificou a importância de investimento para incentivo à qualificação profissional com relação à pós-graduação strictu senso, além da implantação de um projeto de plano de carreira institucional que possa contribuir para a mudança desse cenário.

Por conseguinte, reconhece-se a percepção da equipe multidisciplinar como importante instrumento para a medida da qualidade dos serviços de 
saúde, bem como norteadora para o planejamento das ações, tomada de decisão e monitoramento dos resultados dos serviços de saúde. 
7 REFERÊNCIAS 
Abboud CS, Feldman LB. Implantação do Programa de Gestão de Risco (PGR): experiência do Instituto Dante Pazzanese de Cardiologia de São Paulo. Revista Nursing 2009; 11(129):71-6.

Adami NP. Melhoria da qualidade nos serviços de enfermagem. Acta Paul Enf 2000; 13(Número Especial- Parte I):190-6.

Almeida N. De menino de rua a executivo. São Paulo: Reino Editorial; 2009.

Anselmi ML, Guarte GG, Angerami ELS. "Sobrevivência" no emprego dos trabalhadores de enfermagem em uma instituição hospitalar pública. Rev Latino-am Enfermagem 2001; 9(4):13-8.

Balestrin F. Gerenciamento de risco legal em saúde não evita apenas erros. Consultor Jurídico [periódico na Internet]. 2003 [citado 2011 mar. 19]. Disponível em:

http://www.conjur.com.br/2003-nov$\underline{07 / \text { importancia gerenciamento risco legal saude }}$

Bates DW, Cullen DJ, Laird N, Petersen LA, Small SD, Servi D, et al. Incidence of adverse drug events and potential adverse drug events: implications for prevention. JAMA 1995; 274(1):29-34.

Brasil. Agência Nacional de Vigilância Sanitária. Boas Práticas de Aquisição de Equipamentos Médico-hospitalares. [homepage na Internet]. Brasília; 2004 [citado 2011 fev. 25]. Disponível em: http://www.anvisa.gov.br/DIVULGA/public/tecnovigilancia/bit/2004/01 04.pdf

Brasil. Agência Nacional de Vigilância Sanitária. Segurança no ambiente hospitalar. [homepage na Internet]. Brasília; 2011 [citado 2011 fev. 27]. Disponível em: http://www.anvisa.gov.br/servicosaude/manuais/seguranca hosp.pdf 
Brasil. Lei n.8234, de 17 de setembro de 1991. Regulamenta a profissão de nutricionista e determina outras providências [legislação na internet]. Brasília; 1991 [citado 2011 abr. 23]. Disponível em: http://www.crn5.org.br/data/site/uploads/arquivos/8234\%20de\%2017.09.91\% 20-\%20regulamenta\%20a\%20profissao\%20de\%20nutricionista.pdf

Brasil. Ministério da Saúde. Carta dos direitos dos usuários da saúde. Brasília: Ministério da Saúde; 2006. [citado 2011 abr 23]. Disponível em: http://bvsms.saude.gov.br/bvs/publicacoes/cartilha ilustrada.pdf

Brasil. Ministério da Saúde. Secretaria de Assistência à Saúde. Manual Brasileiro de Acreditação Hospitalar [documento na internet] $3^{\mathbf{a}}$ ed. Brasília: Ministério da Saúde; 2002. [citado 2009 fev. 20]. Disponível em: http://www.fiocruz.br/biosseguranca/Bis/manuais/02 0060 M.pdf

Brasil. Organização Mundial da Saúde (OMS). Monitorização da segurança de medicamentos: diretrizes para a criação e fundamento de um Centro de Farmacovigilância. Brasília: Organização Pan-Americana de Saúde; 2005.

Brasil. Organização Mundial da Saúde. Segurança dos medicamentos: um guia para detectar e notificar reações adversas a medicamentos. Por que os profissionais de saúde precisam entrar em ação. Brasília: OPAS/OMS; 2004.

Brasil. Organização Nacional de Acreditação. Manual das Organizações Prestadoras de Serviços de Saúde. Brasília: Organização Nacional de Acreditação; 2010.

Brasil. Resolução n.50, de 21 de fevereiro de 2002. Dispõe sobre o regulamento técnico para planejamento, programação e avaliação de projetos físicos de estabelecimentos assistenciais de saúde [legislação na internet]. Brasília; 2002. [citado 2011 abr. 23]. Disponível em: http://www.anvisa.gov.br/legis/resol/2002/50 02rdc.pdf 
Brasiliano ACR. Técnicas de analise de riscos. Revista Eletrônica Brasiliano \& Associados 2006; (20); 23-33. [citado 2011 abr. 23]. Disponível em: http://www.brasiliano.com.br/revistas/edicao 20.pdf

Calil SJ. Gerenciamento de Manutenção de Equipamentos Hospitalares. São Paulo: Faculdade de Saúde Pública da Universidade de São Paulo; 1998. [citado 2011 abr. 23]. Disponível em: http://bvsms.saude.gov.br/bvs/publicacoes/saude cidadania volume11.pdf

Capellá D, Laporte JR. Mecanismos de Produção e Diagnóstico Clínico dos Efeitos Indesejáveis Produzidos por Medicamentos. In: Laporte JR, Tognoni G, Rozenfeld S. Epidemiologia do Medicamento. Rio de Janeiro: HUCITECABRASCO; 1989. p.115-124.

Carvalho DB, Santana JM, Santana VM. Humanização e controle social: o psicólogo como ouvidor hospitalar. Psicol Ciênc Prof 2009; 29(1): 172-183.

Carvalho G, Rosemburg CP, Buralli KO. Avaliação de ações e serviços de saúde. Mundo saúde 2000;24(1):72-88.

Carvalho VT, Cassiani SHDB. Erros na medicação e conseqüências para profissionais de enfermagem e clientes: um estudo exploratório. Rev Latinoam Enfermagem 2002; 10(4):523-9.

Castellanos PL. Comparação entre a satisfação do usuário com os serviços oferecidos num hospital geral e a percepção gerencial dessa satisfação [dissertação]. São Paulo: Escola de Administração de Empresas de São Paulo, Fundação Getúlio Vargas; 2002.

Cherubin AN. A arte de ser um administrador hospitalar líder. São Paulo: Editora do Centro Universitário São Camilo; 2003.

Churchill GA, Peter JP. Marketing: criando valor para os clientes. ${ }^{2}{ }^{\mathrm{e}}$ ed. São Paulo: Saraiva; 2003. 
Cintra EA, Pinto AC, Sousa EO, Rosa EV, Lima IA, Rodrigues SO. Utilização de Indicadores de qualidade para avaliação da assistência de enfermagem: opinião dos enfermeiros. J Health Sci Inst 2010;28(1):29-34.

Coelho Júnior C, Maeda ST. Parâmetros para planejamento e dimensionamento da força de trabalho em hospitais gerais. São Paulo: Secretaria de Estado da Saúde de São Paulo; 2006.

Coffey RJ, Richards JS, Remmert CS, Leroy SS, Schoville RR, Baldwin PJ. An introduction to critical paths. Quality Management in Health Care 2005; 1:46-55.

Conceição CS, Fialho FAP, Alves JBM, Gomes LA, Gueudeville RM. Sistemas de Comunicação na Organização Hospitalar. Revista Eletrônica de Sistemas de Informação [periódico na internet]. 2006 [citado 2011 abr 23]; 9(3): [cerca de 5 páginas]. Disponível em: http://revistas.facecla.com.br/index.php/reinfo/article/viewArticle/235

Conselho Nacional de Saúde (CNS). Resolução n.196, de 10 de outubro de 1996. Dispõe sobre diretrizes e normas regulamentadoras de pesquisa envolvendo seres humanos. [legislação na internet]. Brasília; 1996. [citado 2011 abr. 23]. Disponível em: http://dtr2004.saude.gov.br/susdeaz/legislacao/arquivo/Resolucao 196 de 1 $\underline{0} 10$ 1996.pdf

Cruz WBS, Melleiro MM. Análise dos níveis de satisfação dos usuários de um hospital privado. Rev Esc Enf USP 2010;44(1):147-52.

D' Innocenzo M, Feldman LB, Fazenda NRR, Helito RAB, Ruthes RM. Indicadores, auditorias, certificações: ferramentas de qualidade para gestão em saúde. São Paulo: Martinari; 2006.

Deming WE. Qualidade: a revolução da administração. Rio de Janeiro: Marques-Saraiva; 1990. 
Disclosure Working Group. Canadian Disclosure Guidelines. Edmont (AB): Canadian Patient Sfety Institute; 2008. [citado 2011 abr. 23]. Disponível em: http://www.patientsafetyinstitute.ca/English/toolsResources/disclosure/Docu ments/CPSI\%20-\%20Canadian\%20Disclosure\%20Guidlines\%20English.pdf

Donabedian A, Wheeler JR, Wyszewianski L. Quality, cost and health: na interative model. Medical Care 1982;20(6): 975-992.

Edwards R, Biriell C. Hamonizaton in pharmacovigilance. Drug Saf 1994; 10(2):93-102.

Feldman LB. Como alcançar a qualidade nas instituições de saúde. Critérios de avaliações, procedimentos de controle, gerenciamento de riscos hospitalares até a certificação. São Paulo: Matinari; 2004.

Ferreira VR. Análise dos eventos adversos em uma unidade de terapia intensiva neonatal como ferramenta de gestão da qualidade da assistência de enfermagem [dissertação]. Belo Horizonte: Escola de Enfermagem da UFMG, Universidade Federal de Minas Gerais; 2007.

Fitzpatrick R. Surveys of patient satisfaction: important general considerations. BMJ 1991;302(6779):887-888.

Florence G, Calil SJ. Uma nova perspectiva no controle dos riscos da utilização de tecnologia médico-hospitalar. [dissertação]. Campinas: Faculdade de Engenharia Elétrica e de Computação, Universidade Estadual de Campinas (Unicamp); 2005. [citado 2011 abr 23]. Disponível em: http://www.opas.org.br/gentequefazsaude/bvsde/bvsacd/cd49/umanova.pdf

Galloti RMD. Eventos Adversos e óbitos hospitalares em serviços de emergências clínicas de um hospital universitário terciário: um olhar para a qualidade da atenção [tese]. São Paulo: Faculdade de Medicina, Universidade de São Paulo; 2003. 
Gallotti RMD. Eventos adversos: o que são?. Rev. Assoc Med Bras 2004; 50(2):114-114.

Gestão de Riscos - A Norma AS/NZS 4360:2004. Série Risk Management.

Gomes MJVM e Reis AMM (organizadores) Ciências Farmacêuticas: uma abordagem em Farmácia Hospitalar. $1^{\underline{a}}$ ed. São Paulo: Editora Atheneu; 2001. p.125-146.

Guelli A, Zucchi P. A influência do espaço físico na recuperação do paciente e os sistemas e instrumentos de avaliação. Rev Adm Saúde 2005;7(27):4350 .

Hilson D. Gerenciamento de Riscos - Melhores práticas e desenvolvimentos futuros. Revista MundoPM [periódico na internet]. 2005 [citado 2011 mar. 09]; (4): [38-42]. Disponível em:

Hokerberg YHM, Santos MAB, Passos SRL, Rozemberg B, Cotias PMT, Alves $L$, et al. $O$ processo de construção de mapas de risco em um hospital público. Cienc Saúde Coletiva 2006;11(2):503-13.

Hortale VA, Leal MC, Moreira COF, Aguiar AC. Características e limites do mestrado profissional na área da Saúde: estudo com egressos da Fundação Oswaldo Cruz. Ciênc. saúde coletiva 2010 15(4): 2051-2058.

http://www.risk-doctor.com/pdf-files/mundopmpaperoct05portuguese.pdf

Kern AE, Lima APF, Feldman LB. Gerenciamento de riscos. Revista GTH 2010 [citado 2011 abr. 23];2(2):28-30. Disponível em: http://www.gthospitalar.com.br/files/editions/ed1281619030.pdf

Kohn LT, Corrigan JM, Donaldson MS. To Err is Human. Washington (D.C.): Committee on Quality of Health Care in America; 2000. 
Leape L, Berwick D, Clancy C, Conway J, Gluck P, Guest J, et al. Transforming Healthcare: a safety imperative. Qual Saf Health Care 2009;18: 424-428.

Leape LL, Bates DW, Cullen DJ, Cooper J, Demonaco HJ, Gallivan T, et al. Systems analysis of adverse drug events. JAMA 1995; 274(1):35-43.

Maheirie K. Constituição do sujeito, subjetividade e identidade. Interações 2002 [citado 2011 abr. 23]; 7(13):31-34. Disponível em: http://pepsic.bvsalud.org/pdf/inter/v7n13/v7n13a03.pdf

Mahmud SDP. Protocolos clínicos: adesão e aplicabilidade numa instituição hospitalar [trabalho de conclusão]. Rio grande do Sul: Escola de Administração, Universidade Federal do Rio Grande do Sul; 2002. [citado 2011 abr 23]. Disponível em: http://hdl.handle.net/10183/12393

Malta DC, Cecílio LCO, Merhy EE, Franco TB, Jorge AO, Costa MA. Perspectivas da regulação na saúde suplementar diante dos modelos assistenciais. Cienc Saúde Coletiva 2004;9(2):433-44.

Manzo BF. O processo de acreditação hospitalar na perspectiva de profissionais de saúde. [dissertação]. Belo Horizonte: Escola de Enfermagem da UFMG, Universidade Federal de Minas Gerais; 2009.

Marin HF, Bourie P, Safran C. Desenvolvimento de um sistema de alerta para prevenção de quedas em pacientes hospitalizados. Rev Latinoam Enferm 2000;8(3):34-41.

Marodin G, Goldim JR. Confusões e Ambigüidades na classificação de eventos adversos em pesquisa clínica. Rev Esc Enferm USP 2009; 43 (3):690-6.

Mcclelland DC. Introduction to coding. J NIH Res: 2-50; 1996. 
Medeiros WB. Os pilares de humanização da assistência Hospitalar. In: Mezzomo AA. Fundamentos da humanização hospitalar: uma visão multiprofissional. São Paulo (SP): Loyola; 2003.

Melleiro MM, Tronchin DMR. Percepção de acompanhantes-usuários e de enfermeiros sobre qualidade assistencial em unidades pediátricas. Acta Paul Enf 2010;23(5):646-51. Mello JB e Carmargo MO. Qualidade na Saúde Práticas e Conceitos Normas ISSO nas áreas da Médico-Hospitalar e Laboratorial. São Paulo: Editora Best Seller; 1998.

Mello JB, Camargo MO. Qualidade na Saúde Práticas e Conceitos Normas ISSO nas áreas da Médico-Hospitalar e Laboratorial. São Paulo: Editora Best Seller; 1998.

Mendes RIP. Índice de utilização de tecnologias na avaliação dos processo assistenciais de recém-nascidos prematuros. Rio de Janeiro: Fundação Osvaldo Cruz (FIOCRUZ); 2005.

Mendes W, Travassos C, Martins M, Noronha JC. Revisão dos estudos de avaliação da ocorrência de eventos adversos em hospitais. Rev Bras Epidemiol 2005; 8(4):393-406.

Mezomo JC. Gestão da qualidade na saúde: princípios básicos. $1^{\underline{a}}$ ed. São Paulo: Loyola; 2001.

Millan GS, Trez G. Pesquisa de satisfação: um modelo para planos de saúde. RAE [periódico na internet]. 2005 [citado 2009 nov. 18]; 4(2):[cerca de $21 \mathrm{p}]$.

Disponível

em: http://www.rae.com.br/eletronica/index.cfm?FuseAction+Artigo\&ID2165\&Sec $\underline{\mathrm{aO}=\mathrm{ARTIGOS} \& \text { Volume }=4 \& \text { Numero }=2 \& A n o=2005}$.

Monzoni A. Erros de medicação e subnotificação. Rev Coren-SP 2006;8(70):8-9. 
Mückenberger E. O papel da satisfação, confiança e comprometimento na formação de intenções futuras de compra entre clientes com nível de experiência diferenciados [dissertação]. Porto Alegre: Escola de Administração, Universidade Federal do Rio Grande do Sul; 2000.

NIST. Technology Administration US. Department of Commerce. NIST Special Publication 800-26. Security Self-Assessment Guide for Information Technology Systems. AS/NZS 4360:2004. Risk Management Guidelines; 2004.

Nogueira LCL. Gerenciando pela qualidade total na saúde. $2^{a}$ ed. Belo Horizonte: Ed. Desenvolvimento Gerencial; 1999.

Paine LA, Beaker DR, Rosenstein B, Pronovost PJ. The Johns Hopkins Hospital: identifying e addressing risks and safety issues. Jt Comm J Qual Saf 2004;30(10):543-50.

Paiva MCMS, Paiva SAR, Berti HW, Campana AO. Caracterização das quedas de pacientes segundo notificação em boletins de eventos adversos. Rev Esc Enferm 2010;44(1):134-8.

Parasuraman A, Zeithaml V, Berry LL. Refinement and reassessment of the SERVQUAL dimensions. Journal of Retailing 1991;67:420-50.

Pena MM. Análise do grau de satisfação de usuários de um hospital universitário privado: uma abordagem multissetorial [dissertação]. São Paulo: Escola de Enfermagem, Universidade de São Paulo; 2010.

Rattner D. A epidemiologia na avaliação da qualidade: uma proposta. Cadernos de Saúde Pública 1996; Supl 2:1-17.

Ribeiro P. A Importância da Percepção Humana. RH Portal [periódico na internet]. 2008 [citado 2011 abr. 23]; 17(1): [cerca de 1 p.]. Disponível em: http://www.rhportal.com.br/artigos/wmview.php?idc cad=yxjhfmiaw

Rosner B. Fundamentals of Biostatistics. Boston: PWS Publishers; 1986. 
Sackett D. Medicina baseada em evidências: prática e ensino. $2^{\underline{a}}$ ed. São Paulo: Artmed; 2003.

Schffman LG, Kanuk LA. Comportamento do consumidor. Tradução de Vicente Ambrósio. 6ª ed. Rio de Janeiro: LTC; 2000.

Shewhart WA. Statistical Method from the Viewpoint of Quality Control. Washington: Department of Agriculture; 1939.

Souza FC, Garcia GF, Carvalho JM, Campos MA, Mendonça VMF. Caderno de Protocolos Clínicos-Caderno Introdutório. $2^{\underline{a}}$ ed. Belo Horizonte: Fundação Hospitalar do Estado de Minas Gerais (FHEMIG); 2010. [citado 2011 abr 23]. Disponível em: http://www.fhemig.mg.gov.br/pt/protocolosclinicos

Stefanelli MC. Conceitos teóricos sobre comunicação. In: Stefanelli MC, Carvalho EC. A comunicação nos diferentes contextos da enfermagem; Barueri: Manole; 2005. p. 28-46.

Táxis K, Barber N. Ethnographic study of incidence and severity of intravenous drug errors. BMJ 2003 326(7391): 684-687.

Tronchin DMR, Naves LK, Lima RPM, Melleiro MM. Avaliação da assistência de enfermagem: o emprego de indicadores. In: Leite MMJ. Programa de Atualização em Enfermagem: saúde do adulto (PROENF). Porto Alegre: Artmed/Panamericana; 2011. p. 9-22.

Vaitsman J, Andrade GRB. Satisfação e responsividade: formas de medir a qualidade e a humanização da assistência à saúde. Cienc Saúde Coletiva 2005;10(3):599-613.

Varni JW, Burwinkle TM, Dickinson P, Sherman AS, Dixon P, Ervice JA, et al. Evaluation of the built environment at a children's convalescent hospital: development of the pediatric of life inventory parent and staff satisfaction measures for pediatric health care facilities. J Dev Behav Pediatr 2004;25(1):10-20. 
Zeithaml V, Parasuraman A, Berry LL. Delivering service quality: balancing customer perceptions and expectations. New York: The Free Press; 1990.

Zeithaml V, Parasuraman A. Service quality. Cambridge: Marketing Science Institute; 1990. 
8 APÊNDICES 


\section{APÊNDICE 1}

\section{ENCAMINHAMENTO AO COMITÊ DE ÉTICA EM PESQUISA}

de de 2010.

IImo(a) $\operatorname{Sr}(a)$.

Presidente do Comitê de Ética em Pesquisa

Venho solicitar a análise e a autorização para realização da pesquisa intitulada: "Percepção da equipe multidisciplinar acerca de fatores intervenientes na ocorrência de eventos adversos em um hospital universitário" que tem por objetivo analisar a percepção da equipe multidisciplinar de um hospital universitário acerca de fatores intervenientes na ocorrência de eventos adversos e relacionar os fatores intervenientes na ocorrência de eventos adversos com as cinco dimensões de qualidade de Parasuraman, Zelthaml e Berry.

Aproveito o ensejo para esclarecer tratar-se de uma dissertação para obtenção do título de mestre, na área de concentração de Fundamentos e Práticas de Gerenciamento em Enfermagem e em Saúde da Escola de Enfermagem da Universidade de São Paulo, sob orientação da Prof $^{\mathrm{a}}{ }^{\mathrm{Dr}}{ }^{\mathrm{a}}$ Marta Maria Melleiro.

Outrossim, esclareço que serão respeitadas as exigências da Resolução no. 196/96 do Conselho Nacional de Saúde.

Atenciosamente, 


\section{APÊNDICE 2}

\section{SOLICITAÇÃO DE AUTORIZAÇÃO PARA COLETA DE DADOS}

_de_de_de 2010.

IImo(a) $\operatorname{Sr}(a)$.

Superintendente

Prezado(a) $\operatorname{Sr}(a)$

Venho solicitar a autorização para realizar a coleta de dados nesta instituição para o trabalho de pesquisa, intitulado: "Percepção da equipe multidisciplinar acerca de fatores intervenientes na ocorrência de eventos adversos em um hospital universitário" que tem por objetivo analisar a percepção da equipe multidisciplinar de um hospital universitário acerca de fatores intervenientes na ocorrência de eventos adversos e relacionar os fatores intervenientes na ocorrência de eventos adversos com as cinco dimensões de qualidade de Parasuraman, Zelthaml e Berry.

Aproveito o ensejo para esclarecer tratar-se de uma dissertação para obtenção do título de mestre, na área de concentração de Fundamentos e Práticas de Gerenciamento em Enfermagem e em Saúde da Escola de Enfermagem da Universidade de São Paulo, sob orientação da Prof $^{a}{ }^{-} r^{a}$ Marta Maria Melleiro.

Outrossim, informo que não coloco em evidência a identificação de qualquer participante, bem como esta instituição.

Certa de poder contar com sua colaboração coloco-me à disposição para outros esclarecimentos.

No aguardo de sua resposta, aproveito a oportunidade para renovar meu protesto de estima e consideração.

Atenciosamente, 


\section{APÊNDICE 3}

\section{TERMO DE CONSENTIMENTO LIVRE E ESCLARECIDO}

I. Registro dos esclarecimentos da pesquisadora aos participantes da pesquisa.

Eu, Regiane Pereira Martins Lima, enfermeira, mestranda da Escola de Enfermagem da Universidade de São Paulo (EEUSP), venho convidá-lo (a) a participar da pesquisa intitulada:"Percepção da equipe multidisciplinar acerca de fatores intervenientes na ocorrência de eventos adversos em um hospital universitário", sob orientação da Prof ${ }^{a}$. Dr ${ }^{a}$. Marta Maria Melleiro. Esta pesquisa tem por objetivo analisar a percepção da equipe multidisciplinar de um hospital universitário acerca de fatores intervenientes na ocorrência de eventos adversos e relacionar os fatores intervenientes na ocorrência de eventos adversos com as cinco dimensões de qualidade de Parasuraman, Zelthaml e Berry. Para tanto, será aplicado um questionário, constituído de duas partes: na primeira contendo os dados sócio-demográficos dos participantes, na segunda parte uma escala, onde os participantes poderão emitir suas opiniões sobre a percepção e conhecimento sobre evento adverso. Sua participação no estudo será totalmente voluntária, podendo, se desejar, deixalo a qualquer momento e esta desistência não trará nenhum tipo de prejuízo.

O conteúdo do questionário será confidencial, sigiloso e as suas respostas estarão sob minha responsabilidade, sendo que será utilizado apenas para a realização do estudo, podendo os resultados ser apresentados em eventos e publicados em revistas científicas.

Caso aceite participar desta pesquisa, estará contribuindo por meio de sua percepção, acerca de eventos adversos, e com isso melhorias contínuas poderão ser efetuadas, solicito a sua assinatura no item II deste documento. O estudo é independente da condição da pesquisadora ser colaboradora da instituição.

A pesquisadora estará à disposição dos respondentes para esclarecer dúvidas no preenchimento do questionário.

Desde já agradeço a sua atenção e coloco-me à disposição para quaisquer esclarecimentos sobre a pesquisa. Os meus contato são (19) 81792770 e (19) 32039633/ email: regianepmartins@yahoo.com.br

O Comitê ao qual a pesquisa será submetida possuí os seguintes contatos: email: $x$.

Este documento será em duas vias, sendo uma da pesquisadora e a outra do sujeito.

$$
\text { Interior (SP), de de } 2010 .
$$

II. Registro e assinatura do participante da pesquisa

Regiane Pereira Martins Lima

Compreendo o objetivo desta pesquisa e concordo em participar de forma livre da mesma, entendendo que as informações serão utilizadas apenas para realização do estudo, que não sofrerei qualquer tipo de sanção ou prejuízo, caso desista de participar deste estudo.

Declaro, ainda, que ao ser convidado a participar desta pesquisa, todos os esclarecimentos foram prestados pela pesquisadora.

$$
\text { Interior (SP), de de } 2010 .
$$




\section{APÊNDICE 4}

\section{INSTRUMENTO DE COLETA DE DADOS}

\section{PARTE I Dados sociodemográficos}

\begin{tabular}{|c|c|c|c|c|}
\hline $\begin{array}{ll}1 \text { Idade: } \\
\text { _anos }\end{array}$ & $\begin{array}{l}\text { 2 Sexo: } \\
\text { 2.1 Feminino } \\
2.2 \text { Masculino }\end{array}$ & $\begin{array}{l}3 \text { Tempo } \\
\text { (anos): }\end{array}$ & $\begin{array}{ll}\text { de formação } \\
\end{array}$ & 4 Tempo na instituição (anos): \\
\hline \multicolumn{5}{|c|}{5 Titulação(maior): } \\
\hline \multicolumn{5}{|c|}{ 5.1 Bacharel } \\
\hline \multicolumn{3}{|c|}{ Pós - graduação latu senso: 5.2 Especialização } & \multicolumn{2}{|l|}{ 5.3 Residência } \\
\hline \multicolumn{3}{|c|}{ Pós - graduação strictu senso: 5.4 Mestrado } & \multicolumn{2}{|l|}{ 5.5 Doutorado } \\
\hline \multicolumn{5}{|c|}{6 Função exercida na instituição: } \\
\hline \multicolumn{5}{|c|}{6.1 Enfermeiro } \\
\hline \multicolumn{5}{|l|}{ 6.2 Nutricionista } \\
\hline \multicolumn{5}{|c|}{ 6.3 Analista Clínico } \\
\hline \multicolumn{5}{|l|}{ 6.4 Médico } \\
\hline \multicolumn{5}{|l|}{ 6.5 Farmacêutico } \\
\hline \multicolumn{5}{|l|}{ 6.6 Fisioterapeuta } \\
\hline
\end{tabular}

PARTE II Dados referentes à percepção dos profissionais acerca de fatores intervenientes na ocorrência de EA relacionados as dimensões de qualidade Considerando as cinco dimensões de qualidade abaixo descritas, por favor, responda as questões baseando-se em sua experiência profissional na instituição cenário deste estudo.

TANGIBILIDADE: inclui as instalações físicas, os recursos humanos e os materiais/equipamentos, representando os aspectos estruturais da oferta dos serviços, que podem ser percebidos pelos cinco sentidos humanos.

1 Considera os aspectos tangíveis - humanos, materiais e físicos adequados para prestar atendimento ao usuário?
$\operatorname{Sim}($ )
Não ( )

Caso não, porquê? 
2 Conhece os processos referentes às manutenções preventivas dos equipamentos?

$\operatorname{Sim}($ )

Não ( )

Caso não, porquê?

3 Participa da aquisição ou dos testes de materiais, de equipamentos ou de novas tecnologias?

$\operatorname{Sim}($ ) Não ( )

Caso não, porquê?

40 quantitativo e o qualitativo dos recursos humanos da instituição atendem às necessidades do seu serviço?

$\operatorname{Sim}($ )

Não ( )

Caso não, porquê?

5 A estrutura disponibilizada pela instituição oferece riscos ao usuário?

$\operatorname{Sim}()$

Não ( )

Caso sim, porquê? 
CONFIABILIDADE: é a habilidade de o fornecedor executar de forma segura e eficiente o serviço; consiste na capacidade de prestar o serviço prometido de modo confiável. Retrata um desempenho consistente, sem falhas, no qual o usuário possa confiar.

6 Os profissionais executam os procedimentos de acordo com os protocolos assistenciais e administrativos?

$\operatorname{Sim}($ ) Não ( )

Caso não, porquê?

7 As atividades executadas pelos profissionais transmitem segurança ao usuário? Sim ( ) Não ( )

Caso não, porquê?

8 Indicaria a instituição a seus familiares e amigos?

Sim ( )

Não ( )

Caso não, porquê?

9 A instituição possui um setor/serviço onde o usuário possa se manifestar?

Sim ( ) Não ( )

Caso não, porquê? 
10 Os usuários são informados sobre os possíveis riscos inerentes à terapêutica proposta?

$\operatorname{Sim}($ )

Não ( )

Caso não, porquê?

RESPONSIVIDADE: refere-se à disponibilidade dos profissionais em atender os usuários de forma atenciosa, com precisão e rapidez de resposta.

11 A instituição está atenta ao modo como os profissionais desenvolvem suas atividades?

Sim ( ) Não ( )

Caso não, porquê?

12 O usuário pode se recusar a ser submetido a algum procedimento durante o tratamento?

Sim ( ) Não ( )

Caso não, porquê?

13 A comunicação de alterações/mudanças na instituição são prontamente repassadas aos serviços?

Sim ( ) Não ( )

Caso não, porquê? 
14 Os usuários recebem algum tipo de material impresso, no qual possa ter esclarecimentos sobre a internação/terapêutica?

Sim ( ) Não ( )

Caso sim, quais?

15 Participa da elaboração/alteração de protocolos assistenciais ou administrativos?

Sim ( ) Não ( )

Caso não, porquê?

GARANTIA: é identificada como a cortesia e o conhecimento das necessidades e expectativas dos usuários e das habilidades dos colaboradores em transmitir confiança.

$16 \mathrm{Na}$ instituição existem mecanismos que monitoram os processos assistenciais e administrativos?

$\operatorname{Sim}($ ) Não ( )

Caso sim, quais? 
$17 \mathrm{Na}$ instituição existem mecanismos que monitoram os riscos?

$\operatorname{Sim}($ )

Não ( )

Caso sim, quais?

18 Sabe o que é Evento Adverso (EA)?

$\operatorname{Sim}($ ) Não ( )

Caso sim, dê exemplos:

19 Os usuários são informados acerca dos EA ocorridos no seu tratamento?

$\operatorname{sim}($ )

Não ( )

Caso não, porquê?

20 Tem conhecimento das medidas tomadas quando um EA é identificado?

$\operatorname{Sim}($ )

Não ( )

Caso sim, quais?

EMPATIA: capacidade de colocar-se no lugar do usuário, de atendê-lo de forma individualizada, incluindo acessibilidade, sensibilidade e esforço em entender suas expectativas e necessidades.. 
21 Os profissionais atuantes nos serviços são empáticos com os usuários?

Sim ( )

Não ( )

Caso não, porquê?

22 Alguma vez teve que adaptar um procedimento assistencial ou administrativo para atender as expectativas ou necessidades do usuário?

Sim ( )

Não ( )

Caso sim, qual?

23 Os usuários reconhecem e manifestam satisfação ao serem atendidos por profissionais que tenham empatia?

Sim ( )

Não ( )

Caso não, porquê?

24 Os profissionais são capacitados pela instituição para que exerçam atendimento com empatia?

$\operatorname{Sim}($ )

Não ( )

Caso não, porquê? 
25 A empatia é um item considerado na avaliação de desempenho dos profissionais?

$\operatorname{Sim}($ )

Não ( )

Caso não, porquê? 